\title{
Linking functional assessment with diagnostic classification: Development of functional assessment methodology
}

\author{
Cynthia Marie Anderson \\ West Virginia University
}

Follow this and additional works at: https://researchrepository.wvu.edu/etd

\footnotetext{
Recommended Citation

Anderson, Cynthia Marie, "Linking functional assessment with diagnostic classification: Development of functional assessment methodology" (1999). Graduate Theses, Dissertations, and Problem Reports. 3677.

https://researchrepository.wvu.edu/etd/3677

This Dissertation is protected by copyright and/or related rights. It has been brought to you by the The Research Repository @ WVU with permission from the rights-holder(s). You are free to use this Dissertation in any way that is permitted by the copyright and related rights legislation that applies to your use. For other uses you must obtain permission from the rights-holder(s) directly, unless additional rights are indicated by a Creative Commons license in the record and/ or on the work itself. This Dissertation has been accepted for inclusion in WVU Graduate Theses, Dissertations, and Problem Reports collection by an authorized administrator of The Research Repository @ WVU. For more information, please contact researchrepository@mail.wvu.edu.
} 


\title{
Linking Functional Assessment with Diagnostic Classification: Development of Functional Assessment Methodology
}

\author{
Cynthia Marie Anderson \\ Dissertation submitted to the Faculty of the Department of Psychology in the \\ Eberly College of Arts and Sciences at West Virginia University \\ in partial fulfillment of the requirements for the degree of \\ Doctor of Philosophy \\ in \\ Psychology \\ Joseph R. Scotti, PhD, Chairperson \\ Christina Adams, $\mathrm{PhD}$ \\ Georg Eifert, $\mathrm{PhD}$ \\ Donald Kincaid, $\mathrm{PhD}$ \\ Kennon Lattal, $\mathrm{PhD}$ \\ 1999 \\ Morgantown, West Virginia
}

Keywords: Functional Assessment, Childhood Disorders, Diagnosis, Conduct Disorder

Copyright 1999, Cynthia Marie Anderson 


\title{
Linking Functional Assessment with Diagnostic Classification: Development of Functional Assessment Methodology
}

\author{
Cynthia Marie Anderson
}

\begin{abstract}
Much of the assessment conducted by behavioral health providers is nomothetic in nature. For example, a primary goal of many clinicians is to determine the diagnostic category that best fits a given client. This is problematic because simply knowing what diagnosis best fits a client does not necessarily lead to an effective treatment decision. In contrast to a nomothetic approach to assessment, behavior analysis emphasizes idiographic assessments. One example is a functional assessment. The purpose of a functional assessment is to determine the environmental variables of which behavior is a function. Although functional analyses are relatively common within the developmental disabilities literature, they are virtually absent from published studies with other clinical populations. The purpose of this study was to develop and assess the clinical utility of a structured functional assessment interview for typically-developed children exhibiting behavior problems in schools. In the first study, two functional assessment interviews were developed and field tested. The first interview was designed to be administered to teachers and the second to children. Inter-rater agreement was evaluated for the interviews and was found to be high. Agreement between teachers and children was evaluated as well, and was very low. Based on the findings of Study 1, structural changes were made to the interviews prior to beginning Study 2. The purpose of Study 2 was to further evaluate the inter-observer agreement of the interviews and also to conduct an evaluation of the interviews concurrent validity. In this study, the interviews were administered to four additional children, their teachers, and teaching aides. Additionally, direct observation data were collected for approximately 2-hours with each child. Inter-observer agreement was evaluated by comparing the interviews administered to the teachers and children, and the interviews administered to the teachers and teachers' aides. Overall, agreement between teachers and children was poor, however teachers and children did tend to agree on consequences maintaining challenging behavior. Agreement between teachers and their aides was high, overall. Concurrent validity was evaluated by comparing the results of
\end{abstract}


the teacher-administered interviews to 2-hours of direct observations conducted in the school. Overall, agreement between the teacher interview and the direct observation data was acceptable to good. Taken together, the high inter-observer agreement between teachers and aides (both of whom are familiar with the children's behavior in school) and the acceptable concurrent validity suggest that the interviews may be a useful addition to a comprehensive functional assessment for children exhibiting challenging behavior in schools. 


\section{Acknowledgments}

I would like to express my gratitude to my committee members, Donald Kincaid, EdD, Christina Adams, PhD, Georg Eifert, PhD, Kennon Lattal, PhD, and my Committee Chair, Joseph R. Scotti, $\mathrm{PhD}$, for their support and assistance. I would especially like to thank Dr. Scotti for his conceptual guidance and meticulous reviews. Additionally, I would like to thank Jonathan Cassidy for his love and support during the planning and data collection stages of this project; and my mother, Carole Anderson for years of support and guidance. 


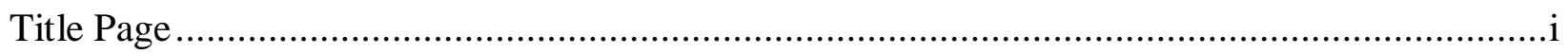

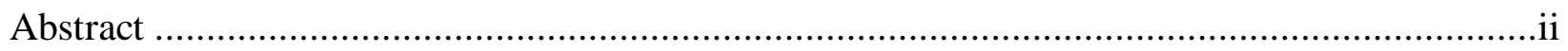

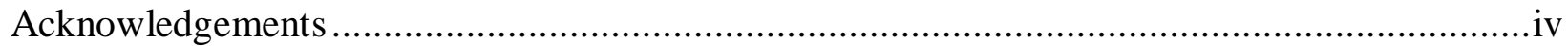

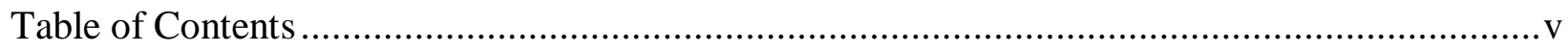

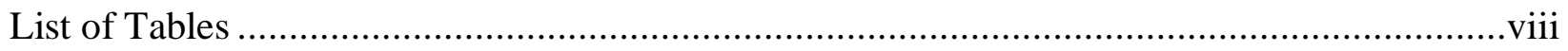

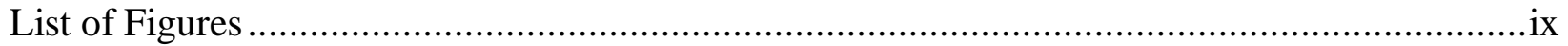

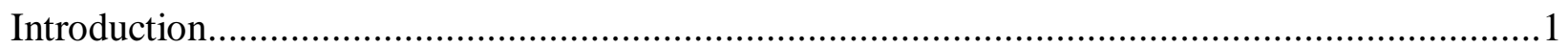

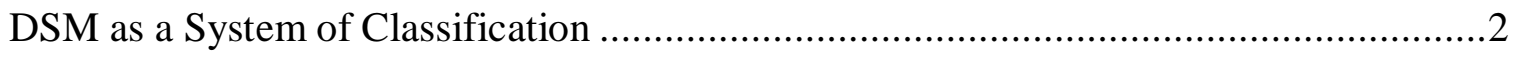

Behavior Analysis and Functional Diagnosis ............................................................

Pragmatism and Contextualism ...............................................................

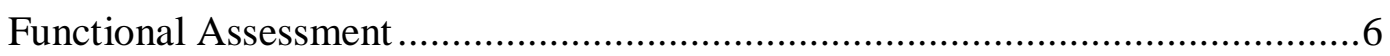

Functional Assessment Defined ..........................................................6

Functional Assessment Methodology ..................................................

Indirect methods of functional assessment.................................... 8

Direct methods of functional assessment ......................................10

Functional Assessment: Current Status and Future Directions...................13

Linking Functional Assessment with DSM criteria ....................................................16

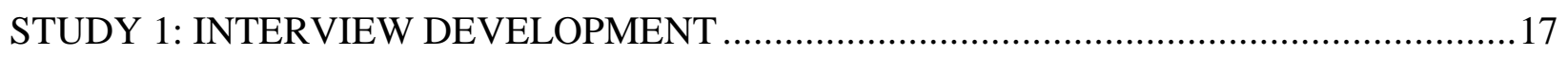

Phase A: Interview Development .............................................................................17

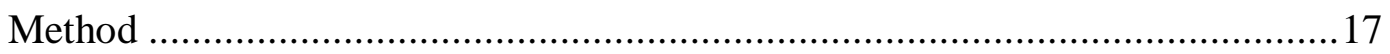

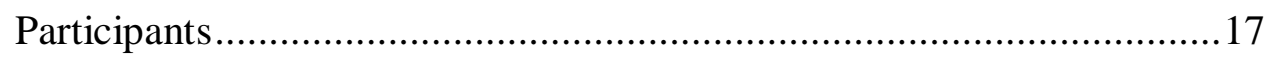

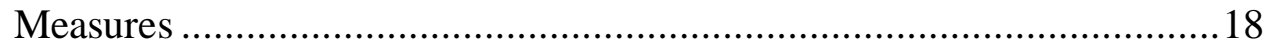

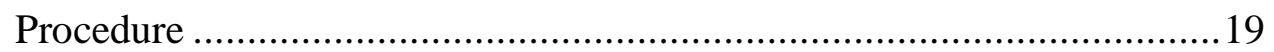

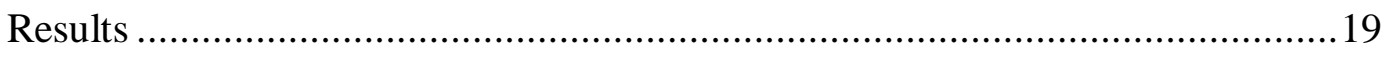

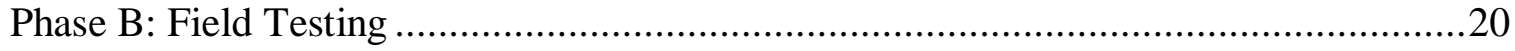

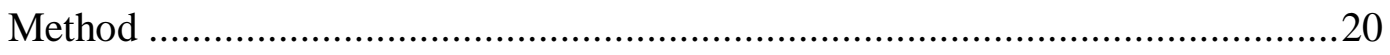

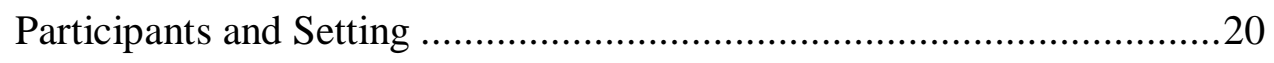

Response Definitions and Measurement..................................................20

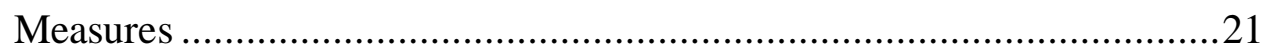




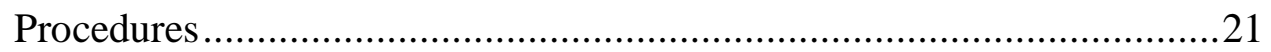

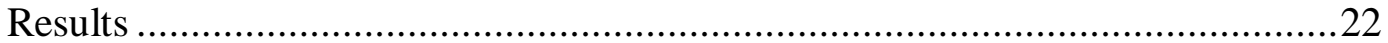

Agreement Scores on the CAFI-C and CAFI-T....................................22

Agreement Scores on the Summary Forms..............................................23

Hypotheses Regarding Functional Relations ..........................................24

Setting events and antecedent stimuli .........................................25

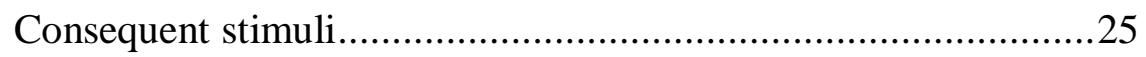

Relation between antecedent events and reported consequences ..26

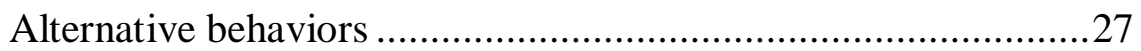

Comparison of CAFI-C and CAFI-T.....................................................

Agreement on setting events and antecedent stimuli ....................27

Agreement on consequences maintaining behavior......................28

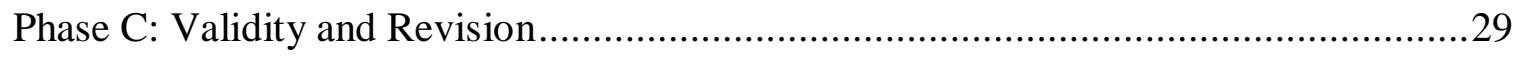

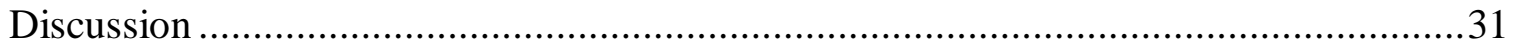

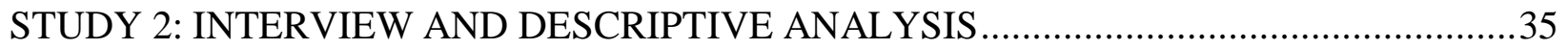

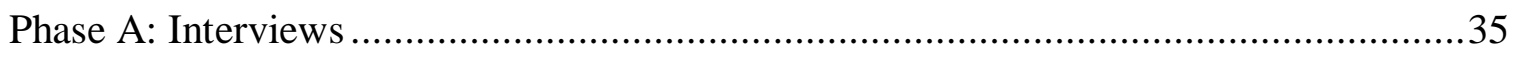

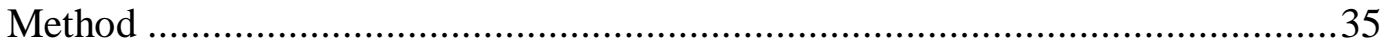

Participants and Setting ........................................................................

Response Definitions and Measurement.................................................37

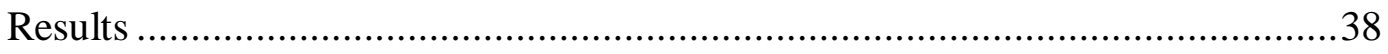

Comparisons of Interviews Administered to Teachers and Aides ..............38

Comparison of CAFI-C and CAFI-T.....................................................39

Agreement on antecedent stimuli, setting events, and alternative skills ...39

Agreement on consequences maintaining challenging behavior ...............39

Relation Between Antecedent Events and Reported Consequences ..........40

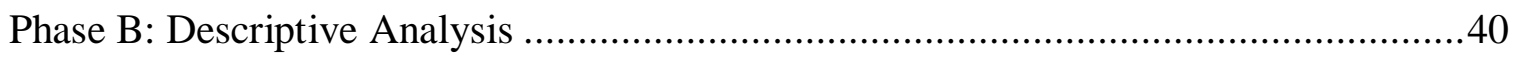

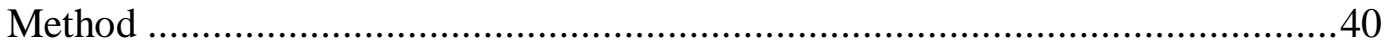

Participants and Setting ....................................................................40

Response Definitions and Measurement.................................................40

Experimental Design and Procedures........................................................43

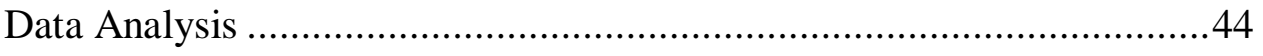




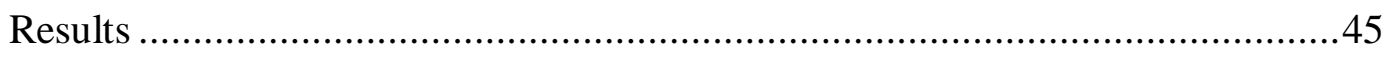

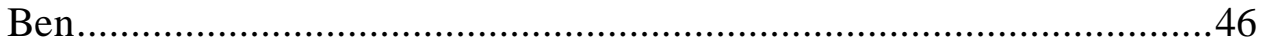

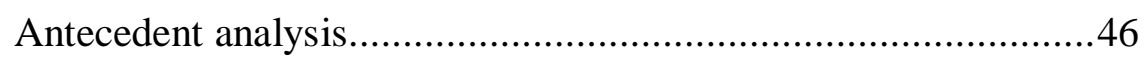

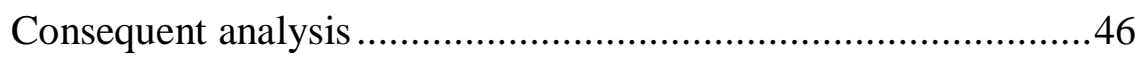

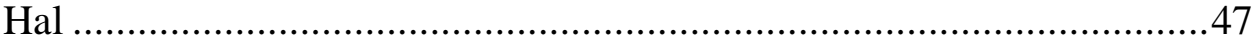

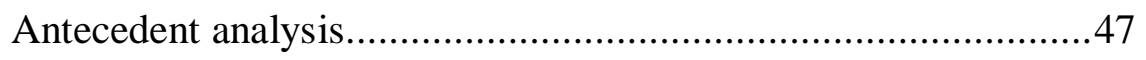

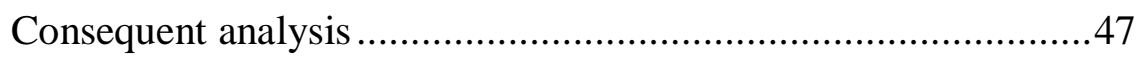

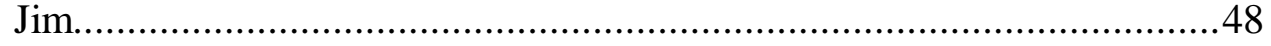

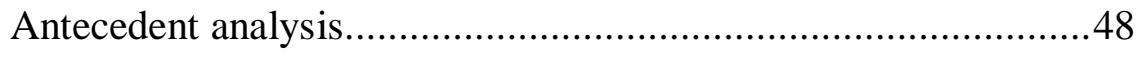

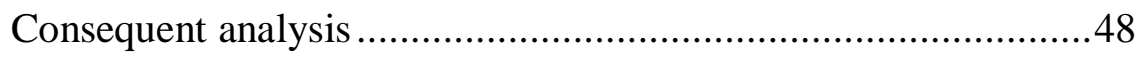

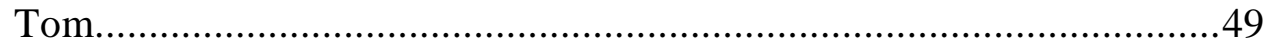

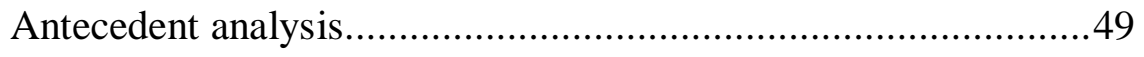

Consequent analysis .................................................................... 49

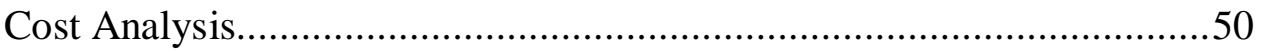

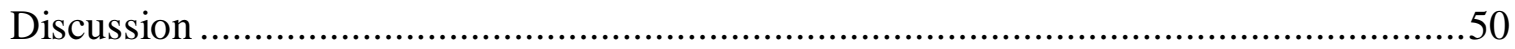

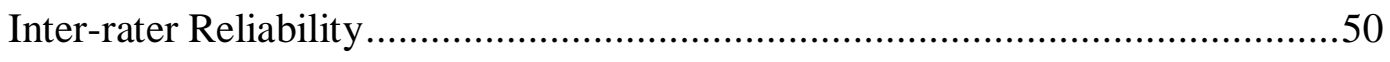

Evaluation of the Content Validity of the Teacher Interview ...............................51

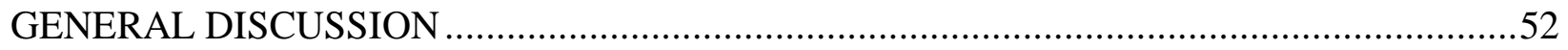

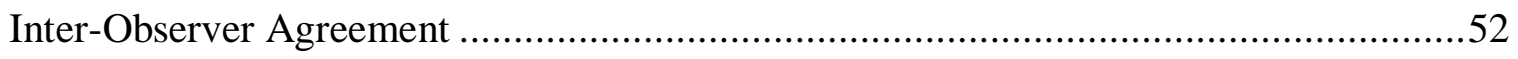

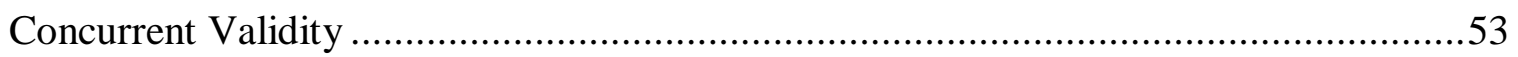

Utility of Functional Assessment with Children in School Settings ................................53

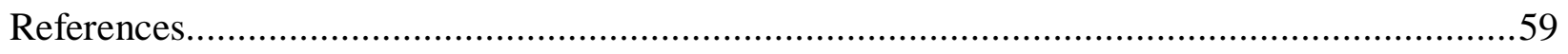

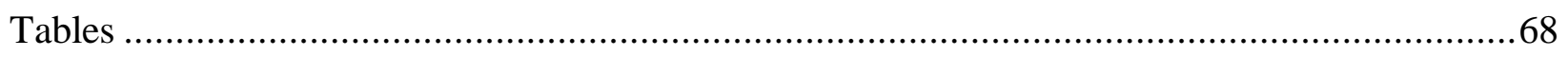

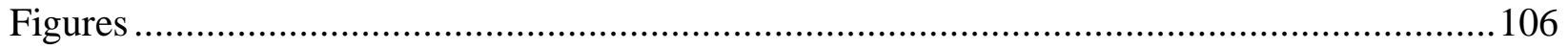

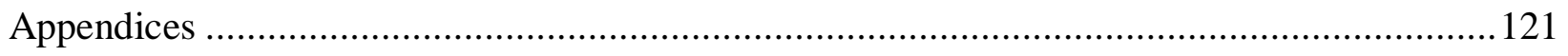

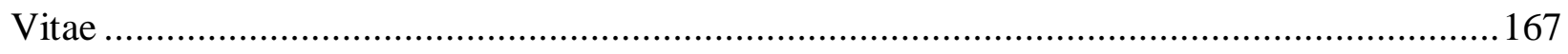




\section{Table Listing}

Table 1. Child Participants in Study 1

Table 2. Target Responses and Operational Definitions for Each Participant in Study 1

Table 3. Percentage Agreement Between Raters on Each Item of the Teacher Version of the CAFI (Study 1, Phase B)

Table 4. Hypothesized Variables Affecting Behavior of Participants in Study 1 (Based on Results of Teacher Version of the CAFI-T)

Table 5. Hypothesized Variables Affecting Behavior of Participants in Study 1 (Based on Results of Child Version of the CAFI)

Table 6. Relation Between Antecedents and Consequences Across Participants in Study 1 Table 7. Alternative Responses Identified by Teachers in Study 1, Phase B

Table 8. Agreement Between Teacher and Child Versions of the CAFI

Table 9. Agreement Between Teachers and Children on Consequences Affecting Behavior

Table 10. Assessment of Content Validity of the CAFI-T: Agreement Scores Between Expert Raters

Table 11. Target Responses and Operational Definitions for Each Participant in Study 2

Table 12. Percentage Agreement Between Teachers and Aides on Each Item of the CAFI-T (Study 2, Phase A)

Table 13. Agreement Between Teachers and Children on the CAFI

Table 14. Hypothesized Variables Affecting Behavior of Participants in Study 2 (Based on Results of Teacher Interviews)

Table 15. Hypothesized Variables Affecting Behavior of Participants in Study 2 (Based on Results of the Child Version of the CAFI)

Table 16. Agreement Between Teachers and Students on Consequences Affecting Behavior Table 17. Relation Between Antecedents and Consequences Across Participants in Study 2 Table 18. Inter-observer Agreement Coefficients for Hal Table 19. Inter-observer Agreement Coefficients for Jim Table 20. Agreement Between Teacher Interview and Direct Observations 


\section{Figure Captions}

Figure 1. Frequency with which consequences were endorsed for each challenging behavior for Participants 1-4 on the CAFI-T (Study 1, Phase B).

Figure 2. Frequency with which consequences were endorsed for each challenging behavior for Participants 5-8 on the CAFI-T (Study 1, Phase B).

Figure 3. Frequency with which consequences were endorsed for each challenging behavior for Participants 9 and 10 on the CAFI-T (Study 1, Phase B).

Figure 4. Frequency with which consequences were endorsed for each challenging behavior for Participants 3, 4, 5, and 7 on the CAFI-C (Study 1, Phase B).

Figure 5. Frequency with which consequences were endorsed for each challenging behavior for Participants 8 and 10 on the CAFI-C (Study 1, Phase B).

Figure 6. Number of items endorsed for a given consequence on the CAFI-T for Ben and Hal (Study 2).

Figure 7. Number of items endorsed for a given consequence on the CAFI-T for Jim and Tom (Study 2).

Figure 8. Proportion of challenging behavior preceded by antecedent stimuli in direct observations of Ben (Study 2).

Figure 9. Proportion of challenging behavior preceding consequent stimuli in direct observations of Ben (Study 2).

Figure 10. Proportion of challenging behavior preceded by antecedent stimuli in direct observations of Hal (Study 2).

Figure 11. Proportion of challenging behavior preceding consequent stimuli in direct observations of Hal (Study 2).

Figure 12. Proportion of challenging behavior preceded by antecedent stimuli in direct observations of Jim (Study 2). 
Figure 13. Proportion of challenging behavior preceding consequent stimuli in direct observations of Jim (Study 2).

Figure 14. Proportion of challenging behavior preceded by antecedent stimuli in direct observations of Tom (Study 2).

Figure 15. Proportion of challenging behavior preceding consequent stimuli in direct observations of Tom (Study 2). 


\section{Linking Functional Assessment with Diagnostic Classification: Development of Functional Assessment Methodology}

Classification systems play an important role in any science because they allow for the identification of similarities and differences between groups (Adams, 1972; Hersen \& Bellack, 1988; Nelson \& Hayes, 1986). Although some (e.g., Szasz, 1961) have argued that classification has no place in psychology, others (e.g., Adams; Hersen \& Bellack; Morey, Skinner, \& Blashfield, 1986; Scotti, Morris, McNeil, \& Hawkins, 1996; Sprock \& Blashfield, 1983) have not only maintained that classification is necessary, but also have delineated some of the purposes of a system of classification within psychology. First, these authors argued that a nosological system allows for communication between and among researchers and clinicians. That is, it provides a common set of terms for describing the phenomena of interest. For example, two psychologists can discuss the prevalence of individuals presenting with mental retardation in their practice, and be sure that they are comparing individuals who are similar to one another in certain ways.

Classification systems also are useful to psychologists because they allow for information retrieval. For example, a researcher can study the prevalence of certain psychological disorders during a given time period by conducting archival searches of the extent to which specific target behaviors (symptoms) were noted in the literature of that period. The ability to retrieve information has clinical utility, as well: a clinician seeking information about a certain diagnosis can simply use that diagnostic label to search a research base.

A third use of classification systems is description. Nelson and Hayes (1986) noted that, "The basis of classification systems is the identification of commonalties within groups of individuals . .. and the identification of differences between groups of individuals" (p. 9). Ideally then, a diagnostic label should provide a psychologist with information about certain behaviors that a person with a given diagnosis does and does not exhibit (Morey et al., 1986).

Classification systems also should allow for predictions about etiology and treatment decisions. That is, diagnostic classification should provide some information about how or why the disorder began as well as about what maintains it. Additionally, a diagnosis should guide clinicians to effective treatments. 
DSM as a System of Classification

The Diagnostic and Statistical Manual of Mental Disorders (DSM-IV; American Psychiatric Association [APA], 1994) is the prominent classification system used by behavioral health providers (e.g., psychologists, psychiatrists, social workers) in the United States. The DSM is a structural nosological system that is based on the medical model (Haynes \& O'Brien, 1990; Hersen \& Bellack, 1988; Kanfer \& Saslow, 1969; Nelson \& Hayes, 1986). The diagnostic categories of the DSM-IV provide a structural description of the behavior(s) of interest (Haynes \& O'Brien, 1990; Hersen \& Bellack, 1988; Nelson \& Hayes, 1986; Scotti, Morris, et al., 1996). That is, a given diagnosis is based on structural properties of responses, such as topography, form, or frequency. DSM criteria, therefore, focus on how people behave: individuals with the same DSM diagnosis should exhibit similar behaviors or patterns of behaviors.

Because the DSM-IV is based on a medical model of pathology (Kanfer \& Saslow, 1969; Luiselli, 1991; Mash \& Terdal, 1988; Morey et al., 1986), a given psychological disorder is often viewed as an $\underline{\text { illness }}$ or a disease resulting from internal, intraorganismic variables (Hayes \& Follette, 1993; Haynes \& O'Brien, 1990; Nelson \& Hayes, 1986). The medical model of behavior pathology has important philosophical, methodological, and political implications (Hayes \& Follette, 1993; Morey et al.). From a philosophical perspective, a focus on internal, underlying "causes" is antithetical to a behavior analytic approach which (as will be illustrated later) emphasizes the contextual variables that are related to the behavior of interest and are important in the prediction and control of behavior (Skinner, 1953). Methodologically, a great deal of research has sought the organic bases for behavioral disorders, rather than examining environmental variables that might also be important in the etiology and maintenance of such disorders (Morey et al., 1986). The medical model also has political implications. Morey et al. noted that, among the behavioral health professions, psychiatry has maintained a dominance, as is evidenced both economically (psychiatrists tend to earn larger salaries than do other professionals) and legally (psychiatrists are typically the only behavioral health practitioners who have admission and commitment privileges at hospitals). The dominance of psychiatrists, who are trained within the medical field, is justified only if behavior pathology is viewed as an illness that is best treated within the medical model (Guze, 1978; Morey et al.).

The utility of the DSM in the behavioral health field has been discussed extensively since its inception in 1952 (e.g., Hayes \& Follette, 1993; Luiselli, 1991; Morey et al., 1986; Nelson \& 
Barlow, 1981; Nelson \& Hayes, 1986; Scotti, Morris, et al., 1996). Rather than review all of these evaluations, the focus here is on the extent to which the DSM meets the goals of a classification system that were delineated earlier.

The DSM certainly has some utility for behavioral health providers. It provides a structure for communication, information retrieval, and description--three of the earlier mentioned purposes of a nosological system. From a behavioral perspective, the DSM is useful for communication, information retrieval, and description because it provides descriptive information about behaviors that tend to covary (Evans \& Nelson, 1986; Mash \& Hunsley, 1990; Nelson \& Barlow, 1981; Nelson \& Maser, 1988; Scotti, Morris, et al., 1996). Specifically, a DSM-IV diagnosis is primarily a list of responses that are more or less likely to occur together. For example, the diagnostic criteria for oppositional defiant disorder is a list of eight responses that are likely to covary (Frick et al., 1994). Although many diagnostic criteria were traditionally constructed based primarily on clinical intuition, there is an increasing use of literature reviews, statistical analyses, and field trials are increasingly to form diagnostic categories (Nelson \& Maser, 1988; Scotti, Morris, et al., 1996).

An emphasis on responses that tend to occur together is compatible with the increasing focus by behavior analysts on interrelations among behaviors (Mash, 1979; Nelson \& Maser, 1988; Scotti, Evans, Meyer, \& DiBenedetto, 1991; Scotti, Morris, et al., 1996). Although behavior therapy was at one time characterized by a focus on a single target behavior (Evans, 1985; Evans \& Nelson, 1986; Voeltz \& Evans, 1982), more recent work has emphasized the need to focus on multiple responses and the relation between them (Evans, 1985; Haynes, 1988; Nelson \& Maser, 1988, Scotti, Evans, Meyer, \& DiBenedetto, 1991; Scotti, Morris, et al., 1996). From this perspective, the term "syndrome" can be seen as a list of responses that tend to covary (Nelson $\&$ Barlow, 1981; Nelson \& Mayser, 1988; Scotti, Morris, et al., 1996). Therefore, the diagnostic category of oppositional defiant disorder is a list of eight responses that tend to occur together. For example, a child diagnosed with oppositional defiant disorder may emit vindictive responses, which results in his having fewer friends at school. As a result of the decreased social-peer interaction, he also is angry and resentful.

Although the utility of DSM nosology for communication, information retrieval, and description is acknowledged, the degree to which the DSM meets the fourth goal of classification systems, etiology and treatment selection, is equivocal (Hayes, Nelson, \& Jarrett, 1987; Korchin 
\& Schuldberg, 1981; McReynolds, 1985; Scotti, Morris, et al., 1996). Because the DSM is based on the medical model, it rests on the assumption that identification of topography (i.e., diagnosis) will lead to identification of etiology and maintenance--and therefore should point out an efficacious treatment strategy (Hayes \& Follette, 1993). The link between diagnostic category and treatment efficacy is not strong, however (Adams, 1972; Hayes \& Follette, 1993; Hayes et al., 1987; Korchin \& Schuldberg, 1981; McReynolds, 1985; Scotti, Morris, et al., 1996) and, as several researchers (e.g., Gresham \& Gansle, 1992; Hayes et al., 1987) have discussed, diagnosis based on DSM criteria does not affect treatment outcome. This is disturbing because, as Hayes and Follette (1993) pointed out, a primary goal of assessment for many clinicians is not to determine the best treatment for a given client but rather to determine the diagnostic category that best matches that client.

From a behavioral perspective, the reason that the DSM does not guide clinicians to efficacious treatment choices is precisely because of its nomothetic, structural base. In contrast to a structural model of classification, behavior analysis endorses a functional classification scheme. That is, the focus is on why behavior is occurring; on what environmental variables are maintaining the behavior of interest.

\section{Behavior Analysis and Functional Diagnosis}

It was noted earlier that the DSM takes a structural approach to behavior: the focus is on the form of the behavior. In contrast, behavior analysis utilizes a functional approach and therefore places emphasis on the why of behavior (Biglan \& Hayes, 1996; Branch, 1987; Nelson \& Hayes, 1986). In further contrast to the structural approach, behavior analysis maintains that the why of behavior is to be found in the environment, in the relations between a given behavior and the environmental variables of which it is a function (Baum, 1994; Baum \& Heath, 1992; Branch, 1987; Skinner, 1969, 1974, 1977, 1981). In this section, the behavior analytic approach to assessment is presented. First, the philosophical foundation for this approach is reviewed. Following this review, one methodology of behavior analytic assessment that is useful in evaluating "the why of behavior," functional assessment, is discussed.

\section{Pragmatism and Contextualism}

Behavior analysis, in contrast to many other psychological traditions, is based on a 
contextualistic philosophical tradition (Baum \& Heath, 1992; Chiesa, 1994; Dougher, 1993; Skinner, 1953, 1974, 1977, 1983). The focus is not on the structure of the behavior but rather on the relation between a given behavior and the context in which it occurs. To illustrate: a behavior analyst interested in determining why a child is swearing would likely observe the occurrence of the behavior over time and in multiple settings. The focus of this evaluation would not be solely on the topography of the swearing, nor would the swearing be taken as a sign of some inner, nonphysical cause (e.g., the child's negativistic attitude, poor sense of self, or defective personality). Rather, the focus would be on the relation between environmental events and the swearing. It is these environmental variables that determine the likelihood that a given behavior-in this case swearing--will occur again in the future. The relation between environmental events and a given behavior is called a functional relation. Skinner (1953) noted that a functional relation describes a change in the dependent variable as a result of a change in the independent variable. In a functional relation, the independent variables include both the environmental events that follow (consequences) and those that precede (antecedents) a given behavior. In the above example, it might be noted that the dependent variable--swearing--was affected by changes in events that occurred after the child swore--the independent variable. For example, when the child was regularly sent to his room after swearing, he began to swear less often, whereas when he was lectured after swearing he swore with greater frequency. Further, because in the past the child was more often lectured by his father and sent to his room by his mother, the presence of his father came to set the occasion for swearing while the presence of his mother did not. A functional relation, because it specifies the environmental events of which behavior is a function, allows for the prediction and control of behavior. That is, it specifies those environmental events that might be manipulated to affect a change in the behavior. To reduce the frequency with which the boy swears, the behavior analyst might instruct both parents to consistently send the boy to his room after swearing, instead of lecturing him.

Functional relations do not necessarily identify the "original" cause. Rather, they identify the variables of which behavior is currently a function. When behavior analysts consider causality, they do so from a pragmatic philosophical perspective. The focus is not necessarily on the underlying cause of behavior, but rather on the extent to which a "causal" explanation allows one to predict and control behavior. That is, "truth" is equated with an explanation that leads to effective action (Baum, 1994; Moore, 1992). Because a functional relation identifies the 
environmental variables that are related to the behavior of interest, it is a useful explanation of behavior. Therefore, an assessment that discerns those functional relations will be useful in guiding treatment decisions.

Behavior that continues to occur is somehow being reinforced. A functional relation specifies those reinforcement contingencies, as well as the environmental conditions under which they occur (i.e., the antecedents and consequences of the behavior of interest). Broadly speaking, all behavior is maintained by either positive or negative reinforcement. Positive reinforcement is the process by which the presentation of a stimulus, contingent on a response, increases the likelihood that response will occur again ( Skinner, 1953). Similarly, a negative reinforcer is a stimulus that, when removed contingent on a response, increases the likelihood that the response will occur again in the future (Skinner, 1953).

\section{Functional Assessment}

It should now be apparent that the philosophical and conceptual basis of behavior analysis is directly related to the goals of assessment: an assessment should identify functional relations because doing so will identify those variables that can be manipulated in order to predict and control behavior (Hawkins, 1986). Functional assessment is the strategy utilized by behavior analysts to identify functional relations (Ferster, 1965; Haynes \& O'Brien, 1990; Kanfer \& Saslow, 1969; Skinner, 1953). Although the term "functional assessment" is pervasive in the behavioral literature, Haynes and O'Brien noted that the term is often used inconsistently and interchangeably with other terms. For example, some authors have suggested that a functional assessment is a method of assessing the effects of the environment on a given behavior (Iwata, Dorsey, Slifer, Bauman, \& Richman, 1982/1994), while others have suggested that a functional assessment identifies target behaviors (e.g., Craighead, Kazdin, \& Mahoney, 1981). Other terms used in place of or in addition to functional assessment include "behavioral case formulation" (Wolpe \& Turkat, 1985), "functional assessment" (e.g., Grace, Kahng, \& Fisher, 1994), and "behavioral assessment" (Munk \& Repp, 1994). Haynes and O'Brien pointed out that these discrepancies hamper communication not only about the nature and role of functional assessment, but also about the methodology that might be used to carry out such an assessment.

Functional Assessment Defined 
Because the identification of functional relations is a crucial aspect of behavioral assessment, it seems important to define adequately the process utilized to identify functional relations. Haynes and O'Brien (1990) defined functional assessment as: "the identification of important, controllable, causal functional relationships applicable to a specified set of target behaviors for an individual client" (p. 654). This definition implies several important characteristics of functional assessment.

First, it identifies only those relations that are: (a) important, (b) controllable, and (c) causal. Important functional relations involve variables that, if manipulated, are likely to affect a change in the dependent variable. For example, while there might be a statistically significant relation between the number of people who go to the beach and the number of people carrying an umbrella on a given day, changing one of these variables is not likely to affect the other. Haynes and O'Brien (1990) stated that functional analyses also identify those variables that are controllable. This is consistent with the pragmatic goal of behavior analysis: the prediction and control of behavior. A functional relation that identifies an important, causal, but uncontrollable variable does not assist in the prediction and control of behavior. In addition to being important and controllable, those variables identified by a functional assessment must be causal. It is important to note that causal does not necessarily imply that these variables are the variables that resulted in the initiation of the behavior; causal variables might also be those variables that are currently maintaining the behavior. That is, "a 'causal' variable is a functional variable whose modification leads (or would lead) to a change in a parameter (e.g., probability, rate, magnitude) of a designated dependent variable" (Haynes \& O'Brien, p. 651).

A second important characteristic of functional assessments is that they are relevant to all of human behavior (Haynes \& O'Brien, 1990; Skinner, 1953). Within the framework of behavior analysis, all events, both public and private are natural, physical events (Baum \& Heath, 1992; Skinner, 1953). Further, these responses are a function of environmental variables. Although private events may acquire discriminative control over other responses, both overt and covert, it is important to note that a complete functional assessment does not stop with the identification of that relation. Rather, the functional assessment must identify both the environmental determinants of the private event and the situations under which that private event exerts stimulus control over other behavior (Anderson, Hawkins, \& Scotti, 1997; Forsyth, Lejuez, Hawkins, \& Eifert, 1996; Hayes \& Brownstein, 1986; Skinner, 1953). 
A final characteristic of functional assessments is that they are idiographic (Haynes \& O'Brien, 1990). That is, a functional assessment evaluates the relation between behavior and the environmental variables that maintain it for a specific individual. The idiographic nature of functional assessment stems from recognition of the fact that although individuals may emit topographically similar responses, it is likely that those responses are the result of distinct learning histories. For example, one child may hit her brother because, in the past this behavior has resulted in attention from her mother. Another child may also hit her brother, but may do so because in the past this behavior resulted in her being sent outside (away from the aversive smoke of her grandfather's cigar). In the first case, the child's behavior was maintained by positive, social reinforcement, while in the second the behavior was maintained by negative reinforcement.

\section{Functional Assessment Methodology}

Conducting a functional assessment to develop hypotheses about environmental variables that are maintaining target behaviors is a crucial part of behavioral assessment. A number of techniques have been developed in recent years to assist in accomplishing this goal. These techniques include both direct and indirect methods of assessment.

Indirect methods of functional assessment. Indirect methods of functional assessment enable the clinician to gather information about the target behavior without directly observing the behavior. Indirect methods that may be utilized include structured and unstructured interviews, rating scales and questionnaires.

Interviews are the most commonly utilized assessment in behavioral health services (Korchin, 1976; Turkat, 1986). There are a wide variety of clinical interviews available; however, only a few of these are designed to provide information about the function(s) of a given behavior. Interviews can be classified as either structured, semi-structured, or unstructured. Structured interviews provide one format for the clinician to indirectly gather detailed information about the individual being assessed. One example is the Functional Assessment Interview (FAI), developed by O'Neill, Horner, Albin, Sprague, Storey, and Newton (1997). The FAI provides a structured format to gather information about the: (a) topography, frequency, and intensity of the behavior(s) of interest; (b) antecedent events (both in terms of setting events and 
establishing operations); and (c) consequences of the behavior. The interview also allows for the assessment of a variety of adaptive behaviors, such as communication and daily living skills, and it may help the clinician identify potential reinforcers. The FAI was designed for use with persons with developmental disabilities and certain sections seem inappropriate for typically developed individuals. For example, one section is devoted to the way that the target individual communicates (e.g., through gestures, verbally). Although this section is appropriate for individuals with limited verbal abilities, the majority of typically developed individuals who exhibit challenging behaviors have adequate verbal communication skills. Although other structured functional assessment interviews exist (e.g., Willis, LaVigna, \& Donnellan, 1987), none are designed for use with typically developed populations, and would thus likely require significant modifications prior to their use.

The developers of the FAI (O'Neill and colleagues) recently published a semi-structured interview designed for use with children exhibiting challenging behavior in schools (O'Neill et al., 1997). This interview, called the Student Directed Functional Assessment Interview asks the student to define the challenging behaviors of concern, use a school schedule to identify the classes and times of day where problems are most likely to occur, and use a list of situations to identify setting events, antecedent stimuli, and consequences related to the challenging behavior. This interview is promising because it gathers information directly from the student, who may be better able to identify the reasons why challenging behavior occurs.

Unstructured interviews are another indirect way of developing hypotheses about maintaining variables. Sturmey (1996) noted that unstructured functional assessment interviews are hypothesis driven. That is, the clinician develops hypotheses about the variables that might be maintaining target behaviors and then structures the interview to determine the validity of those hypotheses. Kanfer and Saslow (1969) proposed a series of steps to be utilized in determining the function(s) of client behaviors in order to develop efficacious treatment. This formulation guides the clinician through a series of steps including: (a) defining the responses of concern, (b) developing hypotheses about the antecedent and consequent stimuli associated with the target responses, (c) determining stimuli that might function as reinforcers or punishers, (d) assessing biological and medical variables that might be related to the presenting problem, (e) determining alternative behaviors in the individual's repertoire, (f) analyzing social relationships, and $(\mathrm{g})$ determining environmental resources and deficits. Although this format provides some 
guidance as to what should be accomplished in an interview, it is considered unstructured because the authors do not provide specific questions or strategies to use in order to obtain the desired information.

Rating scales and questionnaires are a second method of indirect assessment. One example is the Motivation Assessment Scale (MAS), developed by Durand and Crimmins (1988). The MAS was designed to assess whether the targeted behavior is being maintained by positive reinforcement from either access to tangibles or attention, negative reinforcement through escape from tasks, or automatic reinforcement (either positively or negatively reinforced). The MAS was designed for use with individuals with developmental disabilities exhibiting self-injurious behavior. Although it has been extended to other target behaviors in this population, it may be insufficient for use with typically developed individuals.

Indirect assessment methods, such as interviews and rating scales, tend to be convenient and easy to use. Additionally, they may be useful in situations where potentially maintaining variables cannot be easily evaluated, such as when the behavior occurs relatively infrequently or because the individual behaves differently when being observed. Because the clinician only has access to the target behavior through the report of another, there are several limitations to these methods. First, the accuracy of these assessments is directly related to the quality and quantity of the observations conducted by the interviewee. A second difficulty is related to how well the interviewee is able to recall events as they actually occurred. Finally, observer bias and observer expectancies may also come into play (Barlow, Hayes, \& Nelson, 1984). For example, a parent may over-report the intensity of tantrums in hopes that it will lead to treatment being initiated more quickly.

Direct methods of functional assessment. Other methods of assessment involve direct observation of the target behavior. Direct methods involve either directly measuring a client's behavior in the natural environment or utilizing analog methodology to assess behavior in contrived settings.

A functional assessment conducted in the natural environment involves recording each occurrence of the target behavior, as well as antecedent and consequent events. Such assessments, often called descriptive analyses (e.g., Freeman, Anderson, \& Scotti, 1996; Iwata, Vollmer, \& Zarcone, 1990; Lennox \& Miltenberger, 1989; Lerman \& Iwata, 1993), can be used 
to identify correlations between a behavior and its antecedents and consequences. One example of a descriptive analysis is the A-B-C (antecedent-behavior-consequence) analysis chart (SulzerAzaroff \& Mayer, 1977). A clinician using the A-B-C analysis would observe the individual in his or her natural environment and record what occurred just before and just after exhibition of the target behavior(s). This allows for an evaluation of the context in which behavior typically occurs.

Naturalistic observations are advantageous because the clinician is able to observe the client's behavior and the environmental events that are related to it as they actually occur. Further, they may allow the clinician to identify a broad range of potentially maintaining variables. For example, the results of a descriptive analysis may suggest that a participant's self-injury is being maintained by access to soda in the cafeteria but not by access to soda at home. Disadvantages of naturalistic observations also have been noted. First, if the behavior occurs only infrequently, the observer may be forced to conduct lengthy observations to observe even one occurrence of the behavior. Second, because the environmental variables are not being directly manipulated it may be difficult to determine those variables that are functionally-related to the target response. For example, Iwata et al. (1990) suggested that, if the behavior is being reinforced on a thin, intermittent schedule, it may be hard to identify what events are maintaining it. Similarly, because data only are recorded when the target behavior occurs, there is no way of determining whether those same environmental events also are associated with the nonoccurrence of the target behavior (Lerman \& Iwata, 1993). For example, an A-B-C analysis might reveal that each time a child emitted an aggressive response, a math assignment had just been started. Based on this information, one might hypothesize that math assignments were a discriminative stimulus for aggressive behaviors. Perhaps, however, many math assignments were given throughout the day and only a very small percentage of them were followed by aggressive behavior. A third difficulty that may be incurred when naturalistic observations are used is that the consequential stimuli that maintain a behavior may not be readily observable if the target behavior is rulegoverned or otherwise under stimulus control, or if the behavior is maintained on a very thin, intermittent schedule of reinforcement. Another difficulty that may be encountered is that the presence of an observer or recording equipment may result in the individual behaving in a different manner than they otherwise would (Hay, Nelson, \& Hay, 1980; Nay, 1986). A final limitation on the use of naturalistic observation is that the cost in terms of number of staff 
necessary and time commitment may be high (Nay, 1986).

Another way that the function of a targeted behavior may be ascertained is through the use of analog methodology. Analog functional analyses are typically conducted in controlled settings and utilize simulated conditions designed to mimic the natural environment. In analog assessments, both the antecedent conditions that may occasion the target behavior and the consequent events that may be maintaining the behavior are experimentally manipulated. Iwata et al. (1982/1994) developed an example of analog methodology that is frequently cited in the developmental disabilities literature. In this type of analog, four experimental conditions are conducted: (a) social disapproval, designed to test the hypothesis of attention as a maintaining variable; (b) work, designed to test the hypothesis of negative reinforcement in the form of escape from an aversive situation; (c) unstructured play, designed to be both a control condition and an "enriched environment;" and (d) an alone condition, designed to test the hypothesis of automatic or sensory reinforcement. Based on the rates of the target response in each condition relative to the observed rates in other conditions, the experimenter is able to ascertain whether those variables manipulated in the analog are functionally related to the target response.

Because analog methodologies allow for experimental control of environmental variables, the experimenter is able to empirically demonstrate that manipulation of particular antecedent or consequent events affects some temporal characteristic of the target response. Also, the experimenter is able to set up the situation so that those variables hypothesized to be related to the behavior are present. Although many researchers run analogs similar to the Iwata et al. (1982/1994) analysis and use a fairly circumscribed set of variables (e.g., adult attention, preacademic tasks), some researchers (e.g., Mace, Lalli, \& Lalli, 1991; Scotti, Schulman, \& Hojnacki, 1994) have modified the analog methodology to include more idiographic variables. For example, a clinician who hypothesized that a child was skipping a particular class because of the difficulty of the work during that class might set up a situation where level of difficulty was the independent variable.

Although analog assessments allow more experimental control, their use is restricted by several limitations. First, because the majority of analog assessments are carried out in a separate area, away from where the client usually spends their time and typically involve only a restricted range of stimuli, it is possible that the assessment may not reveal all the variables that are maintaining the behavior in the natural environment (Scotti et al., 1994). Additionally, in an 
analog assessment, the contingencies are generally delivered on a set schedule that is probably markedly different from the reinforcement schedule in place in the natural environment. These differences may result in the functional assessment identifying maintaining variables that are different than those variables maintaining the behavior in the natural environment (Iwata et al., 1990; Scotti et al., 1994). The utility of the analog assessment also may be limited in some settings because they require trained staff and can be time consuming.

\section{Functional Assessment: Current Status and Future Directions}

It should be apparent that functional assessment methodology has much to offer clinical psychology. This methodology provides a way to determine those environmental variables that are maintaining behavior. Such methodology leads naturally to selection of treatment strategies that manipulate those variables identified by the functional assessment. For example, Iwata et al. (1994) demonstrated the efficacy of conducting pre-intervention functional analyses with 152 individuals exhibiting self-injurious behavior. This study demonstrated that treatments matched to function were far more effective than other treatments. For example, for those individuals whose self-injury was maintained by social-positive reinforcement, treatments such as noncontingent attention, extinction (no longer attending to self-injury), and differentially reinforcing alternative behaviors were highly effective, while treatments such as verbal reprimands--which provide contingent attention--were not effective. Similarly, Taylor and Miller (1997) demonstrated that time-out from attention was an effective treatment for two children whose challenging behavior was maintained by adult attention, but not for two children whose challenging behavior was maintained by escape from tasks. Further examples of functional assessment guiding treatment can be found in almost every issue of Journal of Applied Behavior Analysis, which recently devoted an entire issue to functional assessment (Neef, 1994).

Based on studies supporting the utility of pre-treatment functional assessments, some organizations have begun to call for their use prior to developing a behavior intervention plan. For example, the Association for Behavior Analysis maintains that all individuals who require behavioral interventions should receive a functional assessment prior to treatment development (Van Houten et al., 1988). ). Additionally, the reauthorization of the Individuals with Disabilities Education Act in 1997 (IDEA, Public Law 105-17) mandates the use of a functional assessment for students with individualized education plans. Although functional assessment technology 
seemingly has much to offer, such assessments are not widely used, even in the developmental disabilities literature where use of behavior analytic technology is most prevalent. Recent metaanalyses conducted on the developmental disabilities literature exemplify this point. Scotti, Ujcich, Weigle, Holland, and Kirk (1996) reported that only $49 \%$ of 171 studies conducted during a five-year period had utilized a functional assessment. Although this is an improvement over a previous study that reported the use of a functional assessment in less than $25 \%$ of surveyed studies (Scotti, Evans, Meyer, \& Walker, 1991), these numbers are still discouraging. In spite of the documented utility of functional assessment in guiding treatment development, this methodology is also vastly underutilized in the behavioral literature with typically developed individuals. To illustrate, Scotti, McMorrow, and Trawitzki (1993) examined published studies with chronic psychiatric disorders spanning a 30-year period and reported that less than 3\% of those studies utilized any form of functional assessment. Kirk (in press) and Mullen (1995) examined the literature on childhood disorders and found that functional assessment strategies are rarely used in published treatment studies for behaviors categorized under the labels attention-deficit disorder (Kirk) or oppositional behavior and conduct problems (Mullen). As was noted by Scotti, Morris, et al. (1996) "if the published behavioral literature provides a poor model for the utilization of functional assessment, it is not at all surprising that functional criteria have not been incorporated into diagnostic schemes such as the DSM" (p. 11).

There are several reasons why functional assessment methodology is rarely used outside of the developmental disabilities literature. First, and as was noted earlier, the wide-spread acceptance of a structural model of pathology has diminished interest in idiographic, contextual analyses of pathology. There are, however, other reasons why this methodology is not widely used; reasons that are related to deficiencies in current functional assessment methodology (Haynes \& O'Brien, 1990; Mace, 1994; Scotti, Morris, et al., 1996). For example, there are no guidelines to help clinicians determine which functional assessment technique to use (Scotti, Morris, et al.), or how to interpret the results of, and derive treatment decisions from a functional assessment (Hayes \& Follette, 1992; Haynes \& O'Brien, 1990; Scotti et al., 1994). Further, few structured methods of functional assessment have been developed for use with typically developed populations. There are also psychometric deficits in the functional assessment technology, including: (a) poor reliability across and within functional assessment methods (Anderson, Freeman, \& Scotti, 1999; Iwata et al., 1994; Lerman \& Iwata, 1993; Mace \& Lalli, 
1991; Scotti, Kirk, et al., 1993; Scotti, Weigle, et al., 1993) and across clinicians evaluating the results (Scotti, Morris et al.), and (b) inconclusive internal validity (Anderson et al., 1999).

Although there are problems with functional assessment methodology as it currently exists, it is important to note that psychometric deficiencies also are pervasive in more traditional methods of assessment (Scotti, Morris, et al., 1996). It does not seem unreasonable to expect that, as more research focuses on functional assessment methodology, many of the current deficiencies will be remediated such efforts are even now apparent in the functional assessment literature. For example, Freeman et al. (1996) developed a strategy to meld the experimental control of analog methodology with the benefits of naturalistic observation. Other researchers (e.g., Hagopian, Fisher, Thompson, \& Owen, 1996) are developing specific criteria for interpreting the results of functional analyses. Finally, others are calling for the inclusion of more complex variables and their interrelations in functional analyses (Carr, 1994; Haynes \& O'Brien, 1990).

If functional assessment technology is ever to be accepted and widely used in clinical psychology, it will have to be shown that conducting a functional assessment increases the clinician's ability to develop an efficacious treatment. Although this has been demonstrated to some degree in the developmental disabilities literature (e.g., Iwata et al., 1994; Scotti, Evans, Meyer, \& Walker, 1991), it does not seem likely that similar results will be demonstrated with other populations until standardized methods of functional assessment are developed for use with typically developed individuals. To illustrate: a great deal of effort has been put into developing more comprehensive analog functional analyses (see, the 1994 special issue of Journal of Applied Behavior Analysis), while only sparse attention has been paid to developing functional assessment interviews and other indirect functional assessment methodologies.

Although highly structured, direct observational methodology may, at times, be appropriate when working with individuals with severe disabilities, such methodology is unlikely to be useful for clinicians working with typically developed clients. For example, an individual presenting with a diagnosis of conduct disorder is likely to emit many behaviors (e.g., stealing, truancy, violating curfew) that would be difficult, if not impossible to evoke in an analog situation. Further, because such behaviors often occur sporadically and somewhat infrequently (i.e., less than once per day), it is not likely that any direct observation technique would be useful in determining the environmental variables maintaining such behavior. It seems important, therefore, that researchers and clinicians begin to develop efficacious indirect functional 
assessment methodologies that are applicable to a wider variety of clients and client problems. Such indirect methods could include questionnaires and ratings scales; however, it seems likely that a semi-structured or structured interview would be highly useful in determining, not only the functions of target behaviors, but other valuable information as well. The analysis developed by Kanfer and Saslow (1969) delineates broad areas that such an interview might assess.

Specifically, researchers could develop interview questions designed to evoke information regarding each of the areas in Kanfer and Saslow's outline. Such an assessment would be useful, not just in delineating the variables maintaining the target behavior but also in identifying environmental supports and deficiencies. Such information is vital in developing a comprehensive treatment plan designed to increase the individual's appropriate skills and decrease problematic behaviors.

\section{Linking Functional assessment with DSM Criteria}

Although there are a number of difficulties with the current state of functional assessment technology, it should be apparent that idiographic assessment of the variables maintaining behavior is a valuable contribution from the behavior-analytic field. Scotti, Morris, et al. (1996) noted that neither the DSM structural system, nor the behavior analytic functional system, are currently at a point where sole utilization of one over the other is supported by the data. They therefore suggested that a strategy linking functional assessment with DSM criteria would allow for the benefits of both systems to be incurred. Such a strategy would utilize the list of possibly covarying responses provided by DSM diagnosis to determine target behaviors for further analysis and intervention. An idiographic functional assessment could then be conducted on these target behaviors to determine the environmental variables that are maintaining responding for that individual. A critical component of this approach is evaluation, not just of the problematic responses, but also of alternative behaviors in the individual's repertoire and of environmental resources and deficits. Such a comprehensive assessment would identify, not only the variables maintaining challenging behavior, but also environmental resources that would be useful in establishing and maintaining more appropriate alternative behaviors.

Although the utility of functional assessment methodology must eventually be evaluated across multiple diagnostic groups and must include treatment outcome data, an important first step is to determine the feasibility and utility of conducting a functional assessment with 
typically developed populations. The purpose of this study was to develop and evaluate the clinical utility of structured functional assessment interviews with typically developed children exhibiting challenging behavior. Additionally, the relation between diagnostic categories and functional relations was explored. To accomplish these goals, two different functional assessment methodologies were compared: semi-structured interviews administered to teachers and children, and direct observations.

The utility of these methods was evaluated by comparing: (a) information provided; (b) cost, in terms of time and staff requirements; and (c) agreement regarding functional relations for each child's behavior. The relation between DSM diagnosis and functional response classes was examined by evaluating the extent to which the target behaviors (symptoms) exhibited by children who met criteria for the same diagnosis varied in both topography and function. To accomplish the goals of this project, two studies were conducted. The first study involved developing structured interviews for use with typically developed children and their teachers, and evaluating the interviews' inter-rater agreement. In the second study, the results of structured interviews and direct observations of target behaviors were compared.

\section{STUDY 1: INTERVIEW DEVELOPMENT}

This study was conducted in three phases. The first phase (A) involved developing and refining a structured interview. The second phase (B) involved administering the interviews to 10 children and their teachers. In the third phase $(C)$, small structural changes were made to the interviews and expert raters evaluated the content validity of the interviews.

\section{Phase A: Interview Development}

\section{Method}

\section{Participants}

Ten professionals familiar with the philosophy and methodology of functional assessment and with externalizing disorders served as reviewers to assist in development of the interview forms. Of these ten professionals, four held doctoral degrees in psychology, three held master's degrees, and three held bachelor's degrees in psychology. The master's and bachelor's-level reviewers were graduate students pursuing advanced degrees in psychology. All doctoral-level reviewers had been active in conducting functional assessment and treating externalizing 
behavior disorders for at least ten years. All reviewers with master's or bachelor's degrees had been conducting functional assessments for at least five years.

\section{Measures}

The measures used in Phase A were two structured interviews developed by the primary investigator. These interviews were developed based on the primary investigator's knowledge of the philosophy of functional assessment and past experience conducting both direct and indirect functional analyses. Additionally, the development of the interview items was guided by existing functional assessment interviews (i.e., O’Neill, Horner, Albin, Storey, \& Sprague, 1990; Reed, Thomas, Sprague, \& Horner, 1997). The first interview was designed for administration to teachers and the second to children. The purpose of the interviews was to assist the interviewer in: (a) defining behaviors of concern in terms of topography, duration, intensity, and frequency; (b) determining the antecedents and consequences of challenging behaviors; (c) developing hypotheses about alternative responses in the same response class as the challenging behaviors; (d) determining any establishing operations related to challenging behaviors; and (e) developing a list of possible reinforcers to be used in treatment development.

Both interviews were divided into several sections. Questions in the first part of the interviews assessed for potential antecedents to challenging behavior. Respondents were asked to rate the extent to which challenging behavior was likely to occur in certain situations, such as when the child was asked to work on a difficult task, using a 5-point Likert rating scale $(1=$ "almost never," 5 = "very often"). If the respondent rated the item as a "3" or above, he or she was asked to list the behaviors that were likely to occur and to describe how others reacted when those behaviors occurred. This allowed for an assessment of the consequences that typically follow challenging behavior in given situations. The second part of the interviews was designed to assist in gathering information about potential rewards or reinforcers. In this section, respondents listed items and activities the child enjoyed. The third part addressed social skills deficits by assessing the extent to which the child enjoyed playing with others, and was sought out by peers to play and work. The fourth part of the interviews assessed possible setting events (e.g., lack of food, illness, family problems) by using a Likert rating scale to determine the extent to which each event might be affecting the child's behavior at school. The fifth and final part of the interviews was designed to assess for alternative behaviors already in the child's repertoire. 
This section also could be used to determine functional skills that might be taught to reduce challenging behavior. Respondents were provided with a list of appropriate behaviors and were asked to rate the extent to which the child exhibited each behavior on a 5-point Likert rating scale. The interview form also contained a summary sheet to assist in the development of hypotheses regarding the function(s) of challenging behaviors.

\section{Procedure}

The ten professionals identified in the "Participants" section reviewed the interviews to determine the extent to which they: (a) provided information useful in developing hypotheses about variables maintaining challenging behavior, (b) allowed for an assessment of alternative behaviors that the child may exhibit, and (c) provided information about potential rewards or reinforcers. Changes and modifications were made to the interviews based on the evaluators' recommendations as described in the Results section.

\section{Results}

Three specific changes were recommended by the reviewers (the modified teacher interview is in Appendix A, the modified child interview is in Appendix B). First, three raters suggested that, instead of providing interviewees with a list of potential alternative behaviors and asking them to select responses the child sometimes emitted, the respondents be asked to identify alternative behaviors for a given response class (e.g., adult attention seeking). Thus, Part V of the teacher interview was modified such that teachers were asked, "What positive strategies does this child sometimes use to (e.g., get your attention)?" For each response provided, the teacher was asked to rate the frequency with which the child emitted the response using a 5-point Likert scale (1 = "almost never," 5 = "all the time").

The second change suggested by all reviewers was to ask questions about events going on at the child's home that might affect behavior. Thus, in Part IV, several setting events specific to the child's home-life were added, including "abuse at home," "fighting at home," and "effect of siblings."

The final change was based on a suggestion by one reviewer to add a question about work that is boring. That is, in addition to assessing whether "difficult" or "easy" work might affect behavior, to also assess whether presentation of work the child found boring might be an 
antecedent stimulus. Following the review and modification of the interviews, the forms were field tested with 10 children (Phase B).

\section{Phase B: Field Testing}

\section{$\underline{\text { Method }}$}

\section{Participants and Setting}

The children who participated in this study were referred to the University Affiliated Center for Developmental Disabilities at West Virginia University or Valley Community Behavioral Health Center in Grafton, WV for the assessment and treatment of behaviors consistent with a diagnosis of oppositional defiant disorder. Because all participants were minors, consent for participation was obtained from the children's parent or guardian prior to participation in this study. The consent form is in Appendix C. All children were typically developed males between the ages of 7 and 11 years. With the exception of one participant (an African-American), all children were Caucasian. Ages of each participant and diagnostic information are presented in Table 1. Three of the children were placed in a classroom for children with behavior disorders, while the others were in regular education classrooms.

All of the teachers who participated in this study were elementary school teachers. They were responsible for one class throughout each day. Class sizes ranged from 18 to 27 children. All teachers had at least five years of teaching experience. The same teacher was interviewed for Participants 5 and 7; the remaining teachers were interviewed for only one child. The consent form signed by teachers is in Appendix D.

All interviews were administered at the child's school. Interviews with participants took place in a room where only the primary investigator and the participant were present. The majority of teacher interviews took place in the teacher's classroom during the teachers' planning period, while most child interviews took place in the school psychologist's office.

\section{$\underline{\text { Response Definitions and Measurement }}$}

Topographies of challenging behaviors focused on in the interviews were identified by asking teachers to complete a questionnaire about the target child's behavior (see Appendix E). The questionnaire consisted of the behavioral criteria for oppositional defiant disorder, conduct disorder, and attention-deficit disorder. Using a Likert-style rating scale, teachers were asked to 
rate the extent to which the target child exhibited each behavior, as compared to most other children his age. The Likert scale ranged from 1 ("almost never") to 4 ("very often"). After completion of the questionnaire, the teacher was asked to focus on those behaviors consistent with a diagnosis of oppositional defiant disorder and to identify the three most problematic behaviors exhibited by the child. The teacher was then asked to provide operational definitions for those three responses (see Table 2 for the target responses and operational definitions for each participant). The three most problematic responses were the focus of the structured functional assessment interviews.

\section{$\underline{\text { Measures }}$}

The measures used in Phase B were two structured interviews, each called the Clinical Analysis of Function Interview (CAFI), developed by the primary investigator. Again, one interview was designed for use with the child's teacher (CAFI-T, see Appendix A) while the other was for use with the target child (CAFI-C, see Appendix B) These interviews were developed based on comments from reviewers in Phase A of this study.

\section{$\underline{\text { Procedure }}$}

Interviews were administered by the primary investigator and were audio-taped for later scoring by the primary investigator and trained undergraduate research assistants. Research assistants were trained by first reading relevant articles on functional assessment and then by practicing coding mock interviews. After administration of the interviews, the primary investigator listened to and coded all interviews, and a second rater (a trained undergraduate research assistant) independently listened to and coded responses for $60 \%$ of the CAFI-T (6 out of 10$)$ and $50 \%$ of the CAFI-C (3 out of 6$)$.

The CAFI-T took approximately 30 minutes to administer and the CAFI-C took approximately 20 minutes to administer. The CAFI-T was administered to the teachers of all 10 children, however the CAFI-C was administered to only six of the children. This occurred for two reasons. First some participants (numbers 1, 2, and 9) refused to participate in the interview process. Second, Participant 6 was suspended from school when the interviews were being administered. After suspension, Participant 6 was placed in a different school (outside of the state). 
$\underline{\text { Results }}$

\section{Agreement Scores on the CAFI-C and CAFI-T}

Inter-rater agreement scores were calculated for each item by evaluating the extent to which raters agreed or disagreed about the response provided. For each item, percentage agreement scores were calculated by dividing the number of "agrees" for that item by the total number of interviews coded by two raters (i.e., six for the CAFI-T, three for the CAFI-C). Agreement scores for the CAFI-T are reported in Table 3.

Agreement between raters was high on the teacher version of the CAFI. In Part I (Antecedents and Consequences), mean agreement on Likert-ratings provided by the respondent was $100 \%$ (see "Rating" column). Agreement about the target responses identified in each item also was high (see "Behavior" column), with a mean agreement of 96\% (range 83-100\%). Also in Part I, respondents were asked to identify how others would respond if the child exhibited a target behavior. Agreement about this was 94\% (range 67-100\%, see "Response" column). In Part II (Preferred Classes and Activities), respondents were asked to identify preferred activities and the frequency with which those activities occurred. Mean agreement about both activities and the frequency with which they occurred was $100 \%$. Items in Part III asked respondents to assess the child's social skills using a Likert scale; mean agreement was 100\%. Items in Part IV focused on potential setting events. Respondents were asked to rate the extent to which an event might be affecting a child's behavior using a Likert scale. Also, if respondents indicated that a given event was having an effect, they were asked to identify how that event was affecting the child. Mean agreement about Likert-ratings (see "Rating" column) was 96\% (range 83-100\%). Mean agreement about the behavior likely to be emitted (see "Behavior" column) was 95\% (range 83-100\%). In Part V of the interviews, respondents were asked to identify alternative responses the child might exhibit, and how often those responses occurred. Mean agreement about the frequency with which responses occurred (see "Rating" column) was $100 \%$. Mean agreement about the responses that might occur (see "Behavior" column) was $96 \%$ (range 83 to 100).

Agreement between raters also was generally high on the child version of the CAFI. In fact, agreement was $100 \%$ for all items with the exception of Part II. In Part II (Preferred Activities and Items), mean agreement about both the activities that were preferred and the frequency was 
variable. The mean agreement score was $84 \%$ (range (67-100\%) for preferred activities, and the mean agreement on the frequency with which those activities occurred was $67 \%$. Mean agreement in Part III (Social Skills) was 100\%. In Part IV (Setting Events), mean agreement about the extent to which an event might be affecting behavior (see "Rating" column) and how that event might have an effect ( "Response" column) were both $100 \%$.

\section{Agreement Scores on the Summary Forms}

After administration of the CAFI-T and CAFI-C, the primary investigator completed the Summary Forms for both interviews for each participant (Summary Forms are included with the interviews in Appendices A and B). To evaluate the extent to which the Summary Forms were useful in developing hypotheses about maintaining variables, the Summary Forms were completed by independent raters (trained undergraduate research assistants) on $60 \%$ of the CAFI-T and 50\% of the CAFI-C. Agreement scores were calculated for Sections I, II, and IV (Antecedent Information, Setting Events Information, and Replacement Behaviors) by dividing the number of rater-pairs who agreed about an item (provided the same response) by the total number of rater-pairs (i.e., 6 for the CAFI-T, 3 for the CAFI-C). Agreement on Section III (Consequences) was evaluated by examining the extent to which rater-pairs agreed that a given consequence was_ or was not—identified for each item. If raters agreed about all functions on an item, an "agree" was scored. If raters disagreed about any function (e.g., one rater scored a function that the other rater did not), a "disagree" was scored. Mean agreement scores were then calculated for each item by dividing the number of rater-pairs that agreed about the identified function on that item by the total number of rater-pairs.

Agreement on the Summary Forms for the teacher version of the CAFI was high for all sections. In fact, agreement was $100 \%$ for all items in Sections I, II, and IV. In Section III (Consequences), agreement was $100 \%$ for 9 of 13 items. On the remaining four items, one pair out of five disagreed about one consequence ( $80 \%$ agreement). Importantly, however, these disagreements did not affect the determination of maintaining variables. That is, all raters agreed at least $80 \%$ of the time about the consequences maintaining challenging behavior.

Agreement scores for child version of the CAFI Summary Forms were high, as well. With the exception of one item in Section II (Item 2, on which one rater-pair disagreed), agreement was $100 \%$ for all items in each section. Most importantly, rater-pairs agreed about the 
function of challenging behavior suggested by each interview $100 \%$ of the time (Section III, Consequences).

\section{Hypotheses Regarding Functional Relations}

After completion of the Summary Forms, hypotheses regarding the function of challenging behavior were developed for each participant. Hypotheses were developed from Sections I, II, and III of the Summary Form.

Hypotheses regarding antecedent stimuli were developed from Section I of the Summary Form. Each stimulus that was rated "yes" (given a rating of "3" or greater on the interview) was coded as an antecedent stimulus. Hypotheses about potential setting events were developed based on Section II of the Summary Form. Again, each stimulus rated "yes" (given a rating of " 3 " or greater on the interview) was coded as a setting event. Hypotheses regarding consequent stimuli were developed based on Section III of the Summary Form. For each participant, the number of items endorsed under each hypothesis (listed in columns) was calculated. That is, the number of items from Part I of the interviews for which a specific function was identified as a consequence for behavior was calculated. This was done to determine the number of situations in which, after a target response occurred, a given consequence occurred. This allowed for hypothesized functions to be rank ordered from most to least important based on the frequency each was reported. For each participant, "combined" challenging behavior was determined by summing the number of items on which a specific consequence was identified. For example, if "Adult Attention" was identified on seven items, the "Combined" number of items would be seven. If a specific consequence was identified for more than one challenging behavior on a given item, that consequence was only counted one time. For example, if on Item 2, the teacher said that both "Blaming Others" and "Argues with Adults" were followed by "Adult Attention," this consequence would only be scored once. Thus, the maximum score for "Combined" was 13 (the total number of items).

Hypothesized variables affecting children's behavior according to the teacher version of the CAFI are in Table 4, variables derived from the child version are in Table 5. For each participant, potential setting events and antecedent stimuli are listed first. Next, consequences identified for each participant are specified. 
Setting events and antecedent stimuli. Teachers and children tended to identify multiple setting events for challenging behavior (mean number of setting events identified by teachers was 3.3 , and 2.2 by children). Further, the stimuli identified as setting events were varied. That is, with the exception of "Social Skills Deficits," which was identified by 9 of 10 teachers and 5 of 6 children, no single setting event was identified more often than any other. Finally, some stimuli (parental health, hunger, siblings) were rarely identified as affecting the child's behavior. Teachers and children tended also to identify multiple antecedent stimuli associated with challenging behavior (mean number of antecedent stimuli identified by teachers was 8.8 , and by children, 3.8). Two antecedent stimuli were identified by all 10 teachers: the presence of peers, and the presence of a difficult task. Three additional stimuli were identified by 9 of the 10 teachers: presence of adults and peers, independent work, and an unstructured situation. Only one stimulus, the presence of peers, was identified as an antecedent by all the children. No children identified the presence of adults only, the presence of adults and peers, boring tasks, or removal of a preferred activity as antecedent stimuli.

Consequent stimuli. The hypotheses regarding maintaining variables (i.e., consequent stimuli functionally related to challenging behavior) developed based on the CAFI-T are displayed in Table 4, and Figures 1,2, and 3. The figures provide a graphic representation of the number of items on the CAFI-T on which a given consequence was reported to follow challenging behavior (Participants 1-4 are in Figure 1, Participants 5-8 are in Figure 2, Participants 9 and 10 are in Figure 3). For example, if the consequence "Peer Attention" was reported as following active defiance on eight items, the bar for that consequence would extend to " 8 " on the ordinate (above the label "Active Defiance" on the abscissa). Hypotheses based on the CAFI-C are in Table 5 and Figures 4 and 5 (data for Participants 3, 4, 5, and 7 are in Figure 4; data for Participants 8 and 10 are in Figure 5). Figures 4 and 5 provide a graphic representation of the number of items on the CAFI-C on which a given consequence was reported to follow challenging behavior.

Tables 4 and 5, and the last set of bars on each graph (labeled "combined" on the abscissa) group all target responses, as would be done in an assessment based on diagnosis. That is, these data represent the frequency with which any response concurrent with a diagnosis of oppositional defiant disorder occurred.

An examination of Tables 4 and 5, and Figures 1 through 5 shows that the challenging 
behavior exhibited by each participant is under the control of multiple environmental stimuli. That is, for the majority of the participants, there were multiple antecedent and consequent stimuli related to challenging behavior. For example, according to the teacher interview, the challenging behavior of Participant 1 appears to be triggered by 10 different antecedent events and maintained by adult attention, task avoidance, and perhaps to a lesser extent, peer attention. By comparing the frequency with which a consequence occurred for "Combined" responses to the frequency of occurrence for separate topographies (Figures 1-5), it can be seen that many of the responses grouped under a similar diagnostic label (e.g., oppositional defiant disorder) may be in different response classes. For example, when the target behaviors of Participant 5 are combined, they appear to be maintained by adult attention, peer attention, and task avoidance. Interestingly, however; only "Active Defiance," is maintained by all of these variables. Annoying Others" seems to be maintained primarily by adult and peer attention, while "Easily Annoyed" is maintained by peer attention only.

Relation between antecedent events and reported consequences. The behavior of the participants tended to be triggered by multiple antecedent stimuli and maintained by multiple contingencies; however several antecedent-consequence relations are evident. That is, for the majority of participants, certain antecedent events tended to be followed by specific consequences. For example, "presence of tasks" was reported as an antecedent event for all participants. For 9 of the 10 participants, escape or avoidance of tasks was a reported consequence. Table 6 depicts the relation between antecedents and consequences for each participant as reported on the teacher version of the CAFI. (Because children tended to endorse few situations as triggering challenging behavior, the relation between antecedents and consequences on the CAFI-C was not examined.) Examination of this table reveals several patterns. First, all participants emitted challenging behavior in the presence of peers and/or adults. In the presence of these antecedents, adult and/or peer attention was a reported consequence for all participants. That is, the presence of others is a discriminative stimulus for challenging behavior maintained by social-positive reinforcement. Second, and as just described, the presence of tasks is a discriminative stimulus for challenging behavior maintained by negative reinforcement--task removal. Additionally, however, the presence of tasks--and particularly boring or difficult tasks--might be a discriminative stimulus for challenging behavior 
maintained by adult attention. Finally, unstructured situations seems to be a discriminative stimulus for the emission of challenging behavior maintained by social-positive reinforcement.

Alternative behaviors. Teachers and children were asked also to identify alternative behaviors, skills that each child already had in their repertoire that might serve the same function as challenging behavior (see Table 7 for alternative responses identified). On the CAFI-T, three teachers were unable to identify any alternative responses exhibited by the target student. Children did not identify any alternative responses.

\section{Comparison of CAFI-C and CAFI-T}

Finally, the extent to which teacher-child pairs agreed about the environmental variables affecting the child's behavior was examined. This was done by evaluating the extent to which teacher-child pairs agreed on antecedent stimuli, setting events, and consequent stimuli that were functionally related to challenging behavior. Because no children identified alternative responses, agreement scores were not calculated for alternative responses.

\section{Agreement on setting events and antecedent stimuli. Agreement between teacher-child} pairs was calculated using the Summary Forms. For items on antecedent stimuli (Section I) and potential setting events (Section II), agreement was calculated in three ways. First, occurrence agreement was calculated for each item by summing the number of teacher-child pairs who agreed that an item influenced the child's behavior, dividing by the number of agreements plus disagreements for occurrence, and multiplying by 100. Next, nonoccurrence agreement was calculated by summing the number of teacher-child pairs who agreed that an item did not influence that child's behavior, dividing by the number of agreements plus disagreements for nonoccurrence, and multiplying by 100 . Finally, total agreement was calculated for each item by summing the number of teacher-child pairs who both agreed the item was or was not a factor, dividing by the total number of agreements plus disagreements, and multiplying by 100 .

Occurrence, nonoccurrence, and total agreement scores for each item are reported in Table 8. Summed across items, mean occurrence agreement was $31 \%$ for Section I and $50 \%$ for Section II. Mean nonoccurrence agreement was 32\% for Section I and 47\% for Section II. Mean total agreement for those sections was $51 \%$ and $70 \%$, respectively. 
Agreement on consequences maintaining challenging behavior. Agreement was calculated on the extent to which teacher-child pairs agreed on the consequences maintaining a child's challenging behavior. Because respondents could identify multiple consequences that might be affecting behavior for any given item, it was not possible to calculate agreement scores for each item. For example, on Item 1 in Section I, a teacher might state that, when other children (but no adults) are present, the consequences for challenging behavior include peer attention and tangible delivery. The child might agree that peer attention is a consequence, but might not identify tangible delivery. Also, the child could identify a different consequence, such as teacher attention in this situation. Looking at teacher-child agreement on consequences also was difficult because children typically did not identify multiple situations in which challenging behavior occurred. Thus, whereas a teacher might have stated that peer attention was a consequence in 9 of the 11 situations, a child might identify that consequence in only three situations.

Because of these difficulties, teacher-child agreement was evaluated by comparing the consequences endorsed by the teacher to the consequences endorsed by the student. One way to calculate such agreement would be to compare the frequency with which a given consequence was endorsed. For example, an agreement might be scored if both the teacher and child endorsed a consequence (e.g., peer attention) five times. Because children tended to endorse relatively few items on the CAFI-C (suggesting that they did not exhibit challenging behavior in many situations), they identified fewer consequences than did their teachers. Therefore, instead of scoring agreement based on the frequency with which a particular consequence was endorsed, agreement was calculated based on occurrence and nonoccurrence agreement. That is, if both teacher and child endorsed a specific consequence at least one time, on any given item, an occurrence agreement was scored. If neither teacher nor child endorsed a specific consequence on any item, a nonoccurrence agreement was scored. Percent occurrence agreement was calculated by dividing the number of consequences a teacher and child agreed occurred by the total number of agreements plus disagreements for occurrence, and multiplying by 100 . Nonoccurrence agreement was calculated by summing the number of consequences teacher-child pairs agreed did not occur and dividing by the number of agreements plus disagreements for nonoccurrence, multiplied by 100. Finally, total agreement was calculated by summing the number of consequences teacher-child pairs agreed both did and did not occur and dividing by 
the total number agreements plus disagreements, multiplied by 100 .

Occurrence, nonoccurrence, and total agreement scores for each participant are presented in Table 9. Summed across participants, mean occurrence agreement was $60 \%$, mean nonoccurrence agreement was $17 \%$ and mean total agreement was $60 \%$. Overall, agreement between teacher-child pairs was moderate to low on all hypotheses about variables that might be maintaining challenging behavior. That is, teacher-child pairs rarely agreed on setting events, antecedent stimuli, or consequent stimuli. In general, teachers tended to identify more stimuli affecting behavior than did the children.

\section{Phase C: Validity and Revision}

After completion of the reliability assessment of the interviews, small structural changes were made in the CAFI-T and CAFI-C (modified interviews are in Appendices F and G). Specifically, both interviews were re-structured such that the first section assessed for potential

setting events, the second section for antecedent and consequent stimuli, and the final section for alternative behaviors. These changes were made so that the order of the interviews followed a behavior-analytic conceptualization of behavior; that is in terms of a four-term contingency of setting events - antecedent stimuli-behavior-consequences. Also, based on the results of Phase B (low agreement between teacher-child pairs), the CAFI-C was modified such that children were provided with a brief description of a situation in which challenging behavior might occur and than asked whether they ever exhibited any of the identified challenging behavior in that situation. Thus, children would be required to provide a "yes" or "no" response instead of a response based on the Likert scale. Also, children were no longer asked how others typically responded. Instead, each item asked, "Why do you exhibit some of these behaviors in this situation?"

After the structure of the CAFI-T and CAFI-C was modified, eight experts, all of whom participated in Phase A, were asked to evaluate the content validity of the CAFI-T (because the CAFI-T and CAFI-C asked similar questions, only the teacher interview was evaluated). The content validity of each question was examined by asking each rater to complete a two-way table, with content areas across the top and interview questions listed in the left-hand column. The content areas included in the table were: (a) setting event, (b) antecedent stimulus, (c) alternative response, (d) potential reinforcer, and (e) consequence. Using this table, the experts 
placed a check mark under the content area they judged each question to be assessing. This table allowed for an evaluation of the content validity of the instruments because it revealed the extent to which each of the content areas was adequately represented by the instrument. Formal agreement scores were calculated to evaluate the content validity of each item in the modified interview. Agreement scores for each item were calculated by dividing the number of raters who agreed about the content area being sampled by the total number of raters, and multiplying by 100 (agreement scores are presented in Table 10).

Agreement between raters about the content area being sampled was high, overall. Specifically, all raters agreed that the items in Part I were assessing for potential setting events. Similarly, all raters agreed that Part II assessed for potential antecedent and consequent stimuli. Only one rater suggested that the items in Part II could be used to identify potential rewards. Such a suggestion is reasonable if the respondent is able to identify correctly the maintaining consequences. That is, if the respondent suggests that peer attention is maintaining challenging behavior - and it is actually a maintaining consequence - then peer attention might be used as a reward for more appropriate behavior. Also in Part II, one rater suggested that items might be used to identify skills deficits. The rater provided a rationale for this perspective, stating that, "I am assuming that exhibiting the excess [challenging behavior] means that other skills are deficient." While such an assumption is certainly a possibility, other factors also might play a role. For example, a child whose behavior is maintained by peer attention might have more appropriate peer-attention seeking responses in his or her repertoire. If those responses are not reinforced as often or as saliently as are challenging behavior, however, then the challenging behavior is likely to continue to occur. Thus, using items in Part II to directly identify skills deficits does not seem warranted.

Agreement was more variable on Part III (designed to assess for skills deficits). While all raters agreed that Item 1 (asking whether the child preferred to play with peers more or less than playing alone) identified a potential reward, only six of the eight raters thought the remaining social skills questions might be used to identify a skills deficit. One rater suggested that all social skills questions ( 1 through 3 in this part) might be used to identify potential rewards, but how this could occur is not clear. Of the remaining items in Part III, 7 out of the 8 raters agreed that all were assessing for potential alternative behaviors. Interestingly, no rater suggested that these questions might be used also to identify skills deficits. It seems that, if a teacher or child stated 
that the child did not emit any alternative responses in a particular situation (e.g., to get teacher attention), this could be taken to mean that the child was deficient in appropriate adult attention seeking skills.

\section{Discussion}

Although the use of a pre-treatment functional assessment is relatively common with people with developmental disabilities exhibiting challenging behavior, such assessments are used less frequently with typically developed populations. The purpose of the three phases described under Study 1 was to develop and conduct preliminary evaluations of a functional assessment interview to be used with typically developed children exhibiting challenging behavior in school settings. Two interviews were used in Study 1, one to be administered to the child and the other to be administered to the child's teacher. Both interviews were designed to gather information about environmental variables functionally related to challenging behavior. The first phase of Study 1 involved developing an interview to be administered to teachers and children. After initial development, the interview was evaluated by 10 individuals with expertise in functional assessment and externalizing behavior disorders. The information provided by these experts was then used to revise the interviews.

The second phase of Study 1 involved administering the interviews to 10 children and their teachers. The purpose of this phase of the study was to evaluate the reliability of the interviews. Reliability was examined in two ways. First, two raters independently coded the interviews. Agreement between rater-pairs was then evaluated. Next, agreement between teacher-child pairs was assessed. Overall, agreement between independent raters was high for both interviews. This suggests that the interview is useful in gathering reliable information. That is, two independent coders are likely to record the same information from a given respondent. Because agreement was high overall, no items were dropped from the interviews. Agreement was high as well on the Summary Form. Because the interviews are several pages long and gather a variety of information about variables affecting a child's behavior, it seemed imperative to have a way to summarize the information into a more useful form. The Summary Forms for the CAFI-C and CAFI-T were developed for this purpose. The high agreement scores obtained from the Summary Forms suggest that they are useful in assisting the rater in identifying the environmental variables suggested by the interviews to be affecting challenging behavior. 
Rater agreement also was evaluated by comparing the extent to which raters agreed about variables functionally related to challenging behavior. Again, agreement was high, overall. Although raters occasionally disagreed about a consequence in an individual item, they generally agreed about the function of a behavior overall. For example, one rater might indicate that adult attention was a maintaining variable in Items 3, 4, 6, 7 and 9, while the second rater might indicate that adult attention was a maintaining variable in Items 3,4, 7, 9, and 11. Overall, however, they were agreeing that adult attention was an important maintaining variable.

The second way that the reliability of the interviews was evaluated was by comparing the teacher and child interviews. Overall, agreement was poor between teacher-child pairs. That is, teacher-child pairs rarely agreed on setting events, antecedent stimuli, or consequent stimuli. In general, teachers tended to identify more stimuli affecting behavior than did the children. This finding is not surprising given the large number of studies showing poor agreement on behavior rating scales and interviews between children within the age groups evaluated in this study (ages 7 to about 12) and parents (e.g., Achenbach, Achenbach, McConaughy, \& Howell, 1987; Kashani, Orvaschel, Burk, \& Reid, 1985; Rey, Schrader, \& Morris-Yates, 1992), and children and teachers (e.g., Argulewicz \& Miller, 1985; Epkins, 1995).

Although poor agreement between children and other informants seems somewhat common, there are at least four potential explanations for this finding that are specific to this study. One possible reason that teachers identified more stimuli than did their children is that children exhibited noncompliant and defiant behavior during the interview. For example, one child said, "I never do that (argue) at school," and proceeded to respond negatively to almost all items. Although the feasibility of this hypothesis was not evaluated through direct observation, anecdotal support does exist. Specifically, many of the children would provide negative responses to items before the interviewer had completed reading the item.

Second, several of the children seemed to have difficulty providing answers based on the Likert-style rating scale. They would frequently respond "yes" or "no" and have to be prompted to use the rating scale. After several prompts, children often would begin to rate each item as " 1," "not likely." A similar problem was that many of the children had difficulty identifying how others typically respond to their exhibition of challenging behavior. They frequently struggled to provide a response to the first one or two questions and then began to rate each item as " 1 " - thus avoiding having to identify how others typically responded (which was required only for ratings 
of " 3 " or above). As a result of these difficulties, the child interview was modified in two ways. First, the children were asked to provide a "yes" or "no" response to indicate whether they exhibited challenging behavior in given situations, instead of using the Likert scale. Second, instead of asking children how others typically respond when the child exhibits challenging behavior, children were asked why they exhibit such behavior.

Finally, it is possible that the children are better able to identify the events triggering their behavior. However, because classroom observations were not conducted in this study, the feasibility of this hypothesis could not be evaluated (note that the direct observations in Study 2 allowed for partial evaluation of this hypothesis).

After the reliability evaluation of the interviews was complete, small structural changes were made to the interviews such that the order was similar to a behavior analytic conceptualization of behavior. Next (in Phase C), eight experts in the area of functional assessment evaluated the content validity of each item on the CAFI-T. Overall, rater agreement was high, suggesting that, in general, raters agreed about the content areas being assessed. This was especially true for the items in the interview designed to assess for those environmental variables functionally related to challenging behavior. High agreement scores on these items are encouraging because the primary purpose of the interview is to identify these variables.

The results of the interviews administered in Phase B suggest several interesting areas for future research. First, the results of both the CAFI-T and the CAFI-C suggest that the majority of participants (9 out of 10) exhibited social skills deficits. Specifically, these children were not sought out by peers during play or work activities, although most reportedly enjoyed playing with others more than playing alone. Also, when asked to identify alternative, more appropriate skills that children used to gain attention from peers or adults, take a break from work, or obtain access to a preferred toy or activity, teachers rarely were able to identify more than one alternative response for a given response class. Other researchers have suggested that children with conduct problems tend to have poor peer relations (e.g., Sprague, Sugai, \& Walker, 1998), and such findings suggest that a remediation of social-skills deficits might be an appropriate avenue for treatment of challenging behavior exhibited by school-aged children.

A second interesting finding involves the varied stimuli that tended to trigger challenging behavior (i.e., antecedent stimuli). Functional assessment research has tended to focus on large response classes, such as behavior maintained by escape from task, or behavior maintained by 
attention. Relatively little attention has been focused on finer analyses. The results of Phase B of this study suggest that, at least for typically developed children, it may be necessary to identify more specific triggers to challenging behavior. For example, for the majority of participants in this study, the presentation of work did not always serve as an antecedent stimulus. Rather, presentation of a specific type of task (e.g., difficult tasks, boring tasks) tended to trigger challenging behavior while other sorts of tasks did not.

Finally, an examination of the consequences hypothesized to be maintaining challenging behavior revealed interesting findings. In determining consequences maintaining challenging behavior, data were graphed for both combined challenging behavior and individual responses. Graphing behavior in this way illustrated that, for some participants, different topographies of challenging behavior appeared to be in different response classes. This point becomes clearer if one examines the frequency with which all target behaviors for a given participant are maintained by the same functions as "Combined" responses. For example, for Participant 1 , "Combined" responses are maintained by adult attention, task avoidance, and peer attention. However, when responses are separated by topography, only two of three responses are maintained by all three functions--"Blaming Others" is maintained only by adult attention. This pattern holds true for the majority of the remaining participants. Only for Participants 2 and 8 did the "Combined" functions match the functions for each specific topography. Two of the three target responses matched the functions suggested for "Combined" responses for Participants 1, 5, 7, and 9. For Participants 3, 4, and 10, only one topography of behavior was maintained by all the functions suggested for "Combined." Participant 6 had two target behaviors, one of which matched the functions for "Combined" responses.

The suggestion that different responses clustered together in a DSM-IV diagnosis often are in different response classes has important implications for treatment development. As stated earlier, a diagnosis of oppositional defiant disorder (or any DSM-IV diagnosis) is based on a list of responses that tend to co-occur. Because these behaviors are grouped together under a particular diagnosis, treatments often are developed to target all responses in a similar way. For example, Parent-Child Interaction Therapy (Hembree-Kigin \& McNeil, 1995) involves the use of a specific aversive consequence-usually time-out—contingent on the exhibition of a variety of challenging behaviors subsumed under the label of ODD. Although such an approach may be effective if all targeted responses are maintained by adult attention, it is not likely to be effective 
if responses serve varied functions. Future research should compare the efficacy of functionallyderived treatments to packaged treatments. Efficacy could be examined in terms of reductions in challenging behavior, increases in adaptive behavior, and time of assessment and treatment.

\section{STUDY 2: INTERVIEW AND DESCRIPTIVE ANALYSIS}

Study 2 consisted of two phases. The first phase involved administering the revised clinical interviews to four children and their teachers. The second phase involved conducting a descriptive analysis with each participant. The teacher interview was administered first, so as to derive operational definitions to be used in the direct observations. Importantly, the results of the CAFI-T were not examined until after the direct observations were completed. This was done to reduce the possibility of observer bias affecting the results of the direct observation. After completion of the direct observation, the child interview was administered.

The purpose of this study was to evaluate the validity of the interviews by comparing the interview results to the results of the descriptive analysis. Also, inter-rater agreement was assessed by comparing the teacher and child interviews and by comparing the teacher interviews to interviews conducted with teaching assistants.

\section{Phase A: Interviews}

$\underline{\text { Method }}$

\section{Participants and Setting}

Child participants. The participants were four children between the ages of 7 and 15 years who attended a residential school in rural West Virginia for children with severe conduct problems. All children in the school were placed there by court order due to exhibition of severe challenging behavior at home, school, or in the community. The children came to participate in the study because the University Affiliated Center for Developmental Disabilities at West Virginia University was asked to assist the school in evaluating and revising their behavior management program, which is described in detail below. Part of the evaluation consisted of conducting a functional assessment with five children in the school, four of whom participated in this study. The four children who participated in this study were identified by the school principal and the program director as children whose behavior was especially problematic. Because the participants were minors, written consent was obtained from each participant's 
parent or legal guardian. The parental consent form is in Appendix H. Parents or legal guardians were fully informed as to the process and procedures of the study.

"Ben" was a 13-year old boy who met criteria for oppositional defiant disorder. At the time of the study, Ben had been at the residential school for six months, and had never progressed beyond Level 1 in the school's behavior management system (described in the "Setting" section). "Hal" was an 11-year old boy who met criteria for oppositional defiant disorder and attentiondeficit/hyperactivity disorder. He had been at the residential school for three months at the time of the study. Hal was at Level 2 of the behavior management system for the duration of the study. "Jim" was a 13-year old boy who met criteria for oppositional defiant disorder and attention-deficit/hyperactivity disorder. At the time of the study, he had been at the residential school for five months and had never moved beyond Level 1 of the behavior management system. "Tom" was a 15-year old boy who met criteria for oppositional defiant disorder. At the time of the study, he had been at the residential school for three months. Tim was on Level 3 of the behavior management system, and was discharged before the study was completed. Thus, the CAFI-C was not completed with Tim.

Teachers and aides. Four teachers and four aides participated in this study (teacher consent forms are in Appendix I). One teacher had been teaching at the school for three years; the other three had been for at least five years. The aides had been at the school from one to four years. Three of the teachers were women, and one was a man. All of the aides were women. The school day was divided into time-blocks, and the children spent each time block with a different teacher, thus all teachers were exposed to every child each day.

Setting. The residential school differed from community-based, nonresidential schools in at least two ways. First, the school had a specific behavior management plan that teachers were required to follow when challenging behavior occurred. Challenging behavior in the school was defined as talking out of turn, not working on an assigned task, not following instructions, arguing with an adult, "insubordination," verbal aggression, stealing, refusing to go to time-out, and physical aggression. The behavior management plan for "Mild" challenging behavior (talking out of turn, not working on an assigned task, not following instructions) consisted of several steps: (a) a warning (i.e., "This is your first warning."), (b) a second warning, (c) 5- 
minute time-out on a chair in the back of the room, and (d) 10-minute exclusionary time-out in an isolated "time-out" room located in the school. Exhibition of "Severe" challenging behavior was immediately followed by chair time-out. In addition to the consequence plan, a level system also was in place, through which children earned access to privileges. Children began on Level 1, where they had minimal privileges (e.g., only three pairs of clothes, no television, one helping of food at meals), and progressed to Level 4, where they had maximal privileges (e.g., choosing roommate, staying up later) based on improvements in behavior. If a child was placed in chair time-out more than twice in one day, the child was moved back to the previous level. If a child was sent to exclusionary time-out, the child moved back to Level 1. Children typically were discharged from the residential school after successfully maintaining their behavior on at least Level 3 for a period of several weeks.

A second difference between this school and typical schools was that the teacher-child ratio was very low. There was one teacher and one aide in each classroom, and there was a maximum of five children in each academic class. In nonacademic classes (e.g., physical education, social skills), there was a maximum of 10 children per class. Often, three or more teachers were present in nonacademic classes. The school day was divided into periods (eight periods per day) and the children went to a new classroom — and new teacher-for each period. Academic classes took place in the morning and were 55 minutes long. Academic classes included reading, math, language arts, social studies, and health. Children participated in each academic class every day. Afternoon classes were 45 to 90 minutes long. On alternate days, children attended either: (a) social skills, physical education, and study hall; or (b) an adventures course (designed to develop trust between children), computer technology, career development, social skills, and developmental counseling.

Interviews with teachers, aides, and children were administered at the residential school. All interviews were conducted in a private room by the primary investigator.

\section{$\underline{\text { Response Definitions and Measurement }}$}

The first phase involved administering the revised clinical interview to the participants in the study. As in Study 1, topographies of challenging behaviors focused on in the interviews were identified by asking teachers to complete a questionnaire about the target child's behavior. Next, the teacher provided operational definitions for those responses (see Table 11 for target 
responses and operational definitions for each participant). Finally, the structured functional assessment interviews were administered. The interviews used in this study were revised based on the findings of Study 1. The CAFI-T used in this study is in Appendix E, the CAFI-C is in Appendix F. The CAFI-T was administered to each participating teacher and his or her aide. Each pair (teacher and aide) focused on the same child on the CAFI-T. The CAFI-T was administered prior to conducting the descriptive analyses (Phase B). To ensure that the children were unaware of the purpose of the observations, the CAFI-C was administered subsequent to Phase B.

\section{Results}

\section{Comparison of Interviews Administered to Teachers and Teaching Aides}

After administration of the CAFI-T to the teachers and their aides, item-by-item agreement was calculated between each teacher and his or her assistant. To calculate agreement scores for each item, if both raters on a given interview recorded the same response, an "agree" was coded. If they recorded different responses, a "disagree" was coded. For each item, percentage agreement scores were calculated by dividing the number of "agrees" for that item by four (the number of teacher-assistant pairs). Certain questions in Part I of the interviews (questions about abuse, parental health, and parental fights) asked about events going on at home that might affect the child's behavior in school. The teachers and aides interviewed in this study reported that, because this was a residential school, they did not know anything about the children's home life, so these items were not included in the analysis. In Part II of the CAFI-T (Antecedents and Consequences), respondents could identify up to three target behaviors for any item. Agreement for "Recorded Behavior" was thus determined by calculating the percentage of target behaviors identified by both teacher and assistant for each item. For example, if a teacher identified two target responses and the assistant identified those two responses and also a third target response, the percentage agreement for that item would be $67 \%$ ( 2 divided by 3 ). To obtain an agreement for "Recorded Behavior" across all participants, the number of responses agreed on was divided by the total number of responses identified across participants. Mean agreement scores for each item are in Table 12.

Agreement between teachers and assistants was variable, but acceptable overall. Mean agreement about the extent to which a variable affected behavior (see "Rating" column) for items 
in Part I (Setting Events) was 84\% (range 25\%-100\%). In Part II (Antecedents and Consequences), mean agreement about the extent to which variables affected behavior (see "Rating" column) was $87 \%$ (range 50\%-100\%). Mean agreement about which target responses would occur (see "Behavior" column) was 73\% (range 40\%-100\%). Mean agreement about how others responded to target responses (see "Response" column) was 89\% (range 50\%-100\%). In Part III (Social Skills and Alternative Responses), mean agreement on rating scales was 82\% (range 50\%-100\%) and mean agreement on the recorded responses was 25 (range 0-50\%).

\section{Comparison of CAFI-C and CAFI-T}

As in Study 1, the extent to which teacher-child pairs agreed about the environmental variables affecting the child's behavior was examined. This was done by evaluating the extent to which teacher-child pairs agreed on antecedent stimuli, setting events, and consequent stimuli that were functionally related to challenging behavior. Because Tim did not complete the CAFI$\mathrm{C}$, his data are not included in the comparison.

Agreement on antecedent stimuli, setting events, and alternative skills. Agreement between

teacher-child pairs was calculated for items on potential setting events (Part I), antecedent stimuli (Part II), and alternative skills (Part III). As in Study 1, three forms of agreement were calculated: occurrence agreement, nonoccurrence agreement, and total agreement. Each form of agreement was calculated using the same formulas as in Study 1. Occurrence, nonoccurrence, and total agreement scores for each item are in Table 13. Summed across items, mean occurrence agreement was 0\% for Part I, 36\% (range 0-100\%) for Part II and 44\% (range 0-100\%) for Section III. Mean nonoccurrence agreement for Parts I, II, and III was 100\%, 31\% (range 0 $100 \%$ ), and 67\% (range 33\%-100\%) respectively. Mean total agreement for those parts was $92 \%$ (range 67\%-100\%), 59\% (range 0-100\%), and 74\% (range 33\%-100\%), respectively.

Agreement on consequences maintaining challenging behavior. Agreement was calculated also on the extent to which teacher-child pairs agreed on the consequences maintaining a child's challenging behavior. Consequences identified by teachers are displayed in Table 14; consequences identified by children are in displayed in Table 15. As was true in Study 1, respondents could identify multiple consequences that might be affecting behavior for any given 
item, thus rendering it impossible to calculate agreement scores for each item. Also, children typically did not identify multiple situations in which challenging behavior occurred. Thus, whereas a teacher might have stated that peer attention was a consequence in 9 of the 11 situations, a child might identify that consequence in only three situations.

Because of these difficulties, teacher-child agreement was evaluated in the same way as in Study 1. Occurrence, nonoccurrence, and total agreement scores for each participant are presented in Table 16. Summed across participants, mean occurrence agreement was $88 \%$ (range $67 \%-100 \%$ ), mean nonoccurrence agreement was 90\% (range 75\%-100\%), and mean total agreement was $94 \%$ (range $83 \%$ to $100 \%$ ). Overall, agreement between teachers and children on consequences maintaining challenging behavior was high.

\section{Relation Between Antecedent Events and Reported Consequences}

As was true in Study 1, although the results of the CAFI-T suggested that the behavior of participants tended to be triggered by multiple antecedent stimuli and maintained by multiple contingencies, several antecedent-consequent relations are evident (see Table 17). First, all participants emitted challenging behavior in the presence of other children. In the presence of this antecedent, peer attention was a maintaining variable for all participants. Second, the presence of tasks (easy, boring, difficult, group or independent work) was an antecedent stimulus for all participants. For three of four participants, escape or avoidance of tasks was a maintaining variable. Interestingly, adult and/or peer attention also was a maintaining variable for all participants.

\section{Phase B: Descriptive Analysis}

\section{Method}

\section{Participants and Setting}

All students who participated in Phase A of this study participated in Phase B, as well. All observations were conducted in the school classrooms.

\section{$\underline{\text { Response Definitions and Measurement }}$}

Response topographies and operational definitions of challenging behavior were determined based on the functional assessment interviews. Thus, target responses varied across participants 
(see Table 11 for target responses and operational definitions).

One purpose of this study was to evaluate the validity of the interviews by comparing them to the results of direct observations. Because all data were collected $\underline{\text { in-vivo, }}$, and audio or video recording of direct observations was not permitted by school officials, it was not practical to collect data on all antecedent and consequent events sampled in the interviews. Thus, data were not collected on events that might serve as setting events. Also, data were not collected to determine whether the stimuli identified in the interviews as rewarding or as enjoyed by the child were actually preferred stimuli. Finally, data were not collected on alternative behaviors already in a child's repertoire. Thus, the direct observations provided validity data only for the sections of the interview assessing immediate antecedent and consequent stimuli related to challenging behavior--the events most typically the focus of a functional analysis. Similarly, the interviews allowed for gathering specific information about the types of work situations that triggered challenging behavior-difficult work, boring work, and easy work. Because this was a subjective rating on the part of the teacher and the student, it was not possible to collect data on these specific antecedents during the direct observations.

The classes of environmental events coded during direct observations were based on situations reported in the literature to be associated with the occurrence of challenging behavior. Eight antecedent and six consequent stimulus categories were identified. Antecedent stimulus categories included: (a) on-going task: child was asked to work on a task, and the task continued for 20 seconds or more (with or without specific prompts to continue working), or work materials were present and the child was asked to work with them at some earlier point (e.g., when class began); (b) prompt or request: adult emits a verbal statement requiring a response from the student; (c) transition to task: child was asked to stop working on a task and begin a new task; (d) transition to setting: child moved from one room to a new room; (e) low work situation: child was in a situation with some behavioral expectations (e.g., sit quietly, watch a video), but no academic demand or specific task was present; (f) adult interaction: child interacted (e.g., talking, working) with an adult for 10 or more seconds; (g) peer interaction: child interacted (e.g., talking, working) with a peer for 10 or more seconds; and (h) work completed: child had completed an assignment but had not been given a new one. Consequent events were defined as: (a) adult attention: adult verbally or non-verbally interacted with or attended to the child (e.g., saying, "stop," or pointing a finger at the child); (b) peer interaction: 
peer verbally or non-verbally interacted with or attended to the child (e.g., talks to student, laughs at student); (c) tangible delivery: child given a tangible (non-work) item by a peer or adult; (d) adult attention removal: adult who was interacting with the child ceases to do so (e.g., walks away or child is sent to time-out and adult attention is withdrawn); (e) peer attention removal: peer who was interacting with the child ceases to do so (e.g., walks away or child is sent to time-out and peer interaction ceases); (f) tangible removal: tangible the child was interacting with was removed (e.g., teacher takes item away, child is sent to time-out and the tangible is removed); and ( $\mathrm{g}$ ) task removal: task the child was working on or had been asked to work on was removed (e.g., child is sent to time-out and the task is withdrawn).

All sessions were coded in-vivo by the primary investigator or a trained graduate assistant. During each session, a partial-interval procedure was used to record the occurrences of a target behavior and any antecedent and consequent stimuli during continuous 20-second intervals, cued by an audio tape or a stopwatch. Occurrences of target behavior were scored continuously throughout the session, whereas environmental events were scored only when they occurred within 20 seconds of a target behavior. For example, if a peer interacted with a student, and no challenging behavior had occurred within the previous 20 seconds, "peer interaction" was not scored. In contrast, if a teacher interacted with the child within 20 seconds after a challenging behavior, "adult attention" would be scored as a consequent event. Antecedent stimuli were coded only if they occurred within the same 20-second interval as a challenging behavior. Inter-observer agreement was collected for each scored response and environmental variable for at least 33\% of the sessions for each participant (range 33\%-43\%). During these sessions, two observers independently collected data on target responses and stimuli. Each observer had a stopwatch or cueing tape and, at the beginning of each session, the primary investigator simultaneously began each stopwatch or audiotape and the observers than moved apart from one another. Inter-observer agreement was evaluated by calculating occurrence, nonoccurrence, and total agreement percentages. Occurrence agreement was determined by summing the number of intervals during which observers agreed the event occurred, dividing by the sum of agreements and disagreements for occurrence, and multiplying by 100 . Nonoccurrence agreement was determined by summing the total number of intervals during which observers agreed the event did not occur, dividing by sum of agreements plus disagreements for nonoccurrence, and multiplying by 100 . Total agreement was calculated by summing the number of intervals 
observers agreed the event both did and did not occur, dividing by the total number of intervals, and multiplying by 100 .

Mean occurrence agreement across challenging behavior for Ben was 89\% (range 66-100\%). Mean nonoccurrence agreement was 99\% (range 98-100\%), and mean total agreement was 99\% (range 98-100\%). Mean occurrence, nonoccurrence, and total agreement across stimulus classes (antecedent and consequent events) was 100\%. Inter-observer agreement coefficients for Hal are in Table 18. Mean occurrence agreement across challenging behavior was 78\% (range 63-93\%), mean nonoccurrence agreement was 99\% (range 98-100\%), and mean total agreement was 99\% (range 98-100\%). Mean occurrence agreement across stimulus classes (antecedent and consequent events) was $87.1 \%$ (range 50-100\%). Mean nonoccurrence agreement was $99 \%$ (range 97-100\%), and mean total agreement was 99\% (range 97-100\%). Inter-observer agreement coefficients for Jim are in Table 19. Mean occurrence, nonoccurrence, and total agreement across challenging behavior was 100\%. Mean occurrence agreement across stimulus classes (antecedent and consequent events) was 92.8\% (range 88-100\%). Mean nonoccurrence agreement was 99 (range 99-100\%), and mean total agreement was 99\% (range 99-100\%). All inter-observer agreement coefficients for Tom were 100\%. Thus, inter-observer agreement coefficients for all students were acceptable to excellent.

\section{Experimental Design and Procedures}

The purpose of the descriptive analysis was to evaluate the effect of environmental variables on a child's behavior. Thus, it was important that the observation samples be representative of the child's school day. Prior to beginning the study, three conditions were proposed based on observations at other schools: a work condition, a low-attention condition, and a peer-interaction condition. The work condition would be run during times the child was asked to work on academic tasks (e.g., taking notes while the teacher lectured, completing a worksheet). The purpose of this condition was to sample the child's behavior during times he was required to complete class work. The low-attention condition would be run during times the child was either taking a break or working on low-demand assignments (e.g., an art project, watching a movie) when the teacher was not immediately available to interact with the child. The purpose of this condition was to assess the child's behavior during times when no academic tasks were present and the child was not interacting with the teacher. Finally, the peer-interaction condition was to 
be run during times peer interaction was highly probable, while adult interaction was less likely to occur (e.g., recess, cafeteria). Although all three of these situations occurred frequently during observations at typical schools, "peer-interaction" situations did not occur at the residential school where this study took place. Such situations were not typical because all children were required to be escorted by an adult at all times. Also, children were not permitted to interact with one another unless a teacher gave them specific permission to do so (e.g., to work together on an assignment). Finally, children did not have recess and ate lunch in their classrooms, sitting at their desks. Because "peer interaction" rarely occurred at school, only two conditions were conducted, the work condition and the low attention condition. All sessions in both conditions were 20 minutes in length. Work conditions were conducted during times the child was in an academic class. Low attention conditions were conducted during times the child was in a nonacademic class, such as physical education, or social skills training. Sessions were conducted on six different days across a five-week period. With Ben, Hal, and Tom, five work and four low attention sessions were conducted. Four work and four low attention sessions were conducted with Jim.

Teachers were not given any specific instructions prior to beginning the sessions; they were instructed to interact with the children as they typically would. Teachers and staff reported that individuals from outside agencies often observed classes, and that the presence of data coders would not be unusual to the children. Children were told that the observers were teaching assistants from another school, and were present to observe the instructional style of the teachers.

\section{Data Analysis}

The comparison of the interviews to direct observation was completed using the teacher interviews only. This was done for three reasons. First, children tended to identify only a small number of situations as being likely to trigger challenging behavior and thus also identified a small number of consequences that might be maintaining their behavior. Second, agreement between teachers and children was low, overall. That is, teachers and children rarely agreed on setting events and antecedents that often preceded challenging behavior. Although teachers and children had higher agreement scores for consequences, children typically endorsed a given consequence on significantly fewer items than did their respective teachers. Although low agreement between teachers and children does not indicate that the teacher interviews are correct 
and child interviews are incorrect, the relatively high agreement between teachers and aides does add support to this hypothesis.

To determine the extent to which the interviews and the descriptive analyses produced similar hypotheses about functions of challenging behavior, the probability of the occurrence of any particular event during the descriptive analysis had to be determined. This was done by calculating conditional probabilities to determine the proportion of challenging preceded by each antecedent event and the proportion of challenging behavior for which each consequent event followed. For antecedent events, this was determined by summing the number of intervals containing an antecedent event that preceded challenging behavior, and dividing that sum by the total number of intervals in which challenging behavior was scored. For consequent events, the number of intervals containing challenging behavior that preceded a consequent stimulus was divided by the total number of intervals in which challenging behavior was scored. Because data were collected on the occurrence of antecedent or consequent stimuli only when they occurred in the same interval as a target response the base rates of the occurrence of these stimuli is unknown. Thus, it was not possible to determine the probability that, if an antecedent stimulus occurred, it would be followed by a target response. Similarly, the probability that a given consequent stimulus followed targeted responses could not be calculated. Conditional probabilities were determined for each target behavior and for all target behaviors combined. The following antecedents were evaluated both in the interviews and direct observations: presence of children and adults, on-going task or prompt, and removal of a preferred activity. The consequences evaluated in the interview and during direct observations included adult attention, peer attention, tangible delivery, task removal, adult avoidance, and peer avoidance. Occurrence and non-occurrence agreement (between the interviews and direct observations) for antecedents and consequences was determined for each participant.

\section{$\underline{\text { Results }}$}

The results for each participant are displayed both in tabular and graphic form. Table 14 displays the antecedents and consequences identified on the CAFI-T for each participant. Figures 6 (Ben and Hal) and 7 (Jim and Tom) display the consequences identified on the CAFI-T graphically. Figures 8 through 15 represent data from the direct observations. Figures 8 and 9 display antecedents and consequences observed with Ben, Figures 10 and 11 are antecedents and 
consequences observed with Hal, Figures 12 and 13 are antecedents and consequences observed with Jim, and Figures 14 and 15 are antecedents and consequences observed with Tom. For each participant, there are separate figures for antecedents and consequences, and data from low attention and work sessions are in separate graphs.

"Combined" challenging behavior was determined by summing the number of items on which a specific consequence was identified. For example, if "Adult attention" was identified on seven items, the "Combined" number of items would be seven. If a specific consequence was identified for more than one challenging behavior on a given item, that consequence was only counted one time. For example, if on Item 2, the teacher said that both "Blame Others" and "Argue with Adults" were followed by "Adult Attention," this consequence would only be scored once. Thus, the maximum score for "Combined" was 13 (the total number of items. Finally, agreement between teacher interviews and direct observations is displayed in Table 20.

\section{$\underline{B e n}$}

Antecedent analysis. The results of the teacher interview (Table 14) suggest that Ben's challenging behavior is triggered by the presence of children and adults, the presence of ongoing tasks (difficult work and group work), and removal of a preferred activity. Figure 8 depicts the proportions of challenging behavior preceded by specific antecedent events in the direct observations. Ben exhibited challenging behavior only during the work condition. Also, all challenging behavior occurred only during intervals when on-going work was present (however, intervals may have occurred during which on-going work was present but was not followed by challenging behavior--the probability of this event could not be determined). Further, a large proportion of Ben's challenging behavior was preceded by prompts to work. This is in agreement with the results of the CAFI-T, suggesting that on-going tasks might be an antecedent stimulus. All direct observations occurred in the presence of children and adults. Activity removal, which was suggested to be an antecedent on the CAFI-T, was not observed as triggering challenging behavior during direct observations. Thus, agreement between the interview and direct observations was observed on two of three stimuli, yielding an agreement score of $67 \%$ (see Table 21).

Consequent analysis. The results of the CAFI-T suggest that all topographies of challenging 
behavior are maintained by task avoidance and adult attention. Additionally peer attention might be a maintaining consequence for "Active Defiance." Figure 9 depicts the proportion of challenging behavior followed by consequent events during direct observations. During Work sessions, blaming others and arguing with adults was followed by adult attention delivery $100 \%$ of the time, suggesting that adult attention might be a maintaining variable. Additionally, $86 \%$ of the time, "active defiance" was followed by escape or avoidance of tasks, suggesting that this response might be negatively reinforced by escape or avoidance, as well. Thus, both the interview and direct observations suggest that challenging behavior is maintained by adult attention and task removal.

Agreement between methods was examined also by combining stimulus classes (antecedents and consequences). For example, occurrence agreement was calculated by summing the number of agreements about antecedents and consequences (4), dividing by agreements and disagreements about occurrences (5), and dividing by 100. Overall occurrence and nonoccurrence agreement on stimuli affecting Ben's challenging behavior was $80 \%$. Total agreement was $89 \%$.

$\underline{\text { Hal }}$

Antecedent analysis. The results of the CAFI-T and direct observations conducted with Hal revealed similar findings as observed with Ben. That is, the results of the teacher interview suggest that Ben's challenging behavior is triggered by the presence of children and adults, the presence of on-going tasks (boring work, difficult work, and group work), and removal of a preferred activity. Figure 10 depicts the proportions of challenging behavior that were preceded by specific antecedent events in the direct observations. Hal exhibited challenging behavior during the work and low attention (during both of which children and adults were always present). Thus, the presence of children and adults and on-going tasks might be antecedent stimuli. Activity removal, suggested to be an antecedent on the CAFI-T, was not observed as triggering challenging behavior during direct observations. Thus, agreement was observed on two of three stimuli (see Table 21), yielding an agreement score of $67 \%$.

Consequent analysis. The results of the CAFI-T suggest that the behaviors "Angry and Resentful" and "Annoy Others" are maintained primarily by adult attention, while "Active 
Defiance" is maintained primarily by escape or avoidance of tasks. Taken together, challenging behavior for Hal is hypothesized to be maintained both by adult attention and escape or avoidance. Figure 11 depicts the proportions of challenging behavior that was followed by specific consequent events during direct observations. These data suggest that, during times when work is not present, and adult attention is low (low attention condition), "Annoy Others" is maintained primarily by peer and adult attention. When on-going work is present (work condition), both "Annoy Others" and "Active Defiance" are maintained by adult attention. "Active Defiance" may occur also to escape or avoid tasks. These data are partially in agreement with the results of the CAFI-T, however the results of the CAFI-T did not suggest peer attention to be a maintaining consequence. Occurrence agreement on consequences for Hal was $67 \%$. Nonoccurrence agreement was $75 \%$.

Overall occurrence agreement across stimulus classes between the two methods was $67 \%$. Nonoccurrence agreement was $60 \%$ and total agreement was $78 \%$.

$\underline{\mathrm{Jim}}$

Antecedent analysis. The teacher interview suggested that Jim's behavior was triggered by multiple events including the presence of peers and adults, presence of tasks (easy, boring, difficult, or group work), unstructured situations, and removal of a preferred activity. Figure 12 depicts the proportions of challenging behavior preceded by specific antecedent events in the direct observations. Challenging behavior occurred in both low work and work conditions, during both of which peers and adults were present. Also, the presence of on-going work (work condition) and prompts (both conditions) preceded all incidences of challenging behavior. Table 21 illustrates the agreement between the CAFI-T and direct observations. The presence of children and adults, and the presence of on-going tasks were suggested to be antecedent stimuli by both instruments. Activity removal, which was suggested to be an antecedent on the CAFI-T, was not observed as triggering challenging behavior during direct observations. Occurrence agreement on antecedent stimuli was $67 \%$.

Consequent analysis. Data from the CAFI-T suggest that challenging behavior is maintained by adult and peer attention. Figure 13 depicts the proportion of challenging behavior that was followed by specific consequent events during direct observations. During one low attention 
session, the response, "Annoy Others" was followed by time-out. Thus, peer removal and adult removal occurred contingent on challenging behavior one time (or $12 \%$ of the intervals in which "Annoy Others" was observed). In agreement with the interview, the direct observations suggest that challenging behavior is maintained by peer and adult attention.

Agreement across stimulus classes for the methods was high, overall. Occurrence and nonoccurrence agreement were $80 \%$ and total agreement was $89 \%$.

\section{$\underline{\text { Tom }}$}

Antecedent analysis. The results of the CAFI-T completed with Tom's teacher again suggested multiple antecedent stimuli. These include the presence of peers and adults, easy, boring, difficult or group work, structured and unstructured situations, and removal of a preferred activity. Figure 14 depicts the proportions of challenging behavior that followed antecedent events during direct observations. During the low attention sessions, the proportion of challenging behavior ("Annoy Others") preceded by low-work was 100\%. During work sessions, $100 \%$ of "Annoy Others" was preceded by on-going work. Activity removal, which was suggested to be an antecedent on the CAFI-T, was not observed as triggering challenging behavior during direct observations. Occurrence agreement on antecedent stimuli was $67 \%$.

Consequent analysis. The results of the CAFI-T suggest that Tom's challenging behavior is maintained by multiple consequences including adult and peer attention and task avoidance. More specifically, while all topographies of challenging behavior are maintained by adult and peer attention, only "Active Defiance" and "Annoy Others" are maintained by task avoidance. Figure 15 depicts the proportion of challenging behavior followed by specific consequent events during direct observations. During the direct observations, Tom exhibited only one topography of challenging behavior, annoying others. The results of the direct observations suggest that this response is maintained both by adult and peer attention. This finding agrees with the results of the CAFI-T; however task avoidance was not suggested by these data to be a maintaining consequence. Thus, occurrence agreement for consequences was $67 \%$ and non-occurrence agreement for consequences was $75 \%$.

Across stimulus classes, occurrence agreement between the two methods was $67 \%$. Nonoccurrence agreement was $60 \%$, and total agreement was $78 \%$. 


\section{Cost Analysis}

The interviews and direct observations were compared in terms of the amount of time necessary to complete them, and staff requirements. The teacher interviews took an average of 25 minutes to complete. The longest teacher interview took 30 minutes and the shortest took just over 20 minutes. The child interviews took between 15 and 20 minutes to complete. The direct observations required significantly more time. In this study two to two and a half hours of direct observations were conducted for each participant across a 5-week period. Also, direct observations required trained observers to collect and analyze the data. Thus, the interviews are more efficient in terms of time and training needed.

\section{Discussion}

The purpose of Study 2 was to further evaluate the utility of two structured functional assessment interviews designed for use with children exhibiting challenging behavior in schools and their teachers. The evaluation involved first assessing the inter-rater reliability of the interviews by comparing the results of interviews administered to teachers to interviews administered to teaching aides. Second, the results of the teacher-administered interviews were compared to the results from the child-administered interviews. Following the reliability evaluation, the concurrent validity of the teacher interview was evaluated by comparing the results of it to direct observational data.

\section{Inter-rater Reliability}

The inter-rater reliability of the functional assessment interviews was evaluated by comparing the results of interviews administered to teachers to interviews administered to the teachers' aides, and by comparing the teacher interviews to the child interviews. Overall, interrater reliability between teachers and their aides was good. The exception to this was Part III of the interviews, which evaluated alternative responses. Teachers and aides rarely agreed about the alternative responses a child might exhibit. One reason for the poor agreement in this section might be that items asking about alternative responses were open-ended; respondents were not required to choose a response from a pre-determined list. Importantly, inter-rater reliability on antecedents and consequences affecting behavior was high (86\%). Because the teachers and 
aides work with the child in the same setting throughout the day, they are likely to observe similar patterns of behavior. High inter-rater reliability thus suggests that the interview is reliably assessing the environmental variables teachers view as related to challenging behavior.

The second way that inter-rater reliability was evaluated was through a comparison of teacher-administered to child-administered interviews. Agreement between teachers and children was poor on all sections of the interview, because children tended to report that they exhibited challenging behavior in few situations. Thus, they identified only a small number of antecedents and consequences. In contrast, teachers tended to report that challenging behavior occurred in many situations, thus identifying a larger number of antecedents and consequences. This finding was observed also in Study 1, and--as was discussed at that time--has been frequently reported in the literature. Interestingly, however, although children and teachers had poor agreement overall, agreement about maintaining consequences was high. This occurred because an agreement was scored if both the teacher and the child reported a specific consequence at least one time. The fact that agreement about consequences was high (in spite of the finding that children identified fewer situations as evoking challenging behavior) suggests that children may be reliable reporters of the reasons they exhibit challenging behavior, even if they do not reliably identify all antecedents.

\section{Evaluation of the Concurrent Validity of the Teacher Interview}

The validity of the teacher interview was assessed by comparing it to the results of structured direct observations. Because the observations were conducted in-vivo, it was not possible to record data on as many event categories as were coded during the interviews. For example, during direct observations, children were scored as either being engaged in work, or not. In contrast, the interviews evaluated differential effects of "boring work," "easy work," and "difficult work." Thus, direct observations provided only a general evaluation of the validity of the interviews. Overall, agreement between direct observations and the teacher interviews was fair to good. For all participants, the results of the teacher interviews suggested that removal of a preferred activity typically preceded challenging behavior; however this finding was not observed during direct observations. For consequent stimuli, agreement and nonoccurrence agreement was $100 \%$ for two children. For the remaining two children, disagreement occurred on one stimulus. 


\section{GENERAL DISCUSSION}

The purpose of these studies was to develop and evaluate the utility of two functional assessment interviews--one designed for use with teachers and the second for use with children. The interviews were designed to assist in the development of hypotheses about environmental variables affecting problem behavior at school. In Study 1, the interviews were developed and modified based on recommendations from 10 experts in functional assessment and externalizing behavior disorders. Also, the interviews were administered to 10 teachers and 6 children to allow for evaluation of the interview's inter-observer and inter-rater agreement. The purpose of Study 2 was to further evaluate the inter-observer agreement of the interviews by comparing the results of interviews administered to teachers and children, and interviews administered to teachers and teachers' aides. Additionally, the concurrent validity of the interviews was evaluated by comparing the results of the teacher interview to direct observation.

\section{Inter-Observer Agreement}

Inter-observer agreement on the interviews provided information about the extent to which multiple individuals (who interact with the target individual) agree or disagree about the variables affecting that person's behavior. In Study 1 and Study 2, inter-rater agreement between children and their teachers was evaluated. Overall, poor inter-rater agreement was observed. After completion of Study 1, several structural changes were made to the interviews to address the possibility that poor agreement was due to structural issues. In Study 2, agreement about setting events and antecedents was still low, however agreement about consequences was considerably higher, suggesting that the structural changes were effective. Inter-observer agreement also may have been low in these studies because the children were exhibiting the target ("oppositional") responses during the interviews. As discussed in Study 1, multiple published studies comparing results of child-administered behavior rating scales and interviews to those administered to adults show poor agreement (e.g., Achenbach et al., 1987; Argulewicz \& Miller, 1985; Epkins, 1995; Kashani et al., 1985; Rey et al., 1992).

Inter-observer agreement between children and teachers might have been poor because the children were better able to identify variables functionally related to challenging behavior. This hypothesis was addressed in two ways in Study 2. First, inter-observer agreement between 
teachers and teachers' aides was evaluated. Second, the teacher interviews were compared to direct observation data (evaluation of concurrent validity). Inter-rater agreement between teachers and aides was high, overall. More specifically, teachers and aides tended to agree about the events that set the occasion for challenging behavior, the antecedent stimuli that often preceded challenging behavior, and the consequences that followed behavior. This information is what is gathered most often in a functional assessment. Additionally, teachers and aides agreed about the extent to which target children exhibited appropriate or poor social skills. The high inter-observer agreement between teachers and aides suggesting that the teacher interview is useful in gathering reliable information about variables functionally related to challenging behavior. Although good inter-observer agreement does not imply that the information gathered by the interviews is accurate (i.e., the interviews are measuring true variables affecting behavior), it does provide support for the reliability of the interviews. That is, the high interobserver coefficients demonstrate that consistent information can be achieved using the interviews.

\section{Concurrent Validity}

The second part of Study 2 involved an evaluation of the interview's concurrent validity. Specifically, the results of the interviews were compared to data obtained from direct observations of the children in the educational setting. The evaluation of the concurrent validity of the interviews focused only on the broad variables (e.g., large stimulus classes of antecedents and consequences) commonly evaluated in a functional assessment. These classes include presence or absence of tasks, presence or absence of adult attention, and presence or absence of preferred tangibles as antecedents and removal of tasks, delivery of attention, and delivery of preferred tangibles as consequences. Thus, although the data collected in the interviews provided a finer analysis of these variables (e.g., differentially evaluating the effects of difficult versus easy versus boring tasks), the evaluation of the concurrent validity focused only on broad stimulus classes. Overall, agreement between interviews and direct observation was good. That is, the interviews and direct observations were equally useful in determining environmental variables functionally related to behavior.

Taken together, these studies suggest that the functional assessment interviews may be a useful in gathering information about environmental variables affecting challenging behavior. As 
has been noted elsewhere (e.g., O'Neill et al., 1997), a thorough functional assessment should include multiple methods including perhaps functional assessment interviews, a second interview or rating scale, or direct observation. A complete functional assessment should allow one to predict the variables that will and will not evoke the challenging behavior, as well as the variables that do and do not maintain that behavior. O'Neill et al. note that, if confident prediction is possible after conducting a less intensive functional assessment, such as an interview, there is no need to use more intensive methods. If, clear patterns are not evident, however, than the clinician should use other methods, such as direct observation or analog methodology. Thus, a comprehensive functional assessment might be complete after simply conducting an interview with several respondents (e.g., two teachers, a teacher and child). If clear patterns are not evident, further assessment should be conducted, including perhaps different interviews, direct observations, or a structured functional assessment.

\section{Utility of Functional Assessment with Children in School Settings}

Functional assessment methodology is increasingly being called for in the assessment of school-aged children exhibiting challenging behavior (e.g., Lewis \& Sugai, 1996; O'Neill et al., 1997; Reed et al., 1997; Walker et al., 1996). One reason that functional assessment is receiving increased attention may be the drastic increases in school-based violent and delinquent acts. As suggested by Colvin, Kameenui, and Sugai (1993) the growing violence in schools provides good evidence that "traditional" school discipline is not effective for many children. They noted that most traditional discipline programs tend to be reactive and punitive, relying primarily on reprimands, loss of privileges, detention, suspension, and expulsion. The underlying premise of such programs is that, "by experiencing these reactive consequences, ... students will learn the 'right way' of behaving and be motivated sufficiently to comply to the expectations of the school" (Colvin et al., 1993, p. 364). Unfortunately, this supposition has not been found to be true, most children with severe behavior problems continue to have problems throughout their time in school, and often end up dropping out of school or being expelled (Colvin et al., 1993; Walker et al., 1996).

In addition to suspension, detention, and expulsion, schools tend to deal with "severe" discipline problems by separating "problem" students. This is typically done based on diagnostic labels, although not usually DSM labels. Schools may separate children based on labels such as 
level of mental retardation, "behavior disordered," and "severely emotionally disturbed." Like DSM labels, these categories are based on topography of behavior being emitted. For example, the Nebraska Department of Education's Regulations and Standards for Special Education Programs (Rule 51, Title 92) defines "behavior disordered" as a condition that includes: (a) an inability to learn unexplainable by cognitive, sensory, or health factors; (b) an inability to build or maintain typical relationships with peers and teachers; (c) the exhibition of inappropriate behavior or feelings; (d) pervasive unhappiness or depression; or (e) the exhibition of "physical symptoms associated with personal or school problems" (p. 3). Unfortunately, this policy of exclusion, combined with reactive and punitive discipline has been generally ineffective, and as was noted earlier, may lead to increased incidences of violent and delinquent behavior.

The results of the two studies reported here provide some evidence as to why traditional behavior management strategies may be ineffective. First, most school discipline programs provide reactive, punitive consequences based on the topography of the challenging behavior. Weigle (1995) found that teachers reported treating all challenging behavior exhibited by students in the same way, instead of making treatment decisions based on the function of the challenging behavior. For example, in the residential school where Study 2 was conducted, all incidents of noncompliance resulted in time-out. Such programs are also common in more typical schools where behaviors such as "insubordination" or property destruction may result in office referral (i.e., removal from the classroom and thus removal of academic demands). The studies presented here add to the growing body of literature (e.g., Iwata et al., 1994; Taylor \& Miller, 1997) demonstrating that the function of a behavior is the key factor in determining whether a treatment will be effective. For many of the participants in these studies, escape or avoidance of tasks was a maintaining consequence. This suggests that behavior management programs that remove a child (and thus remove academic work) may be ineffective in reducing challenging behavior and may actually result in increases in the very behaviors they are designed to reduce.

A second reason such programs may be ineffective is that they do not teach children more appropriate behaviors. The results of these studies suggest that many of the participants were lacking in social skills (all participants in Study 1, and nine of 10 participants in Study 2). Deficient social skills may be one reason that these children exhibited inappropriate behavior maintained by peer attention. An effective treatment might thus involve, not simply 
implementing consequences for behavior, but also teaching these children more appropriate ways of getting and maintaining peer attention (and ensuring that these more appropriate behaviors are being reinforced). For example, children could be taught age-appropriate attention seeking and conversational skills. Also, they could be taught strategies to use when working on a group project.

Similarly, teachers in both studies had difficulty identifying alternative behaviors children typically used to meet a specific function. For example, teachers typically could not identify more appropriate ways that a child sometimes used to ask for a break from work or to get the teachers attention. This suggests that, at least for the children participating in this study, an effective treatment for challenging behavior must include not only consequences (matched to function) for challenging behavior, but also a program to teach and reward more appropriate behaviors that serve the same function as the challenging behavior. Teaching alternative skills could occur in several different ways. First, children could be taught general skills, such as social skills or leisure skills, to use across situations. Second, children could be taught specific skills matched to the function of the challenging behavior they exhibit. For example, if a child's challenging behavior is maintained by escape or avoidance of tasks, the child could be taught to request a drink of water when he or she needs a break. Finally, children could be taught skills to use in situations that typically evoke challenging behavior, such as before a test is given, or when a peer teases them. Examples include relaxation training and problem solving. Importantly, the skills that are taught must be reinforced when they occur. For example, if a child is taught to ask for a drink when he or she wants a brief break from work, it is important that the child be permitted to leave the classroom upon making such a request.

Although a comprehensive functional assessment should provide useful information for developing treatments for all children exhibiting challenging behavior in schools, it would be unrealistic to expect schools to carry out a comprehensive functional assessment for all children exhibiting any problem behavior. An alternative approach is to use functional assessment technology within a comprehensive system of behavior support.

Experts on school behavior problems suggest that, in any school, three types of students can be found: (a) typical students who are not at risk for problems, (b) students with an elevated risk for developing problems, and (c) students with persistent and severe challenging behavior (e.g., Larsen, 1994; Moffitt, 1994; Walker et al., 1996). A comprehensive system must address the 
needs of all of these types of students. Such a system begins with a comprehensive school-based approach for use with all children in school. Such programs provide a consistent, preventative, and positive way of managing challenging behavior. For example, all children are taught skills such as problem solving and anger management. Additionally, effective reward programs are in place for appropriate behavior (e.g., using problem solving or anger management skills; for details and comprehensive reviews of existing school programs see Colvin, et al., 1993; Colvin, Sugai, Good, \& Lee, 1997; Taylor-Greene et al., 1997; Walker et al., 1996). Walker and colleagues argued that, if a good, comprehensive school-wide system of support is used, the behavior of approximately $75-85 \%$ of the students in a school will be effectively managed. In addition to a comprehensive school-wide program, schools should have a secondary prevention program. Such programs will be effective for students who are not yet exhibiting severe behavior problems, but, without intervention, may begin to. For example, these students may be exhibiting mild oppositional behavior, dawdling in the halls, or having difficulties relating to peers. Walker et al. (1996) stated that secondary prevention programs consist of ". . interventions that provide behavioral or academic support, mentoring, skill development, and assistance to more severely at risk students" (p. 201). Additionally, some students at this level may benefit from a functional assessment (e.g., interviews) to determine environmental variables maintaining challenging behavior. A secondary prevention program will effectively manage the behavior of the majority of the remaining students.

Finally, schools should have a tertiary program for students with very severe behavior problems. Tertiary program are comprehensive, individualized, in evidence over the long-term, and involve a team of individuals consisting of the child (if he or she is old enough to participate), his or her parents or guardians, teachers, and possibly peers (Walker et al, 1996). Tertiary programs utilize comprehensive functional assessments to develop an individualized treatment program for each child. Most likely children at this level will require a multi-method functional assessment including interviews and direct observations to effectively develop hypotheses about challenging behavior.

Taken together, the findings of these studies suggest that the CAFI-T and CAFI-C may be useful methods for determining the function of challenging behavior exhibited by children in schools. These two measures were found to have good inter-rater reliability and good interobserver reliability (between teachers and aides). Further, good agreement was found between 
children and teachers on the functions of challenging behavior in Study 2. Finally, the results of the interview were supported adequately by the results of direct observations, providing some evidence for the concurrent validity of the teacher interview.

Although these results are promising, further research is needed to fully support the efficacy of the CAFI-T and CAFI-C. First, Study 2 should be replicated with a larger sample in a typical school. This would allow for a broader evaluation of the reliability and validity of the interviews. Also, conducting the study in a more typical setting might allow for the inclusion of a broader range of variables (e.g., setting events going on at home, interactions with peers). Second, the CAFI-C could be modified such that children are provided with a restricted range of items from which to choose setting events, antecedents, and consequences maintaining challenging behavior. If students were provided with possible choices, they might be better able to identify controlling variables. Finally, treatment outcome studies could be conducted to evaluate the external validity of the interviews. That is, treatments based on the results of the interviews could be developed and evaluated. If the interviews result in more effective treatments than would otherwise have been used (e.g., typical school behavior management programs such as time-out or suspension), than their utility will be demonstrated. 


\section{References}

Adams, J. (1972). The contribution of the psychological evaluation to psychiatric diagnosis. Journal of Personality Assessment, 36, 561-566.

Achenbach, T. M., Achenbach, T. M., McConaughy, S., \& Howell, C. (1987). Child/adolescent behavioral and emotional problems: Implications of cross-informant correlation for situational specificity. Psychological Bulletin, 101, 213-232.

American Psychiatric Association. (1994). Diagnostic and statistical manual of mental disorders (4th ed.). Washington, DC: Author.

Anderson, C. M., Freeman, K. A., \& Scotti, J. R. (1999). Evaluation of the reliability and validity (generalizability) of analog functional assessment. Behavior Therapy, 30, 31-50.

Anderson, C. M., Hawkins, R. P., \& Scotti, J. R. (1997). Private events in behavior analysis: Conceptual basis and clinical relevance. Behavior Therapy, 28, 157-159.

Argulewicz, E. N., \& Miller, D. (1985). Self-reported and teachers rankings of anxiety among firstgrade children. School Psychology Review, 14, 75-78.

Baum, W. M. (1994). Understanding behaviorism. New York: Harper Collins.

Baum, W. M., \& Heath, J. L. (1992). Behavioral explanations and intentional explanations in psychology [Special Issue]. American Psychologist, 47, 1312-1317.

Barlow, D. H., Hayes, S. C., \& Nelson, R. O. (1984). The scientist practitioner: Research and accountability in clinical and educational settings. New York: Pergamon.

Biglan, A., \& Hayes, S. C. (1996). Should the behavioral sciences become more pragmatic? The case for functional contextualism in research on human behavior. Applied and Preventive Psychology, 5, 47-57.

Branch, M. N. (1987). Behavior analysis: A conceptual and empirical base for behavior therapy. Behavior Therapist, 10, 79-84.

Carr, E. G. (1994). Emerging themes in the functional assessment of problem behavior. Journal of Applied Behavior Analysis, 27, 393-399.

Chiesa, M. (1994). Radical behaviorism: The philosophy and the science. Boston: Author's Cooperative, Inc. 
Colvin, G., Kameenui, E. J., \& Sugai, G. (1993). Reconceptualizing behavior management and school-wide discipline in general education. Education and Treatment of Children, 16, 361381.

Colvin, G., Sugai, G., Good, R. H., \& Lee, Y. (1997). Using active supervision and precorrection to improve transition behaviors in an elementary school. School Psychology Quarterly, 12, 344363.

Craighead, W. E., Kazdin, A. E., \& Mahoney, M. J. (1981). Behavior modification: Principles, issues, and applications. Boston: Houghton Mifflin Co.

Dougher, M. J. (1993). On the advantages and implications of a radical behavioral treatment of private events. Behavior Therapist, 16, 204-206.

Durand, V. M., \& Crimmins, D. B. (1988). Identifying the variables maintaining self-injurious behavior. Journal of Autism and Developmental Disorders, 18, 99-117.

Epkins, C. C. (1995). Teachers ratings of inpatient children's depression, anxiety, and aggression: A preliminary comparison between inpatient-facility and community-based teachers ratings and their correspondence with children's self-reports. Journal of Clinical-Child Psychology, 24, 63-70.

Evans, I. M. (1985). Response-structure and the triple-response mode concept. In R. O. Nelson \& S. C. Hayes (Eds.), Conceptual foundations of behavioral assessment (pp. 131-155). New York: Guilford Press.

Evans, I. M., \& Nelson, R. O. (1986) Assessment of children. In A. R. Ciminero, K. S. Calhoun, \& H. E. Adams (Eds.), Handbook of behavioral assessment (2nd ed., pp. 601-630). New York: Wiley.

Ferster, C. B. (1965). Classification of behavioral pathology. In L. Krasner \& L. P. Ulmann (Eds.), Research in behavior modification (pp. 6-26). New York: Holt, Rinehart, \& Winston.

Forsyth, J. P., Lejuez, C. W., Hawkins, R. P., \& Eifert, G. H. (1996). Cognitive versus contextual causation: Different world views but perhaps not irreconcilable. Journal of Behavior Therapy and Experimental Psychiatry, 27, 369-376.

Freeman, K. A., Anderson, C. M., \& Scotti, J. R. (1996). Structured descriptive analysis: Addressing a gap in functional assessment methodology. Manuscript submitted for publication. Department of Psychology, West Virginia University, Morgantown. 
Frick, P. J., Lahey, B. B., Applegate, B., Kerdyck, L., Ollendick, T., Hynd, G. W., Garfinkel, B. Greenhill, L., Biederman, J., Barkley, R. A., McBurnett, K., Newcorn, J., \& Waldman, I. (1994). DSM-IV field trial for the disruptive behavior disorders: Symptom utility estimates. Journal of the American Academy of Child and Adolescent Psychiatry, 33, 529-539.

Grace, N. C., Kahng, S., \& Fisher, W. W. (1994). Balancing social acceptability with treatment effectiveness of an intrusive procedure: A case report. Journal of Applied Behavior Analysis, 27, 171-172.

Gresham, F. M., \& Gansle, K. A. (1992). Misguided assumptions of DSM-III-R: Implications for school psychology practice. School Psychology Quarterly, 7, 79-95.

Guze, S. B. (1978). Nature of psychiatric illness: Why psychiatry is a branch of medicine. Comprehensive Psychiatry, 19, 295-307.

Hagopian, L. P, Fisher, W. W., Thompson, R. H., \& Owen, J. S. (1996, May). Toward the development of structured criteria for interpretation of functional assessment data. In B. A. Iwata (Chair), Current research on the functional assessment of severe behavior disorders. Symposium conducted at the 22nd annual convention of the Association for Behavior Analysis, San Francisco, CA.

Hawkins, R. P. (1986). Selection of target behaviors. In R. O. Nelson \& S. C. Hayes (Eds.), Conceptual foundations of behavioral assessment (pp. 331-385). New York: Guilford.

Hay, L. R., Nelson, R. O., \& Hay, W. M. (1980). Methodological problems in the use of participant observers. Journal of Applied Behavior Analysis, 13, 501-504.

Hayes, S. C., \& Brownstein, A. J. (1986). Mentalism, behavior-behavior relations, and a behavioranalytic view of the purpose of science. Behavior Analyst, 9, 175-190.

Hayes, S. C., \& Follette, W. C. (1992). Can functional assessment provide a substitute for syndromal classification. Behavioral Assessment, 14, 345-365.

Hayes, S. C., \& Follette, W. C. (1993). The challenge faced by behavioral assessment. European Journal of Psychological Assessment, 9, 182-188.

Hayes, S. C., Nelson, R. O., \& Jarrett, R. (1987). Treatment utility of assessment: A functional approach to evaluating the quality of assessment. American Psychologist, 42, 963-974.

Haynes, S. N. (1988). Causal models and the assessment-treatment relationship in behavior therapy. Journal of Psychopathology and Behavioral Assessment, 10, 171-183. 
Haynes, S. N., \& O'Brien, W. H. (1990). Functional assessment in behavior therapy. $\underline{\text { Clinical }}$ Psychology Review, 10, 649-668.

Hersen, M., \& Bellack, A. S. (1988). DSM-III and behavioral assessment. In A. S. Bellack \& M. Hersen (Eds.). Behavioral assessment: A practical handbook (3rd ed., pp. 67-84). New York: Pergamon.

Hembree-Kigin, T. L, \& McNeil, C. (1995). Parent-child interaction therapy. New York: Plenum Press.

Individuals with Disabilities Education Act of 1997, Pub. L. No. 105-17 (West, 1997).

Iwata, B. A., Dorsey, M. F., Slifer, K. J., Bauman, K. E., \& Richman, G. S. (1994). Towards a functional assessment of self-injury. Journal of Applied Behavior Analysis, 27, 197-209. (reprinted from Analysis and Intervention in Developmental Disabilities, 2, 3-20, 1982).

Iwata, B. A., Pace, G. M., Dorsey, M. F., Zarcone, J. R., Vollmer, T. R., Smith, R. G., Rodgers, T. A., Lerman, D. C., Shore, B. A., Mazaleski, J. L., Goh, H., Cowdery, G. E., Kalsher, M. J., McCosh, K. C., \& Willis, K. D. (1994). The functions of self-injurious behavior: An experimental-epidemiological analysis. Journal of Applied Behavior Analysis, 27, 215-240.

Iwata, B. A., Vollmer, T. R., \& Zarcone, J. R. (1990). The experimental (functional) analysis of behavior disorders: Methodology, applications and limitations. In A. C. Repp \& N. N. Singh (Eds.), Perspectives on the use of nonaversive and aversive interventions for persons with developmental disabilities (pp. 301-330). Sycamore, IL: Sycamore Publishing Company.

Kanfer, F. H., \& Saslow, G. (1969). Behavioral diagnosis. In C. M. Franks (Ed.), Behavior therapy: Appraisal and status (pp. 417-444). New York: McGraw-Hill.

Kashani, J. H., Orvaschel, H., Burk, J., \& Reid, J. (1985). Informant variance: The issue of parentchild disagreement. Journal of the American Academy of Child Psychiatry, 24, 437-441.

Kirk, K. (in press). Issues in selecting intervention strategies for persons with attention deficit hyperactivity disorder. In J. R. Scotti \& L. H. Meyer (Eds.), Behavioral interventions: Principles, models, and practices. Baltimore, MD: Paul H. Brookes.

Korchin, S. J. (1976). Modern clinical psychology. New York: Basic Books.

Korchin, S. J., \& Schuldberg, D. (1981). The future of clinical assessment. American Psychologist, 36, $1147-1158$.

Larson. J. (1994). Violence prevention in the schools: A review of selected programs and procedures. School Psychology Review, 23, 151-164. 
Lennox, D. B., \& Miltenberger, R. G. (1989) Conducting a functional assessment of problem behavior in applied settings. Journal of the Association for Persons with Severe Handicaps, 14, 304-311.

Lerman, D. C., \& Iwata, B. A. (1993). Descriptive and experimental analyses of variables maintaining self-injurious behavior. Journal of Applied Behavior Analysis, 26, 293-319.

Lewis, T. J., \& Sugai, G. (1996). Descriptive and experimental analysis of teacher and peer attention and the use of assessment-based intervention to improve pro-social behavior. Journal of Behavioral Education, 6, 7-24.

Luiselli, J. K. (1991). Assessment-derived treatment of children's disruptive behavior disorders. Behavior Modification, 15, 294-309.

Mace, F. C. (1994). The significance and future of functional assessment methodologies. Journal of Applied Behavior Analysis, 27, 385-392.

Mace, F. C., \& Lalli, J. S. (1991). Linking descriptive and experimental analyses in the treatment of bizarre speech. Journal of Applied Behavior Analysis, 24, 553-562.

Mace, F. C., Lalli, J. C., \& Lalli, E. P. (1991). Functional assessment and the treatment of aberrant behavior. Research in Developmental Disabilities, 12, 155-180.

Mash, E. J. (1979). What is behavioral assessment? Behavioral Assessment, 1, 23-29.

Mash, E. J., \& Hunsley, J. (1990). Behavioral assessment: A contemporary approach. In A. S. Bellack, M. Hersen, \& A. E. Kazdin (Eds.), International handbook of behavior modification and therapy (2nd ed., pp. 87-106). New York: Plenum.

Mash, E. J., \& Terdal, L. G. (1988). Behavioral assessment of childhood disorders (2nd ed.) New York: Guilford.

McReynolds, P. (1985). Psychological assessment and clinical practice: Problems and prospects. In J. N. Butcher \& C. D. Spielberger (Eds.), Advances in personality assessment, Vol. 4 (pp. 130). Hillsdale, NJ: Erlbaum.

Moffitt, T. (1994). Adolescence-limited and life course-persistent antisocial behavior: A developmental taxonomy. Psychological Review, 100, 674-701.

Moore, J. (1992). On private events and theoretical terms. Journal of Mind and Behavior, 13, 329346. 
Morey, L. C., Skinner, H. A., \& Blashfield, R. K. (1986). Trends in the classification of abnormal behavior. In A. R. Ciminero, K. S. Calhoun, \& H. E. Adams (Eds.), Handbook of behavioral assessment (2nd ed., pp. 47-75). New York: Wiley.

Mullen, K. B. (1995). The educative approach to intervention with childhood behavior problems: Toward an application with child intervention packages. Unpublished manuscript. Department of Psychology, West Virginia University, Morgantown.

Munk, D. D., \& Repp, A. C. (1994). Behavioral assessment of feeding problems with individuals with severe disabilities. Journal of Applied Behavior Analysis, 27, 241-250.

Nay, W. R. (1986). Analogue measures. In A. R. Ciminero, K. S. Calhoun, \& H. E. Adams (Eds.), Handbook of behavioral assessment (2nd ed., pp. 223-252). New York: Wiley.

Neef, N. A. (Ed.). (1994). Functional assessment approaches to behavioral assessment and treatment [Special Issue]. Journal of Applied Behavior Analysis, 27(2).

Nelson, R. O., \& Barlow, D. H. (1981). An overview of behavioral assessment with adult clients: Basic strategies and initial procedures. In D. H. Barlow (Ed.), Behavioral assessment of adult disorders (pp. 14-43). New York: Guilford.

Nelson, R. O., \& Hayes, S. C. (1986). The nature of behavioral assessment. In R. O. Nelson \& S. C. Hayes (Eds.), Conceptual foundations of behavioral assessment (pp. 3-41). New York: Guilford.

Nelson, R. O., \& Maser, J. D. (1988). The DSM and depression: Potential contributions of behavioral assessment. Behavioral Assessment, 10, 45-65.

O'Neill, R. E., Horner, R. H., Albin, R. W., Sprague, J. R., Storey, K., \& Newton, J. S. (1997). Functional assessment and program development for problem behavior: A practical handbook (2nd ed.). New York: Brooks/Cole Publishing Co.

O'Neill, R. E., Horner, R. H., Albin, R. W., Storey, K., \& Sprague, J. R. (1990). Functional assessment of problem behavior: A practical assessment guide. Sycamore, IL: Sycamore Press.

Reed, H., Thomas, E., Sprague, J. R., \& Horner, R. H. (1997). The child guided functional assessment interview: An analysis of child and teacher agreement. Journal of Behavioral Education, 7, 33-49.

Rey, J. M., Schrader, E., \& Morris-Yates, A. (1992). Parent-child agreement on children's behaviors reported by the Child Behavior Checklist (CBCL). Journal of Adolescence, 15, 219-230. 
Scotti, J. R., Evans, I. M., Meyer, L. H., \& DiBenedetto, A. (1991). Individual repertoires as behavioral systems: Implications for program design and evaluation. In B. Remington (Ed.), The challenge of severe mental handicap: A behaviour analytic approach (pp. 139-163). London: Wiley.

Scotti, J. R., Evans, I. M., Meyer, L. H., \& Walker, P. (1991). A meta-analysis of intervention research with problem behavior: Treatment validity and standards of practice. American Journal on Mental Retardation, 96, 233-256.

Scotti, J. R., Kirk, K. S., Weigle, K. L., Cuddihy, K., Lumley, V., Magruda, A. Rasheed, S., \& Cohen, T. (1993, May). Analog functional assessments and nonaversive interventions in special education classrooms: A comparison of brief versus extended assessments. Poster presented at the annual meeting of the Association for Behavior Analysis, Chicago, IL.

Scotti, J. R., McMorrow, M. J., \& Trawitzki, A. L. (1993). Behavioral treatment of chronic psychiatric disorders: publication trends and future directions. Behavior Therapy, 24, 527550.

Scotti, J. R., Morris, T. L., McNeil, C. B., \& Hawkins, R. P. (1996). DSM-IV and disorders of childhood and adolescence: Can structural criteria be functional? Journal of Consulting and Clinical Psychology, 64, 1177-1191.

Scotti, J. R., Schulman, D. E., \& Hojnacki, R. M. (1994). Functional assessment and unsuccessful treatment of Tourette's syndrome in a man with profound mental retardation. Behavior Therapy, 25, 721-738.

Scotti, J. R., Ujcich, K. J., Weigle, K. L., Holland, C. M., \& Kirk, K. S. (1996). Interventions with challenging behavior of persons with developmental disabilities: A review of current research practices. Journal of the Association for Persons with Severe Handicaps, 21, 123134.

Scotti, J. R., Weigle, K. L., Kirk, K. S., Ellis, J. T., Jackson, S., Kennedy, C., \& Schreiber, R. (1993, May). A comparison of three functional assessment strategies with the excess and positive behaviors of children with developmental disabilities. Poster presented at the annual meeting of the Association for Behavior Analysis, Chicago, IL.

Skinner, B. F. (1953). Science and human behavior. New York: Free Press.

Skinner, B. F. (1969). Contingencies of reinforcement. New York: Appleton-Century-Crofts.

Skinner, B. F. (1974). About behaviorism. New York: Knopf. 
Skinner, B. F. (1977). Why I am not a cognitive psychologist. Behaviorism, 5, 1-10.

Skinner, B. F. (1981). Selection by consequences. Science, 213, 501-504.

Skinner, B. F. (1983). Can the experimental analysis of behavior rescue psychology? Behavior Analyst, 6, 9-17.

Sprague, J., Sugai, G., \& Walker, H. (1998). Antisocial behavior in schools. In T. S. Watson \& F. M. Gresham (Eds.) Handbook of child behavior therapy: Issues in clinical child psychology (pp. 451-474). New York: Plenum Press

Sprock, J., \& Blashfield, R. K. (1983). Classification and nosology. In. M. Hersen, A. E. Kazdin, \& A. S. Bellack (Eds.), The clinical psychology handbook (pp. 289-307). New York: Pergamon.

Sturmey, P. (1996). Functional assessment in clinical psychology. New York: Wiley.

Sulzer-Azaroff, B., \& Mayer, G. R. (1977). Applying behavior-analysis procedures with children and youth. New York: Holt, Rinehart, \& Winston.

Szasz, T. (1961). The myth of mental illness: Foundations of a theory of personal conduct. New York: Harper.

Taylor, J., \& Miller, M. (1997). When timeout works some of the time: The importance of treatment integrity and functional assessment. School Psychology Quarterly, 12, 4-22.

Taylor-Greene, S., Brown, D., Nelson, L., Longton, J., Gassman, T., Cohen, J., Swartz, J., Horner, R. H., Sugai, G., \& Hall, S. (1997). School-wide behavioral support: Starting the year off right. Journal of Behavioral Education, 7, 99-112.

Turkat, I. D. (1986). The behavioral interview. In A. R. Ciminero, K. S. Calhoun, \& H. E. Adams (Eds.), Handbook of behavioral assessment (2nd ed., pp. 109-149). New York: Wiley.

Van Houten, R., Axelrod, S., Bailey, J. S., Favell, J. E., Foxx, R. M., Iwata, B. A., \& Lovaas, O. I. (1988). The right to effective behavioral treatment. Behavior Analyst, 11, 111-114.

Voeltz, L. M., \& Evans, I. M. (1982). The assessment of behavioral interrelationships in child behavior therapy. Behavioral Assessment, 4, 131-165.

Walker, H. M., Horner, R. H., Sugai, G., Bullis, M., Sprague, J. R., Bricker, D., \& Kaufman, M. J. (1996). Journal of Emotional and Behavioral Disorders, 4, 194-209.

Weigle, K. (1995). The effects of functional analysis information on ratings of treatment acceptability and effectiveness. Unpublished master's thesis, Department of Psychology, West Virginia University, Morgantown. 
Willis, T. J., LaVigna, G. W., \& Donnellan, A. M. (1987). Behavior assessment guide. Los Angeles: Institute for Applied Behavior Analysis.

Wolpe, J., \& Turkat, I. D. (1985). Behavioral formulation of clinical cases. In I. Turkat (Ed.), Behavioral case formulation (pp. 213-244). New York: Plenum Press. 
Table 1

Child Participants in Study 1

\begin{tabular}{lll}
\hline Participant & Age & Diagnosis \\
\hline & & \\
2 & 8 & Oppositional defiant disorder, attention-deficit/hyperactivity disorder \\
3 & 9 & Oppositional defiant disorder \\
4 & 7 & Oppositional defiant disorder, attention-deficit/hyperactivity disorder \\
5 & 10 & Oppositional defiant disorder, attention-deficit/hyperactivity disorder \\
6 & 10 & Oppositional defiant disorder \\
7 & 9 & Oppositional defiant disorder \\
8 & 9 & Oppositional defiant disorder \\
9 & 7 & None \\
10 & 11 & Oppositional-defiant disorder, conduct disorder \\
\hline
\end{tabular}

Note. Participants are coded as meeting criteria for oppositional defiant disorder if their teachers rated three or more behaviors as a " 3 " or a " 4 " on the questionnaire about behavior. Conduct disorder is coded if the teacher rated behaviors consistent with three or more of the sub-categories of behaviors for conduct disorder (i.e., aggression toward people and animals, destruction of property, deceitfulness or theft, serious violations of rules) as a "3" or a " 4 " on the questionnaire. Attention-deficit/hyperactivity disorder is coded if teachers rated six or more behaviors consistent with either the inattention subcategory or the hyperactivity subcategory of the diagnostic criteria for the disorder as a " 3 " or a " 4 ." 
Table 2

$\underline{\text { Target Responses and Operational Definitions for Each Participant }}$

\begin{tabular}{|c|c|c|}
\hline Participant & Target response & Operational definition \\
\hline \multirow[t]{3}{*}{1} & 1. Blame others & $\begin{array}{l}\text { 1. Stating that others are responsible for his behavior } \\
\text { (e.g., "It is not my fault." "He did it.") }\end{array}$ \\
\hline & 2. Active defiance & $\begin{array}{l}\text { 2. Saying "No," or "You can't make me," when asked to } \\
\text { work on assignments or given a specific request }\end{array}$ \\
\hline & 3. Lose temper & 3. Yells, stomps foot, throws objects \\
\hline \multirow[t]{3}{*}{2} & 1. Lose temper & 1. Stomps feet, kicks people, throws self into walls \\
\hline & 2. Active defiance & 2. Says "No," or "make me" \\
\hline & 3. Argue with adults & $\begin{array}{l}\text { 3. Tells adults they are wrong, and that he knows they } \\
\text { are lying to him }\end{array}$ \\
\hline \multirow[t]{3}{*}{3} & 1. Lose temper & 1. Stomps his feet, attempts to leave the room, yells \\
\hline & 2. Argue with adults & $\begin{array}{l}\text { 2. Argues about how a task should be done (e.g., "This } \\
\text { is how you are supposed to do math.") }\end{array}$ \\
\hline & 3. Blame others & $\begin{array}{l}\text { 3. Says "The devil made me do it," that peers told him to } \\
\text { do it, or that his father told him to do it }\end{array}$ \\
\hline
\end{tabular}

(table continues) 
Table 2 (continued)

\begin{tabular}{|c|c|c|}
\hline Participant & Target response & Operational definition \\
\hline \multirow[t]{3}{*}{4} & 1. Lose temper & $\begin{array}{l}\text { 1. Kicks objects and people, cries, throws items, knocks } \\
\text { items off his desk, swears, attempts to leave the room, } \\
\text { hangs out the window }\end{array}$ \\
\hline & 2. Active defiance & $\begin{array}{l}\text { 2. Refuses to do required assignments or follow specific } \\
\text { requests, leaves the room, says, "No," scribbles on } \\
\text { assignments, walks around the classroom }\end{array}$ \\
\hline & 3. Annoy others & $\begin{array}{l}\text { 3. Stands very close to people (i.e., within } 1-2 \text { inches of } \\
\text { them), slams doors, squeaks shoes, taps people on their } \\
\text { heads }\end{array}$ \\
\hline \multirow[t]{3}{*}{5} & 1. Active defiance & $\begin{array}{l}\text { 1. Refuses to follow school rules or complete } \\
\text { assignments, says "No," makes excuses about why he } \\
\text { cannot work (e.g., "Today is a family holiday."), } \\
\text { dawdles, whines about having to do school work }\end{array}$ \\
\hline & 2. Annoy others & $\begin{array}{l}\text { 2. Barks like a dog, pokes people, teases peers (e.g., } \\
\text { "You look like a pig."), mimics others }\end{array}$ \\
\hline & 3. Easily annoyed & $\begin{array}{l}\text { 3. Yells at peers or threatens them, (e.g., "I am going to } \\
\text { beat you up.") }\end{array}$ \\
\hline
\end{tabular}

(table continues) 
Table 2 (continued)

\begin{tabular}{|c|c|c|}
\hline Participant & Target response & Operational definition \\
\hline \multirow[t]{5}{*}{6} & 1. Annoys others & 1. Takes others materials (e.g., pencils), loudly breaks \\
\hline & & his pencil and tosses it across the room, takes other's \\
\hline & 2. Blame others & snacks \\
\hline & 3. Easily annoyed & 2. Says that a peer told him to misbehave \\
\hline & & $\begin{array}{l}\text { 3. If someone touches him he yells at them or gets the } \\
\text { teacher }\end{array}$ \\
\hline \multirow[t]{3}{*}{7} & 1. Lose temper & $\begin{array}{l}\text { 1. Walks out of the room, swears, threatens to hurt } \\
\text { another person, throws items }\end{array}$ \\
\hline & 2. Annoy others & 2. Teases, pokes people, calls people derogatory names \\
\hline & 3. Argue with adults & $\begin{array}{l}\text { 3. Insists on being right, says "You are wrong," "you } \\
\text { can't make me." }\end{array}$ \\
\hline \multirow[t]{4}{*}{8} & 1. Annoy others & $\begin{array}{l}\text { 1. Teases peers, calls them derogatory names, takes their } \\
\text { work off their desk, pokes peers }\end{array}$ \\
\hline & 2. Blame others & 2. Says that someone else made him misbehave or that \\
\hline & & his mother told him not to do his homework \\
\hline & 3. Spiteful or mean & $\begin{array}{l}\text { 3. If another student comes close to him, he will push } \\
\text { them }\end{array}$ \\
\hline
\end{tabular}

(table continues) 
Table 2 (continued)

\begin{tabular}{lll}
\hline Participant & Target response & Operational definition \\
\hline 9 & 1. Lose temper & $\begin{array}{l}\text { 1. Punches objects (e.g., file cabinet), pushes others, } \\
\text { knocks items (e.g., desks) over }\end{array}$ \\
& $\begin{array}{l}\text { 2. Angry and resentful } \\
\text { 3. Active defiance }\end{array}$ & $\begin{array}{l}\text { 3. Pretends not to hear a request, puts head down on } \\
\text { desk }\end{array}$ \\
& $\begin{array}{l}\text { 1. Sings, hums, talks out of turn } \\
\text { 10 Annoy others }\end{array}$ & $\begin{array}{l}\text { 2. Says that his misbehavior is someone else's fault } \\
\text { 2. Blame others }\end{array}$ \\
3. Angry and resentful & $\begin{array}{l}\text { 3. Scrunches up his face, calls people derogatory names, } \\
\text { jumps up and down, hits people }\end{array}$ \\
\end{tabular}


Table 3

Percentage Agreement Between Raters on Each Item of the Teacher Version of the

CAFI (Study 1, Phase B)

\begin{tabular}{|c|c|c|c|c|c|c|}
\hline Item & Rating $^{\mathrm{a}}$ & Behavior $^{\mathrm{b}}$ & Response $^{c}$ & Activity $^{\mathrm{d}}$ & Frequency $^{\mathrm{e}}$ & Effect ${ }^{\mathrm{f}}$ \\
\hline \multicolumn{7}{|c|}{ Part I: Antecedents and Consequences } \\
\hline 1 & 100 & 100 & 100 & & & \\
\hline 2 & 100 & 100 & 100 & & & \\
\hline 3 & 100 & 100 & 100 & & & \\
\hline 4 & 100 & 100 & 100 & & & \\
\hline 5 & 100 & 100 & 100 & & & \\
\hline 6 & 100 & 100 & 83 & & & \\
\hline 7 & 100 & 83 & 100 & & & \\
\hline 8 & 100 & 83 & 100 & & & \\
\hline 9 & 100 & 100 & 83 & & & \\
\hline 10 & 100 & 100 & 83 & & & \\
\hline 11 & 100 & 83 & 67 & & & \\
\hline 12 & 100 & 100 & 100 & & & \\
\hline 13 & 100 & 100 & 100 & & & \\
\hline
\end{tabular}

(table continues) 
Table 3 (continued)

\begin{tabular}{|c|c|c|c|c|c|c|}
\hline Item & Rating $^{\mathrm{a}}$ & Behavior $^{b}$ & Response $^{c}$ & Activity $^{\mathrm{d}}$ & Frequency $^{\mathrm{e}}$ & Effect $^{\mathrm{f}}$ \\
\hline \multicolumn{7}{|c|}{ Part II: Preferred Classes and Activities } \\
\hline 1 & & & & 100 & 100 & \\
\hline 2 & & & & 100 & 100 & \\
\hline \multicolumn{7}{|c|}{ Part III: Social Skills } \\
\hline 1 & & & 100 & & & \\
\hline 2 & & & 100 & & & \\
\hline 3 & & & 100 & & & \\
\hline \multicolumn{7}{|c|}{ Part IV: Setting Events } \\
\hline 1 & 100 & 100 & & & & \\
\hline 2 & 83 & 100 & & & & \\
\hline 3 & 100 & 100 & & & & \\
\hline 4 & 100 & 100 & & & & \\
\hline 5 & 100 & 83 & & & & \\
\hline 6 & 83 & 83 & & & & \\
\hline 7 & 100 & 100 & & & & \\
\hline Abuse & 100 & 100 & & & & \\
\hline Fighting & 83 & 83 & & & & \\
\hline
\end{tabular}

(table continues) 
Table 3 (continued)

\begin{tabular}{|c|c|c|c|c|c|c|}
\hline Item & Rating $^{\mathrm{a}}$ & Behavior $^{\mathrm{b}}$ & Response $^{\mathrm{c}}$ & Activity $^{\mathrm{d}}$ & Frequency $^{\mathrm{e}}$ & Effect ${ }^{\mathrm{f}}$ \\
\hline Health & 100 & 100 & & & & \\
\hline Siblings & 100 & 100 & & & & \\
\hline Medicine A & 100 & & & & & 100 \\
\hline Medicine B & 100 & & & & & 100 \\
\hline \multicolumn{7}{|c|}{ Part V: Alternative Responses } \\
\hline 1 & 100 & 100 & & & & \\
\hline 2 & 100 & 100 & & & & \\
\hline 3 & 100 & 83 & & & & \\
\hline 4 & 100 & 100 & & & & \\
\hline
\end{tabular}

${ }^{a}$ Agreement between raters about the response provided on the Likert scale. ${ }^{b}$ Agreement between raters about the challenging behavior listed by the respondent. ${ }^{c}$ Agreement between raters about the ways that others typically respond. ${ }^{\mathrm{d}}$ Agreement between raters about the activities named by the respondent. ${ }^{\mathrm{e}}$ Agreement between raters about the frequency the respondent stated activities occurred. ${ }^{\mathrm{f}}$ Agreement between raters about the effectiveness rating provided by the respondent for a given medication. 
Table 4

Hypothesized Variables Affecting Behavior of Participants in Study 1 (Based on Results of Teacher Version of the CAFI-T)

Participant

Variable

\begin{tabular}{llllllllll}
\hline 1 & 2 & 3 & 4 & 5 & 6 & 7 & 8 & 9 & 10
\end{tabular}

Setting Events

Social skills deficit

$\begin{array}{lllllllll}X & X & X & X & X & X & X & X & X\end{array}$

Feeling ill

$X \quad X \quad X$

Hungry

Sleeping habits

$\mathrm{X} \quad \mathrm{X}$

Parental fights

Abuse

Parental health

$\begin{array}{llll}X & X & X\end{array}$

$\mathrm{X}$

$\mathrm{X} \quad \mathrm{X}$

$\begin{array}{lll}X & X & X\end{array}$

X $\quad X \quad X$

$\mathrm{X}$

$\mathrm{X}$

X

$\mathrm{X}$

Siblings

$$
\text { X X }
$$

Medication

Antecedent

$\begin{array}{lllllllllll}\text { Presence of peers } & X & X & X & X & X & X & X & X & X & X \\ \text { Presence of adults } & X & & X & X & X & & X & & & \\ \text { Presence of adults and } & X & & X & X & X & X & X & X & X & X \\ \text { peers } & & & & & & & & & & \end{array}$


Table 4 (continued)

\begin{tabular}{|c|c|c|c|c|c|c|c|c|c|c|c|}
\hline \multirow[b]{2}{*}{ Variable } & & \multicolumn{6}{|c|}{ Participant } & \multirow[b]{2}{*}{7} & \multirow[b]{2}{*}{8} & \multirow[b]{2}{*}{9} & \multirow[b]{2}{*}{10} \\
\hline & & 1 & 2 & 3 & 4 & 5 & 6 & & & & \\
\hline & Absence of others & & $\mathrm{X}$ & & & & & & & $X$ & \\
\hline & Easy task & $X$ & $\mathrm{X}$ & $X$ & & $X$ & & & & & \\
\hline & Boring task & $\mathrm{X}$ & & $\mathrm{X}$ & $\mathrm{X}$ & $X$ & & $\mathrm{X}$ & $\mathrm{X}$ & & $\mathrm{X}$ \\
\hline & Difficult task & $X$ & $\mathrm{X}$ & $\mathrm{X}$ & $\mathrm{X}$ & $\mathrm{X}$ & $\mathrm{X}$ & $\mathrm{X}$ & $\mathrm{X}$ & $X$ & $\mathrm{X}$ \\
\hline & Group work & & $\mathrm{X}$ & $\mathrm{X}$ & $X$ & $\mathrm{X}$ & $\mathrm{X}$ & & $X$ & $X$ & $\mathrm{X}$ \\
\hline & Independent work & $\mathrm{X}$ & $\mathrm{X}$ & $X$ & $X$ & $X$ & $X$ & $\mathrm{X}$ & & $\mathrm{X}$ & $X$ \\
\hline & Structured situation & $X$ & $\mathrm{X}$ & $\mathrm{X}$ & & $\mathrm{X}$ & $\mathrm{X}$ & & & & \\
\hline & Unstructured situation & $\mathrm{X}$ & $\mathrm{X}$ & & $\mathrm{X}$ & $\mathrm{X}$ & $\mathrm{X}$ & $\mathrm{X}$ & $X$ & $\mathrm{X}$ & $\mathrm{X}$ \\
\hline & Unexpected change & & $\mathrm{X}$ & & & $\mathrm{X}$ & & & $X$ & & $X$ \\
\hline & $\begin{array}{l}\text { Preferred activity is } \\
\text { removed }\end{array}$ & $\mathrm{X}$ & $\mathrm{X}$ & $\mathrm{X}$ & $\mathrm{X}$ & & & $\mathrm{X}$ & & $\mathrm{X}$ & \\
\hline \multicolumn{12}{|c|}{ Consequences } \\
\hline & Adult attention & 11 & & 7 & 6 & 8 & 3 & 7 & 3 & 6 & 7 \\
\hline & Peer attention & 2 & 2 & 1 & 3 & 6 & 4 & 3 & 4 & 3 & 2 \\
\hline & Tangible delivery & & & & & & & & & & \\
\hline & Task avoidance & 6 & 5 & 5 & 2 & 3 & 3 & 1 & 3 & 4 & \\
\hline & Adult avoidance & & & & & & & & & & \\
\hline & Peer avoidance & & & & & & & & & & \\
\hline
\end{tabular}

Note. Numerals refer to the number of items in Section I of the CAFI-T on which a given consequence was endorsed. 
Table 5

Hypothesized Variables Affecting Behavior of Participants in Study 1 (Based on Results of Child Version of the CAFI)

\begin{tabular}{|c|c|c|c|c|c|c|c|}
\hline \multirow[b]{2}{*}{ Variable } & & \multicolumn{4}{|c|}{ Participant } & \multirow[b]{2}{*}{8} & \multirow[b]{2}{*}{10} \\
\hline & & 3 & 4 & 5 & 7 & & \\
\hline \multicolumn{8}{|c|}{ Setting events } \\
\hline & Social skills deficit & $\mathrm{X}$ & $X$ & & $X$ & $\mathrm{X}$ & $\mathrm{X}$ \\
\hline & Feeling ill & & & & & $\mathrm{X}$ & \\
\hline & Hungry & & & & $X$ & & \\
\hline & Sleeping habits & & $X$ & & $X$ & $\mathrm{X}$ & $X$ \\
\hline & Medication & & & & & & \\
\hline \multicolumn{8}{|c|}{ Antecedent } \\
\hline & Presence of peers & $\mathrm{X}$ & $\mathrm{X}$ & & $\mathrm{X}$ & $\mathrm{X}$ & $\mathrm{X}$ \\
\hline & Presence of adults & & & & & & \\
\hline & Presence of adults and peers & & & & & & \\
\hline & Absence of others & $\mathrm{X}$ & & & & & \\
\hline & Easy task & & & & $\mathrm{X}$ & & $\mathrm{X}$ \\
\hline & Boring task & & & & & & \\
\hline & Difficult task & & & & & $\mathrm{X}$ & \\
\hline & Group work & & & & $X$ & $\mathrm{X}$ & \\
\hline & Independent work & & & & $X$ & $\mathrm{X}$ & $\mathrm{X}$ \\
\hline & Structured situation & & & & $X$ & & \\
\hline
\end{tabular}

(table continues) 
Table 5 (continued)

\begin{tabular}{|c|c|c|c|c|c|c|c|}
\hline \multirow[b]{2}{*}{ Variable } & & \multicolumn{6}{|c|}{ Participant } \\
\hline & & 3 & 4 & 5 & 7 & 8 & 10 \\
\hline \multirow{9}{*}{ Conseque } & Unstructured situation & & & & $\mathrm{X}$ & $\mathrm{X}$ & \\
\hline & Unexpected change & & & & $X$ & $\mathrm{X}$ & \\
\hline & Preferred activity is removed & & & & & & \\
\hline & Adult attention & 2 & & & 3 & 1 & 1 \\
\hline & Peer attention & 1 & 1 & & 3 & 4 & 2 \\
\hline & Tangible delivery & & & & & & \\
\hline & Task avoidance & & 1 & & 1 & & \\
\hline & Adult avoidance & & & & & & \\
\hline & Peer avoidance & & & & & & \\
\hline
\end{tabular}

Note. Numerals refer to the number of items on which a given consequence was endorsed in Section I of the CAFI-T. 
Table 6

$\underline{\text { Relation Between Antecedents and Consequences Across Participants in Study } 1}$

\section{Consequent stimuli}

$\begin{array}{llll}\text { Antecedent stimuli } & \text { Adult } & \text { Peer } & \text { Task } \\ \text { Attention } & \text { Attention } & \text { Tvoidance } & \begin{array}{l}\text { Tangible } \\ \text { delivery }\end{array} \\ \text { Presence of other children } & 1,3,4,5,7 & & 1 \\ \text { Presence of adults } & 1,3,4,5,6,7,8,9,10 & 1,4,5,7,8,9,7,8,9,10 & \\ \text { Presence of children and adults } & & 1,5 & 1,2,3 \\ \text { No-one is present } & 5 & 1 & 1,3,4,7,8 \\ \text { Easy task } & 3,4,5,7,10 & 1 & 1,2,4,5,6,7,8,9 \\ \text { Boring task } & 3,4,5,7,10 & 2,4,5,6,8,9,10 & 1,3,4,6,8,9,10 \\ \text { Difficult task } & 2,4,8,9 & 1 & 1,2,3,4,5,6,7,9 \\ \text { Group activity } & 3,4,5,6,9,10 & 1,5 & 1,2,3,6 \\ \text { Independent work } & 3,6 & 4,5,7,8,9,10 & 1 \\ \text { Structured situation } & 1,5,6,7,10 & 8 & \\ \text { Unstructured situation } & 8,10 & & \\ \text { Unexpected change occurs } & 2,3,4,7,9 & & \end{array}$

Note. Numerals refer to participants 
Table 7

Alternative Responses Identified by Teachers in Study 1, Phase B

\begin{tabular}{lll} 
Participant & $\begin{array}{l}\text { Hypothesized function of } \\
\text { alternative response }\end{array}$ & Alternative responses identified by teachers \\
\hline 3 & Obtain adult attention & Say "hi, " hug teacher \\
& Obtain peer-attention & Ask peer to play \\
4 & Obtain adult attention & Exhibit good manners \\
& Obtain peer-attention & Ask peer to play \\
5 & Obtain adult attention & Hug adult \\
& Obtain break from work & Ask to use bathroom or to get a drink \\
7 & Obtain adult attention & Show work \\
& Obtain peer-attention & Ask peer to play \\
& Obtain break from work & Says "I need a break." \\
\hline
\end{tabular}

(table continues) 
Table 7 (continued)

\begin{tabular}{lll}
\hline Participant & $\begin{array}{l}\text { Hypothesized function of } \\
\text { alternative response }\end{array}$ & Alternative responses identified by teachers \\
\hline 8 & Obtain adult attention & Tries to do work \\
9 & Obtain peer-attention & Buys ice cream for peers \\
& Obtain adult attention & Ask for help \\
& Obtain peer-attention & Try to help them, ask a peer to play \\
& Obtain adult attention & Complete homework, show work \\
& Obtain peer-attention & Show peers toys from home \\
\hline
\end{tabular}

$\underline{\text { Note. Alternative responses were not identified for Participants 1, 2, and } 6 .}$ 
Table 8

Agreement Between Teacher and Child Versions of the CAFI

\begin{tabular}{|c|c|c|c|}
\hline Item & Occurrence Agreement & Nonoccurrence agreement & Total agreement \\
\hline \multicolumn{4}{|c|}{ Section I: Antecedent Information } \\
\hline 1 & 83 & 0 & 83 \\
\hline 2 & 0 & 33 & 33 \\
\hline 3 & 67 & 0 & 67 \\
\hline 4 & 100 & 100 & 100 \\
\hline 5 & 20 & 20 & 33 \\
\hline 6 & 33 & 0 & 33 \\
\hline 7 & 33 & 0 & 33 \\
\hline 8 & 20 & 20 & 33 \\
\hline 9 & 20 & 20 & 33 \\
\hline 10 & 0 & 50 & 50 \\
\hline 11 & 33 & 66 & 50 \\
\hline 12 & 0 & 60 & 67 \\
\hline 13 & 0 & 50 & 50 \\
\hline \multicolumn{4}{|c|}{ Section II: Setting Event Information } \\
\hline 1 & 83 & 0 & 83 \\
\hline 2 & 50 & 50 & 67 \\
\hline
\end{tabular}

(table continues) 
Table 8 (continued)

\begin{tabular}{llll}
\hline Item & Occurrence Agreement & Nonoccurrence agreement & Total agreement \\
\hline & & & \\
3 & 0 & 50 & 50 \\
4 & 67 & 33 & 50 \\
9 & & 100 & 100 \\
\hline
\end{tabular}

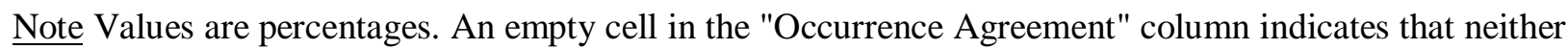
teacher nor child reported that item as occurring. 
Table 9

Agreement Between Teachers and Children on Consequences Affecting Behavior

\begin{tabular}{llll}
\hline Participant & $\begin{array}{l}\text { Percent occurrence } \\
\text { agreement }\end{array}$ & $\begin{array}{l}\text { Percent nonoccurrence } \\
\text { agreement }\end{array}$ & $\begin{array}{l}\text { Percent total } \\
\text { agreement }\end{array}$ \\
\hline 3 & 50 & 0 & 50 \\
4 & 68 & & 67 \\
5 & 0 & 0 & 0 \\
7 & 74 & 0 & 75 \\
8 & 67 & 0 & 67 \\
10 & 100 & 0 & 100 \\
\hline
\end{tabular}


Table 10

Assessment of Content Validity of the CAFI-T: Agreement Scores Between Expert Raters

\begin{tabular}{|c|c|c|c|c|c|c|c|}
\hline Item & $\begin{array}{l}\text { Setting } \\
\text { event }\end{array}$ & $\begin{array}{l}\text { Antecedent } \\
\text { event }\end{array}$ & $\begin{array}{l}\text { Consequent } \\
\text { event }\end{array}$ & $\begin{array}{l}\text { Potential } \\
\text { reward }\end{array}$ & $\begin{array}{l}\text { Skills } \\
\text { deficit }\end{array}$ & $\begin{array}{l}\text { Alternative } \\
\text { behavior }\end{array}$ & Other \\
\hline \multicolumn{8}{|c|}{ Section I: Setting Events } \\
\hline 1 & 100 & & & & & & \\
\hline 2 & 100 & & & & & & \\
\hline 3 & 100 & & & & & & \\
\hline 4 & 100 & & & & & & \\
\hline 5 & 100 & & & & & & \\
\hline 6 & 100 & & & & & & \\
\hline 7 & 100 & & & & & & \\
\hline 8 & 100 & & & & & & \\
\hline \multicolumn{8}{|c|}{ Section II: Antecedent and Consequent Stimuli } \\
\hline 1 & & 100 & 100 & 13 & 13 & & \\
\hline 2 & & 100 & 100 & 13 & 13 & & \\
\hline 3 & & 100 & 100 & 13 & 13 & & \\
\hline
\end{tabular}

(table continues) 
Table 10 (continued)

\begin{tabular}{|c|c|c|c|c|c|c|c|}
\hline Item & $\begin{array}{l}\text { Setting } \\
\text { event }\end{array}$ & $\begin{array}{l}\text { Antecedent } \\
\text { event }\end{array}$ & $\begin{array}{l}\text { Consequent } \\
\text { event }\end{array}$ & $\begin{array}{l}\text { Potential } \\
\text { reward }\end{array}$ & $\begin{array}{l}\text { Skills } \\
\text { deficit }\end{array}$ & $\begin{array}{l}\text { Alternative } \\
\text { behavior }\end{array}$ & Other \\
\hline 4 & & 100 & 100 & 13 & 13 & & \\
\hline 5 & & 100 & 100 & 13 & 13 & & \\
\hline 6 & & 100 & 100 & 13 & 13 & & \\
\hline 7 & & 100 & 100 & 13 & 13 & & \\
\hline 8 & & 100 & 100 & 13 & 13 & & \\
\hline 9 & & 100 & 100 & 13 & 13 & & \\
\hline 10 & & 100 & 100 & 13 & 13 & & \\
\hline 11 & & 100 & 100 & 13 & 13 & & \\
\hline 12 & & 100 & 100 & 13 & 13 & & \\
\hline 13 & & 100 & 100 & 13 & 13 & & \\
\hline \multicolumn{8}{|c|}{ Section III: Skills Deficits } \\
\hline 1 & & & & 100 & & & \\
\hline 2 & & & & 13 & 75 & & 13 \\
\hline 3 & & & & 13 & 75 & & 13 \\
\hline 4 & & & & & & 88 & \\
\hline
\end{tabular}

(table continues) 
Table 10 (continued)

\begin{tabular}{|c|c|c|c|c|c|c|c|}
\hline Item & $\begin{array}{l}\text { Setting } \\
\text { event }\end{array}$ & $\begin{array}{l}\text { Antecedent } \\
\text { event }\end{array}$ & $\begin{array}{l}\text { Consequent } \\
\text { event }\end{array}$ & $\begin{array}{l}\text { Potential } \\
\text { reward }\end{array}$ & $\begin{array}{l}\text { Skills } \\
\text { deficit }\end{array}$ & $\begin{array}{l}\text { Alternative } \\
\text { behavior }\end{array}$ & Other \\
\hline 5 & & & & & & 88 & \\
\hline 6 & & & & & & 88 & \\
\hline 7 & & & & & & 88 & \\
\hline 8 & & & & & & 88 & \\
\hline 9 & & & & & & 88 & \\
\hline
\end{tabular}


Table 11

$\underline{\text { Target Responses and Operational Definitions for Each Participant in Study } 2}$

\begin{tabular}{|c|c|c|}
\hline Participant & Target response & Operational definition \\
\hline \multirow[t]{3}{*}{ Ben } & 1. Argue with adults & $\begin{array}{l}\text { 1. Tells adults that they are wrong, says he knows how } \\
\text { things really happened }\end{array}$ \\
\hline & 2. Blame others & 2. Says, "it is not my fault, " "I didn't do it." \\
\hline & 3. Active defiance & $\begin{array}{l}\text { 3. Does not work on assignment, refuses to follow } \\
\text { directions, says "no." }\end{array}$ \\
\hline \multirow[t]{3}{*}{ Hal } & 1. Angry and resentful & $\begin{array}{l}\text { 1. Squints his eyes, tenses his muscles, does not make } \\
\text { eye contact, says "I can say what I want." }\end{array}$ \\
\hline & 2. Annoy others & $\begin{array}{l}\text { 2. Talks over someone else, talks without raising his } \\
\text { hand }\end{array}$ \\
\hline & 3. Active defiance & $\begin{array}{l}\text { 3. Tries to distract others by talking to them about non- } \\
\text { work topics, stares into space, says "I don't have to." }\end{array}$ \\
\hline
\end{tabular}

(table continues) 
Table 11 (continued)

\begin{tabular}{|c|c|c|}
\hline Participant & Target response & Operational definition \\
\hline \multirow[t]{3}{*}{ Jim } & 1. Annoy others & $\begin{array}{l}\text { 1. Blurts out answers, gets out of line, talks out of turn, } \\
\text { talks without raising his hand }\end{array}$ \\
\hline & 2. Blame others & $\begin{array}{l}\text { 2. Says that someone else did it, says an adult told him } \\
\text { to do the behavior }\end{array}$ \\
\hline & 3. Argue with adults & $\begin{array}{l}\text { 3. Tells adults that someone else said that (the point of } \\
\text { disagreement) was true, says that an adult told him that } \\
\text { he didn't have to work }\end{array}$ \\
\hline \multirow[t]{3}{*}{ Tom } & 1. Refuse requests & $\begin{array}{l}\text { 1. Calls people derogatory names, says "no" or "you } \\
\text { can't make me" when asked to complete a request }\end{array}$ \\
\hline & 2. Annoy others & $\begin{array}{l}\text { 2. Interrupts, talks out of turn, makes jokes, engages in } \\
\text { inappropriate touching (e.g., touching a woman's } \\
\text { breasts), pokes others, kicks peers' chairs }\end{array}$ \\
\hline & 3. Blame others & $\begin{array}{l}\text { 3. Makes excuses for his behavior, says that someone } \\
\text { else did it }\end{array}$ \\
\hline
\end{tabular}


Table 12

Percentage Agreement Between Teachers and Aides on

Each Item of the CAFI-T (Study 2, Phase A)

\begin{tabular}{|c|c|c|c|}
\hline Item & Rating $^{\mathrm{a}}$ & Behavior $^{\mathrm{b}}$ & Response $^{c}$ \\
\hline \multicolumn{4}{|c|}{ Part I: Setting events } \\
\hline 1 & 100 & & \\
\hline 2 & 75 & & \\
\hline 3 & 100 & & \\
\hline 4 & 100 & & \\
\hline 5 & 100 & & \\
\hline 6 & 25 & & \\
\hline Peers in cottage & 75 & & \\
\hline Medication & 100 & & \\
\hline \multicolumn{4}{|c|}{ Part II: Antecedents and consequences } \\
\hline 1 & 100 & 71 & 67 \\
\hline 2 & 100 & 75 & 100 \\
\hline 3 & 100 & 89 & 75 \\
\hline 4 & 100 & 50 & 100 \\
\hline 5 & 100 & 50 & 100 \\
\hline 6 & 100 & 40 & 100 \\
\hline
\end{tabular}

(table continues) 
Table 12 (continued)

\begin{tabular}{cccc}
\hline Item & Rating $^{\mathrm{a}}$ & Behavior $^{\mathrm{b}}$ & Response $^{\mathrm{c}}$ \\
\hline 7 & 100 & 60 & 100 \\
8 & 75 & 100 & 100 \\
9 & 75 & 100 & 50 \\
10 & 75 & 67 & 100 \\
11 & 75 & 85 & 67 \\
12 & 75 & 67 & 100 \\
13 & 50 & 100 & 100 \\
Part III: Social skills and alternative responses & \\
1 & 100 & & \\
2 & 100 & & \\
3 & 100 & & 50 \\
4 & 50 & & 0 \\
5 & 67 & & \\
6 & 75 & & \\
\hline
\end{tabular}

${ }^{a}$ Agreement between raters about the response provided on the Likert scale. ${ }^{b}$ Agreement between raters about the challenging behavior listed by the respondent. ${ }^{\mathrm{c}}$ Agreement between raters about the ways that others typically respond. ${ }^{\mathrm{d}}$ Agreement between raters about the activities named by the respondent. ${ }^{\mathrm{e}}$ Agreement between raters about the frequency the respondent stated activities occurred. ${ }^{\mathrm{f}}$ Agreement between raters about the effectiveness rating provided by the respondent for a given medication. 
Table 13

$\underline{\text { Agreement Between Teachers and Children on the CAFI }}$

\begin{tabular}{llll}
\hline & & & \\
Item & Occurrence agreement & Nonoccurrence agreement & Total agreement \\
\hline & & & \\
Part I: Setting events & & \\
& & & \\
1 & 0 & 100 & 67 \\
2 & & 100 & 100 \\
3 & 100 & 100 \\
Medication & & 100 & 100 \\
Part II: Antecedents and consequences & & \\
1 & 0 & 0 & 0 \\
2 & 0 & 67 & 67 \\
3 & 100 & & 100 \\
4 & & 100 & 100 \\
5 & 33 & 33 & 67 \\
6 & 0 & 33 & 33 \\
7 & 67 & 0 & 67 \\
8 & 67 & 0 & 67 \\
9 & 07 & 0 & 33 \\
10 & & & \\
\hline
\end{tabular}

(table continues) 
Table 13 (continued)

\begin{tabular}{llll}
\hline Item & Occurrence agreement & Nonoccurrence agreement & Total agreement \\
\hline & & & \\
11 & 0 & 0 & 0 \\
12 & 33 & 33 & 100 \\
13 & & 67 & \\
Part III: Social skills and alternative responses & 100 \\
1 & & 100 & 67 \\
2 & 33 & 33 & 67 \\
3 & 0 & 67 & 33 \\
4 & 0 & 67 & 67 \\
5 & & 67 & 67 \\
6 & 100 & 100 & 100 \\
7 & 33 & 33 & 67 \\
8 & 100 & 100 & 100 \\
9 & & & \\
\hline
\end{tabular}

Note. Values are percentages. An empty cell in the "Occurrence Agreement" column indicates that that neither the teacher nor the child reported that item as occurring. An empty cell in the "Nonoccurrence Agreement" column indicates that neither teacher nor child reported that item as not occurring. 
Table 14

Hypothesized Variables Affecting Behavior of Participants in Study 2

(Based on Results of Teacher Interviews)

\begin{tabular}{|c|c|c|c|c|c|}
\hline \multirow[b]{2}{*}{ Variable } & & \multicolumn{4}{|c|}{ Participant } \\
\hline & & Ben & Hal & Jim & Tom \\
\hline \multicolumn{6}{|c|}{ Setting events } \\
\hline & Social skills deficit & & & & \\
\hline & Feeling ill & $\mathrm{X}$ & & & $\mathrm{X}$ \\
\hline & Hungry & & & & \\
\hline & Sleeping habits & & & & \\
\hline & Parental fights & & & & \\
\hline & Abuse & & & & \\
\hline & Parental health & & & & \\
\hline & Peers in cottage & $\mathrm{X}$ & $X$ & & $\mathrm{X}$ \\
\hline & Medication & & & & \\
\hline \multicolumn{6}{|c|}{ Antecedent } \\
\hline & Presence of peers & $\mathrm{X}$ & $\mathrm{X}$ & $\mathrm{X}$ & $\mathrm{X}$ \\
\hline & Presence of adults & & $X$ & & \\
\hline & Presence of adults and peers & $\mathrm{X}$ & $X$ & $\mathrm{X}$ & $\mathrm{X}$ \\
\hline & Absence of others & & & & \\
\hline & Easy task & & & $X$ & $X$ \\
\hline
\end{tabular}

(table continues) 
Table 14 (continued)

\begin{tabular}{|c|c|c|c|c|c|}
\hline \multirow[b]{2}{*}{ Variable } & & \multicolumn{2}{|c|}{ Participant } & \multirow[b]{2}{*}{ Jim } & \multirow[b]{2}{*}{ Tom } \\
\hline & & Ben & Hal & & \\
\hline & Boring task & & $X$ & $\mathrm{X}$ & $\mathrm{X}$ \\
\hline & Difficult task & $\mathrm{X}$ & $X$ & $X$ & $\mathrm{X}$ \\
\hline & Group work & $X$ & $\mathrm{X}$ & $\mathrm{X}$ & $\mathrm{X}$ \\
\hline & Independent work & & $\mathrm{X}$ & & \\
\hline & Structured situation & $X$ & $\mathrm{X}$ & & $\mathrm{X}$ \\
\hline & Unstructured situation & $\mathrm{X}$ & $\mathrm{X}$ & $X$ & $\mathrm{X}$ \\
\hline & Unexpected change & & & & \\
\hline & Preferred activity removed & $X$ & & $X$ & $\mathrm{X}$ \\
\hline \multicolumn{6}{|c|}{ Consequences } \\
\hline & Adult attention & 4 & 6 & 7 & 8 \\
\hline & Peer attention & 1 & 1 & 7 & 12 \\
\hline & Tangible delivery & & & & \\
\hline & Task avoidance & 6 & 7 & & 4 \\
\hline & Adult avoidance & & & & \\
\hline & Peer avoidance & & & & \\
\hline
\end{tabular}

Note. Numerals refer to the number of items on Part II of the CAFI-T on which a given consequence was endorsed. 


\section{Table 15}

Hypothesized Variables Affecting Behavior of Participants in Study 2

(Based on Results of the Child Version of the CAFI)

Participant

Variable

Ben Hal Jim

Setting events

Social skills deficit

Feeling ill

Hungry

Sleeping habits

$\mathrm{X}$

Medication

Antecedent

Presence of peers

X

Presence of adults

Presence of adults and peers $\quad$ X $\quad$ X

Absence of others

Easy task

X

Boring task

X

Difficult task

X

(table continues) 
Table 15 (continued)

\begin{tabular}{lllll}
\hline & & \multicolumn{3}{c}{ Participant } \\
\cline { 3 - 4 } Variable & & Ben & Hal & Jim \\
\hline & & & & \\
& Group work & $\mathrm{X}$ & & $\mathrm{X}$ \\
& Independent work & & $\mathrm{X}$ & $\mathrm{X}$ \\
& Structured situation & $\mathrm{X}$ & $\mathrm{X}$ \\
& Unstructured situation & & & \\
& Unexpected change & & & \\
& Preferred activity removed & & & \\
& & & \\
Adult attention & & 3 & 1 \\
& Peer attention & 2 & 1 & 1 \\
& Tangible delivery & & & \\
Task avoidance & 2 & 3 & 3 \\
& Adult avoidance & & & \\
Peer avoidance & & & \\
\hline
\end{tabular}

Note. Numerals refer to the number of items on Section II of the CAFI-T on which a given consequence was endorsed. 
Table 16

Agreement Between Teachers and Students on Consequences Affecting Behavior

\begin{tabular}{llll}
\hline Participant & $\begin{array}{l}\text { Occurrence } \\
\text { agreement }\end{array}$ & $\begin{array}{l}\text { Nonoccurrence } \\
\text { agreement }\end{array}$ & $\begin{array}{l}\text { Total } \\
\text { Agreement }\end{array}$ \\
\hline & & & 100 \\
Ben & 100 & 100 & 100 \\
Hal & 100 & 100 & 83 \\
Jim & 67 & 75 & \\
\hline
\end{tabular}

Note. All values are percentages. 
Table 17

$\underline{\text { Relation Between Antecedents and Consequences Across Participants in Study } 2}$

Consequent stimuli

\begin{tabular}{|c|c|c|c|c|}
\hline \multirow[t]{2}{*}{ Antecedent stimuli } & Adult & Peer & Task & Tangible \\
\hline & Attention & Attention & Avoidance & delivery \\
\hline Presence of other children & Ben & Ben, Jeff, Hal, Tom & & \\
\hline Presence of adults & Hal, Jeff & Jeff & Hal & \\
\hline Presence of children and adults & Ben, Hal & & Ben & \\
\hline \multicolumn{5}{|l|}{ No-one is present } \\
\hline Easy task & Hal, Jeff & Jeff, Tom & Tom & \\
\hline Boring task & Hal, Jeff & Jeff, Tom & Hal, Tom & \\
\hline Difficult task & Jeff & Jeff, Tom & Ben, Hal, Tom & \\
\hline Group activity & Jeff, Tom & Jeff, Tom & Ben, Hal & \\
\hline Independent work & Hal & & Hal & \\
\hline Structured situation & Hal, Tom & Tom & Ben, Hal & \\
\hline Unstructured situation & Jeff, Tom & Tom & Ben, Hal & \\
\hline Unexpected change occurs & Tom & Tom & & \\
\hline Preferred item is removed & Ben, Jeff, Tom & Jeff, Tom & & \\
\hline
\end{tabular}


Table 18

$\underline{\text { Inter-observer Agreement Coefficients for Hal }}$

\begin{tabular}{|c|c|c|c|c|}
\hline Event class & Event & $\begin{array}{l}\text { Occurrence } \\
\text { agreement }\end{array}$ & $\begin{array}{l}\text { Nonoccurrence } \\
\text { agreement }\end{array}$ & $\begin{array}{l}\text { Total } \\
\text { agreement }\end{array}$ \\
\hline \multicolumn{5}{|c|}{ Target behavior } \\
\hline & Angry and resentful & & 100 & 100 \\
\hline & Annoy others & 93 & 98 & 98 \\
\hline & & $(79-100)$ & $(94-100)$ & $(95-100)$ \\
\hline & Active defiance & 63 & 98 & 98 \\
\hline & & $(50-75)$ & $(96-100)$ & $(95-100)$ \\
\hline \multicolumn{5}{|l|}{ Antecedent } \\
\hline & On-going work & 80 & 98 & 98 \\
\hline & & $(66-94)$ & $(98-100)$ & $(98-100)$ \\
\hline & Low-work & 100 & 100 & 100 \\
\hline & Prompt or request & 100 & 100 & 100 \\
\hline & Transition (task) & & 100 & 100 \\
\hline & Transition (setting) & & 100 & 100 \\
\hline & Adult interaction & 67 & 98 & 98 \\
\hline & & & $(98-100)$ & $(98-100)$ \\
\hline
\end{tabular}

(table continues) 
Table 18 (continued)

\begin{tabular}{lllll}
\hline Event class & Event & $\begin{array}{l}\text { Occurrence } \\
\text { agreement }\end{array}$ & $\begin{array}{l}\text { Nonoccurrence } \\
\text { agreement }\end{array}$ & $\begin{array}{l}\text { Total } \\
\text { agreement }\end{array}$ \\
\hline Consequence & Peer interaction & 100 & 100 & 100 \\
& & & & \\
& Adult attention & 100 & 100 & 100 \\
& Peer attention & 100 & 100 & 100 \\
& Tangible delivery & & 100 & 100 \\
& Adult removal & & 100 & 100 \\
& Peer removal & & 100 & 97 \\
& Task removal & 50 & 97 & 100 \\
& Tangible removal & & 100 & \\
\hline
\end{tabular}

Note. Values are percentages. Ranges are in parentheses. If a value is below $100 \%$ and no range is given, then that event class was observed only in one session. Empty cells in the "Occurrence Agreement" column occur when neither observer recorded the occurrence of the event. 
Table 19

$\underline{\text { Inter-observer Agreement Coefficients for Jim }}$

\begin{tabular}{|c|c|c|c|c|}
\hline Event class & Event & $\begin{array}{l}\text { Occurrence } \\
\text { agreement }\end{array}$ & $\begin{array}{l}\text { Nonoccurrence } \\
\text { agreement }\end{array}$ & $\begin{array}{l}\text { Total } \\
\text { agreement }\end{array}$ \\
\hline \multicolumn{5}{|c|}{ Target behavior } \\
\hline & Annoy others & 100 & 100 & 100 \\
\hline & Blame others & & 100 & 100 \\
\hline & Argue with adults & 100 & 100 & 100 \\
\hline \multicolumn{5}{|l|}{ Antecedent } \\
\hline & On-going work & 88 & 99 & 99 \\
\hline & & $(75-100)$ & $(98-100)$ & $(98-100)$ \\
\hline & Low-work & 88 & 99 & 99 \\
\hline & & $(75-100)$ & $(98-100)$ & $(98-100)$ \\
\hline & Prompt or request & & 100 & 100 \\
\hline & Transition (task) & & 100 & 100 \\
\hline & Transition (setting) & & 100 & 100 \\
\hline & Adult interaction & & 100 & 100 \\
\hline & Peer interaction & & 100 & 100 \\
\hline
\end{tabular}

(table continues) 
Table 19 (continued)

\begin{tabular}{lllll}
\hline Event class & Event & $\begin{array}{l}\text { Occurrence } \\
\text { agreement }\end{array}$ & $\begin{array}{l}\text { Nonoccurrence } \\
\text { agreement }\end{array}$ & $\begin{array}{l}\text { Total } \\
\text { agreement }\end{array}$ \\
\hline Consequence & & & & \\
& Adult attention & 89 & 99 & 99 \\
& & $(83-100)$ & $(98-100)$ & $(98-100)$ \\
& Peer attention & 100 & 100 & 100 \\
& Tangible delivery & & 100 & 100 \\
& Adult removal & 92 & 99 & 99 \\
& & $(83-100)$ & $(98-100)$ & $(98-100)$ \\
& Peer removal & 100 & 100 & 100 \\
& Task removal & & 100 & 100 \\
& Tangible removal & & 100 & 100 \\
\hline
\end{tabular}

Note. Values are percentages. Ranges are in parentheses. If a value is below $100 \%$ and no range is given, then that event class was observed only in one session. Empty cells in the "Occurrence Agreement" column occur when neither observer recorded the occurrence of the event. 
Table 20

$\underline{\text { Agreement Between Teacher Interview and Direct Observations }}$

\begin{tabular}{lllll}
\hline Stimuli & \multicolumn{5}{c}{ Participants } \\
& Ben & Hal & Jim & Tom \\
\hline Antecedent stimuli & Both & Both & Both & Both \\
Presence of children \adults & Both & Both & Both & Both \\
On-going task $\backslash$ prompt & Interview & Interview & Interview & Interview \\
Preferred activity removed & & & & \\
Consequent stimuli & Both & Both & Both & Both \\
$\begin{array}{l}\text { Adult attention } \\
\text { Peer attention }\end{array}$ & & Observe & Both & Both \\
$\begin{array}{l}\text { Tangible delivery } \\
\text { Task removal }\end{array}$ & Both & Both & & \\
Adult avoidance & & & & Interview \\
Peer avoidance & & & & \\
\hline
\end{tabular}

Note. "Both" indicates that variable was identified on the teacher interview and during direct observations. "Observe" indicates that variable was identified only during direct observations. "Interview" indicates that variable was identified only on the interview. 

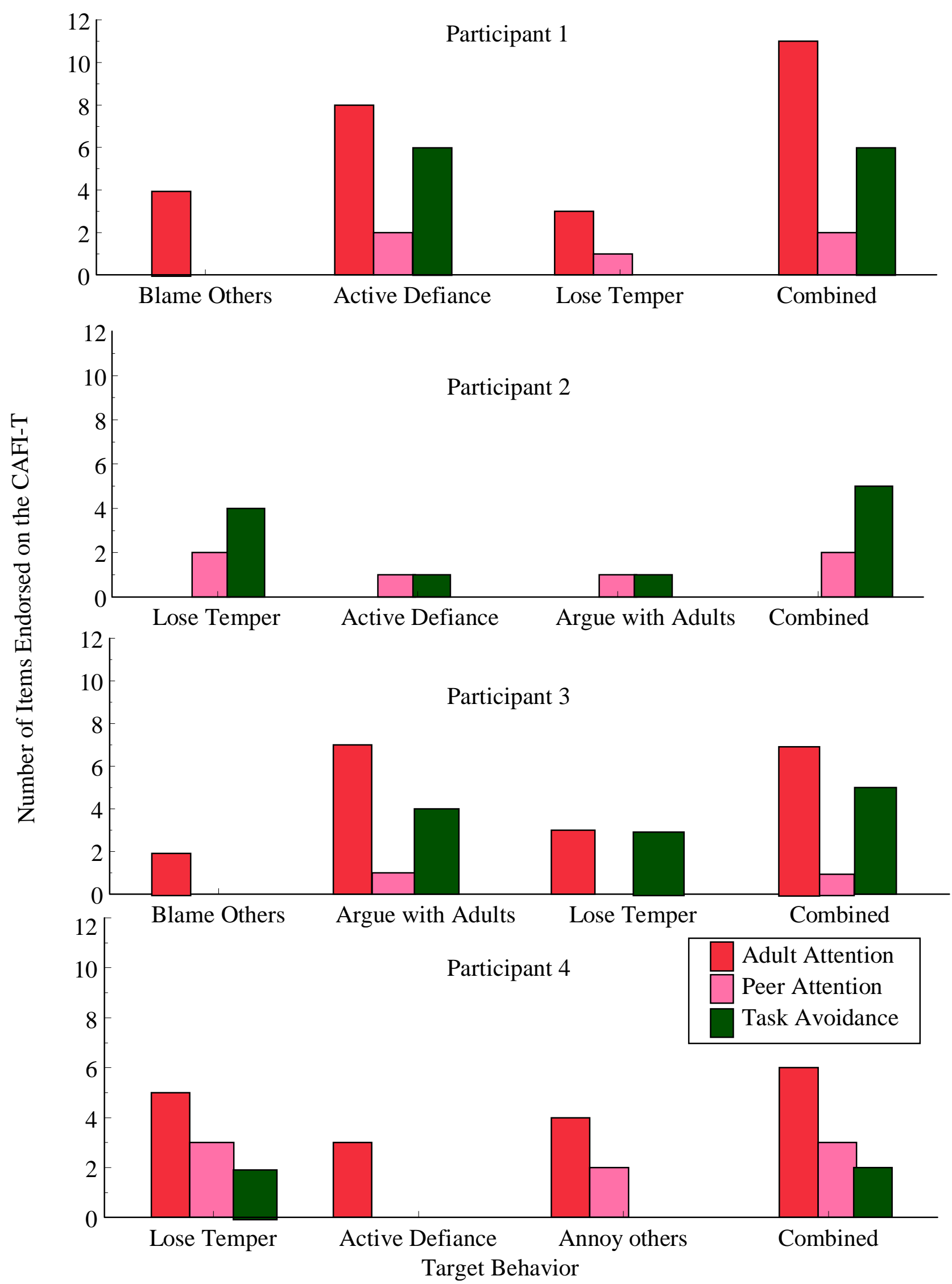

Figure 1. Frequency with which consequences were endorsed for each challenging behavior for Participants 1-4 on the CAFI-T (Study 1, Phase B). 


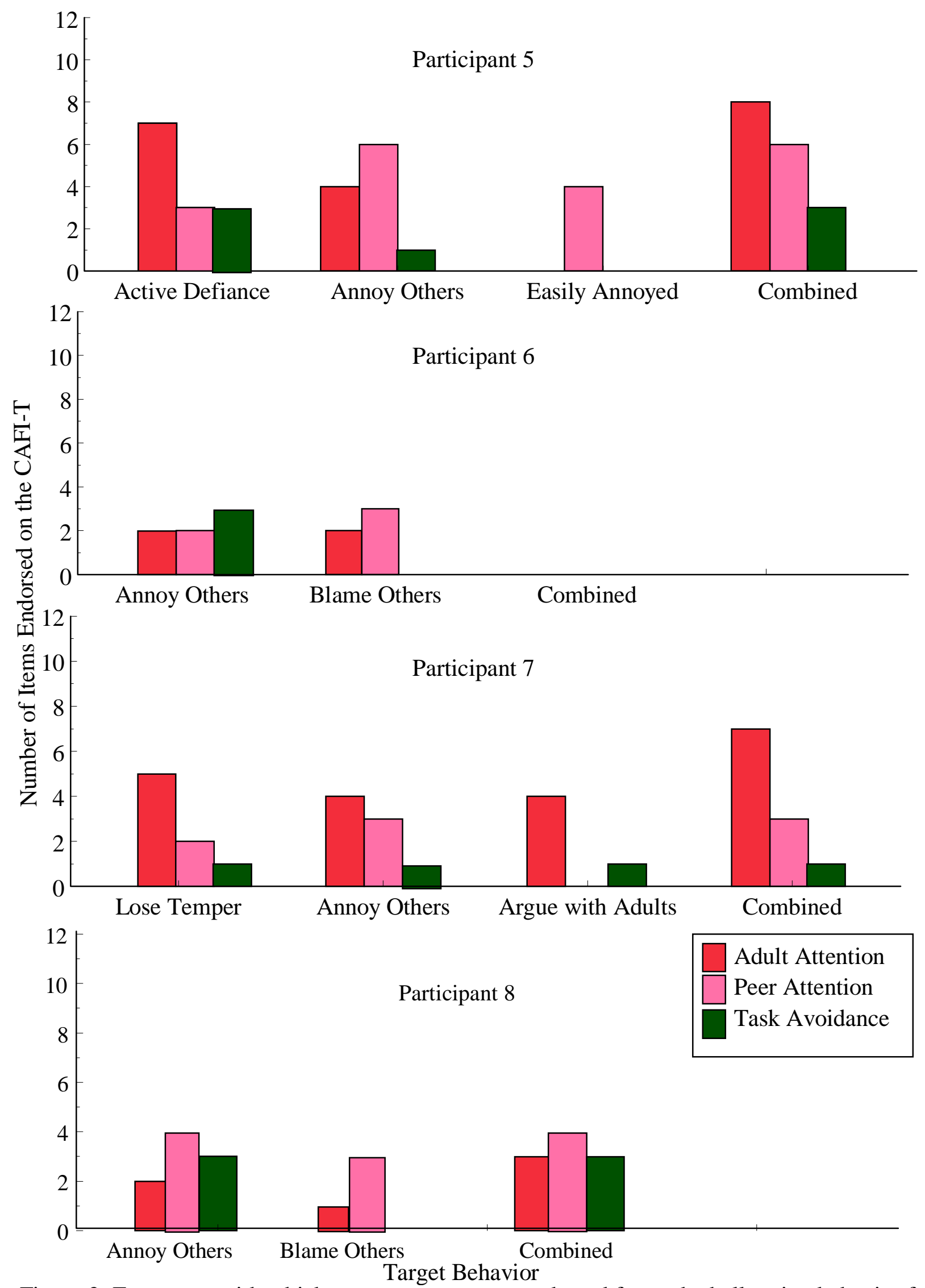

Figure 2. Frequency with which consequences were endorsed for each challenging behavior for Participants 5-8 on the CAFI-T (Study 1, Phase B). 


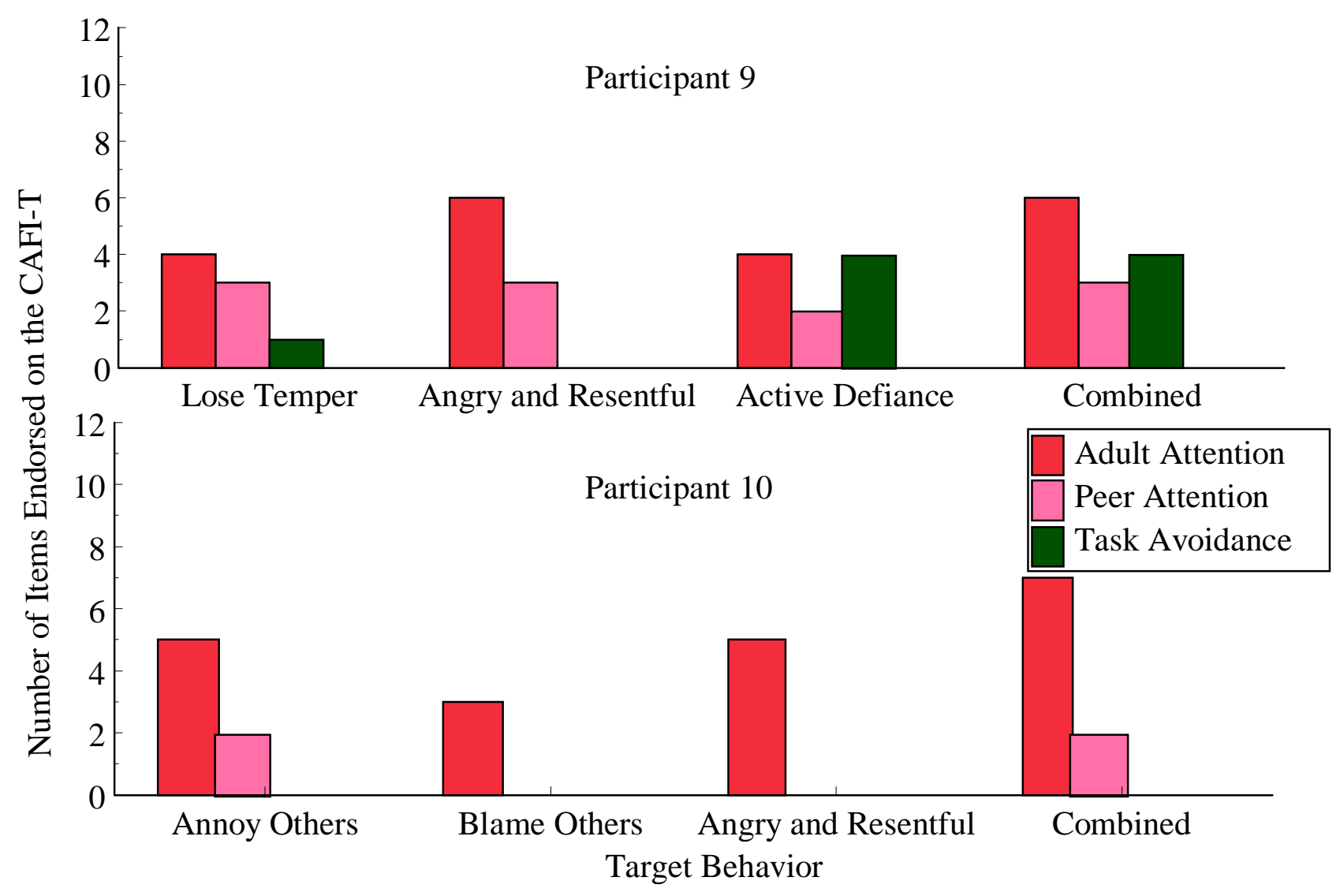

Figure 3. Frequency with which consequences were endorsed for each challenging behavior for Participants 9 and 10 on the CAFI-T (Study 1, Phase B). 


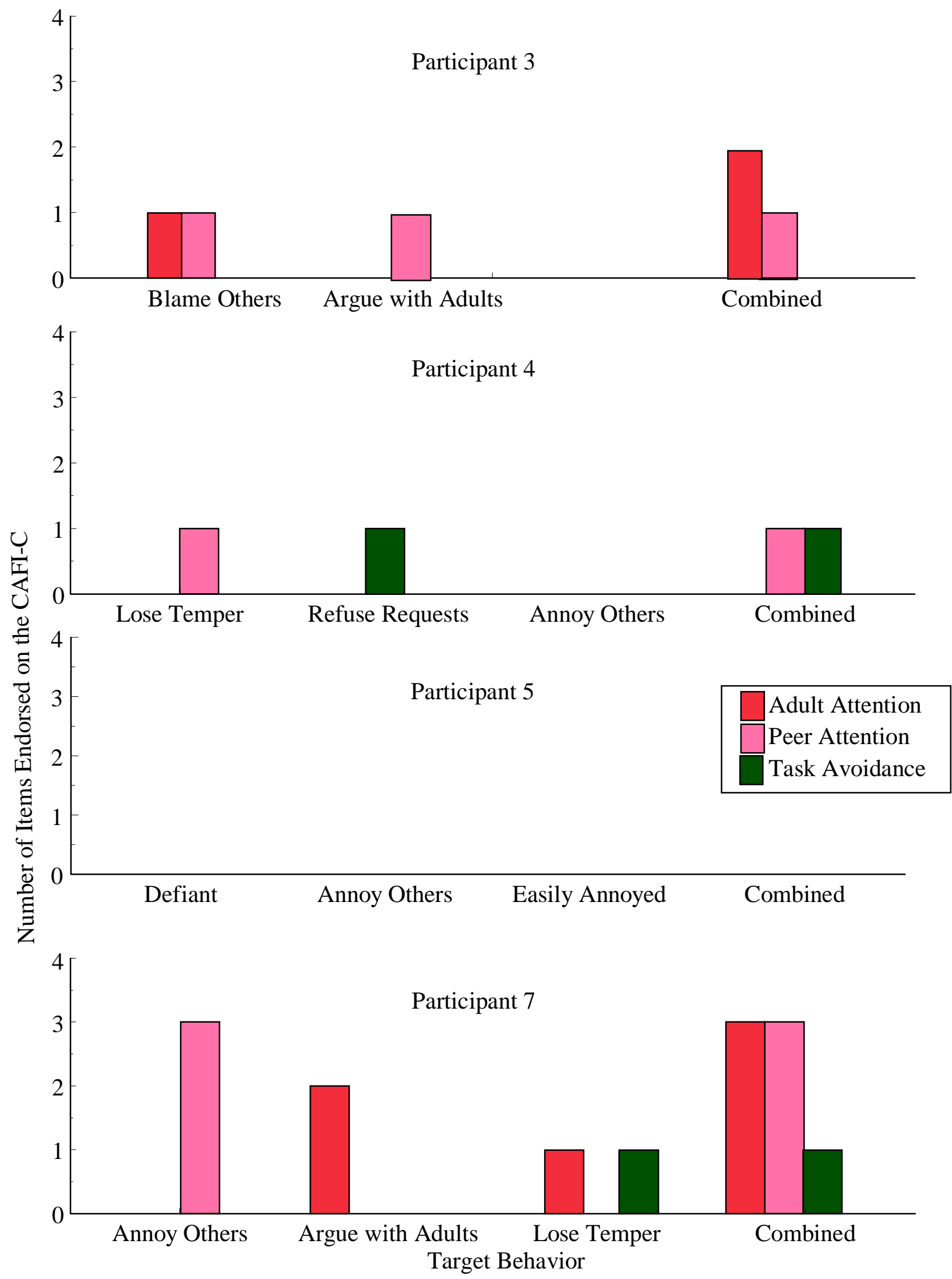

Figure 4. Frequency with which consequences were endorsed for each challenging behavior for Participants 3, 4, 5, and 7 on the CAFI-C (Study 1, Phase B). 


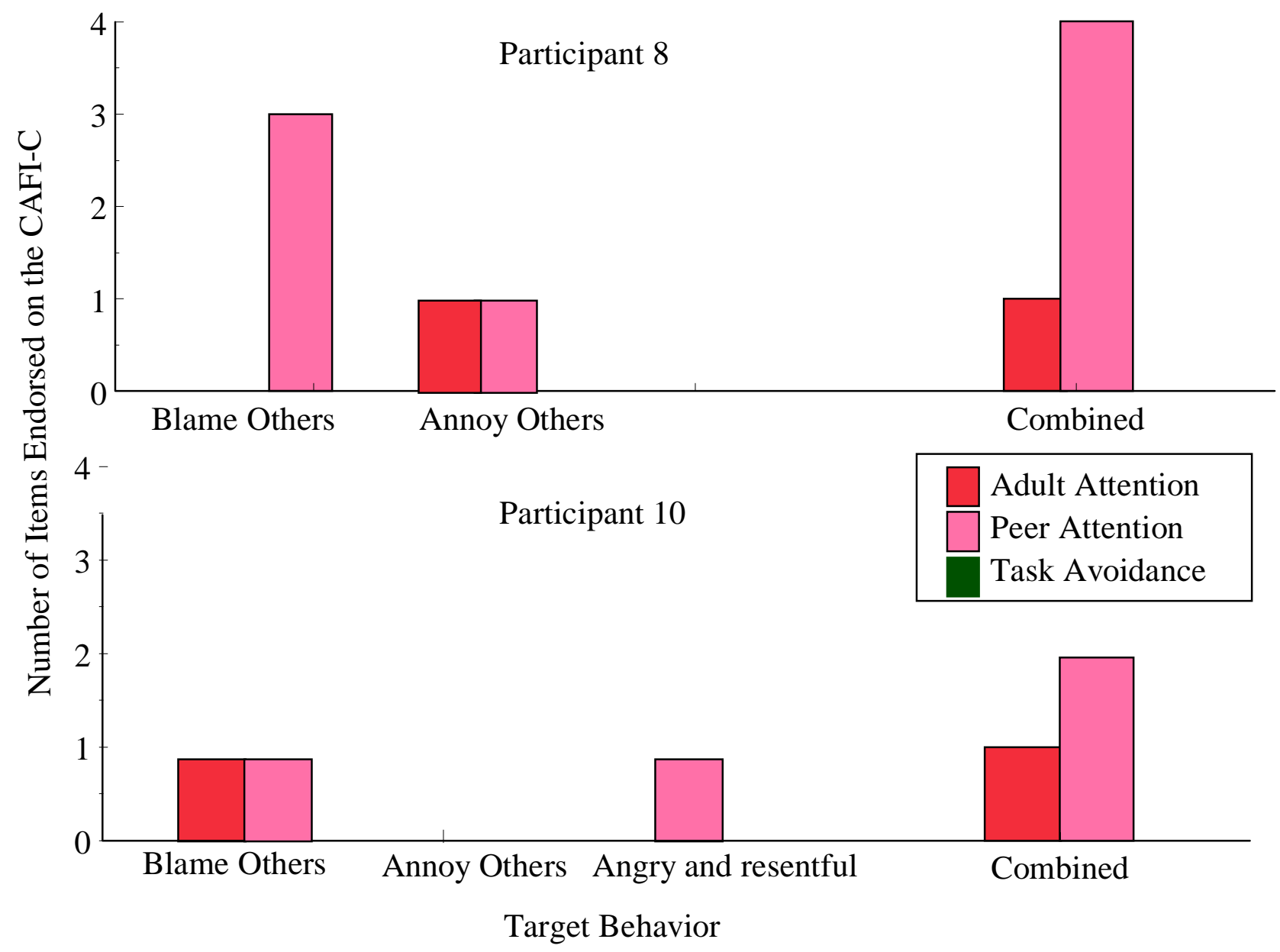

Figure 5. Frequency with which consequences were endorsed for each challenging behavior for Participants 8 and 10 on the CAFI-C (Study 1, Phase B). 


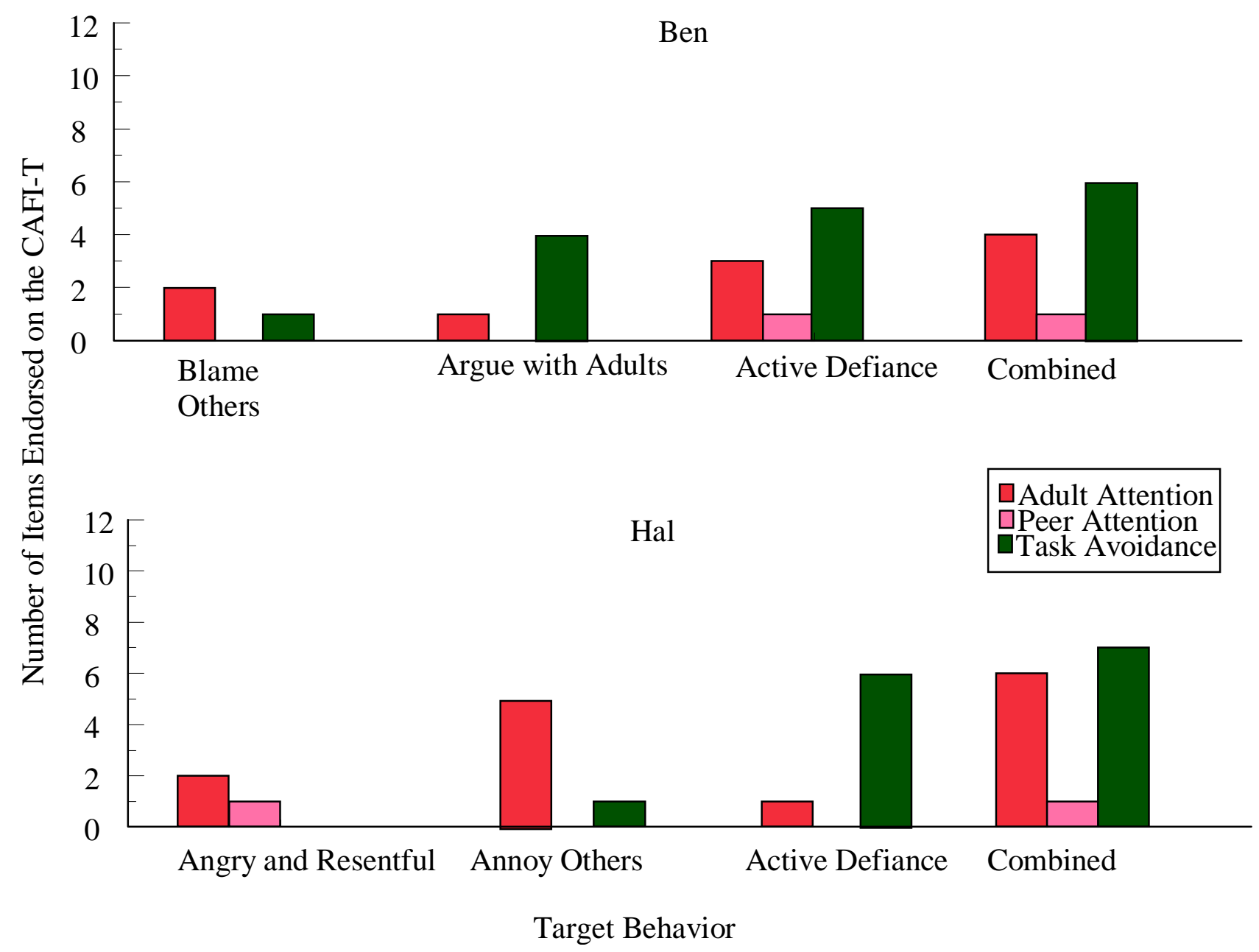

Figure 6. Number of items endorsed for a given consequence on the CAFI-T for Ben and Hal (Study 2). 


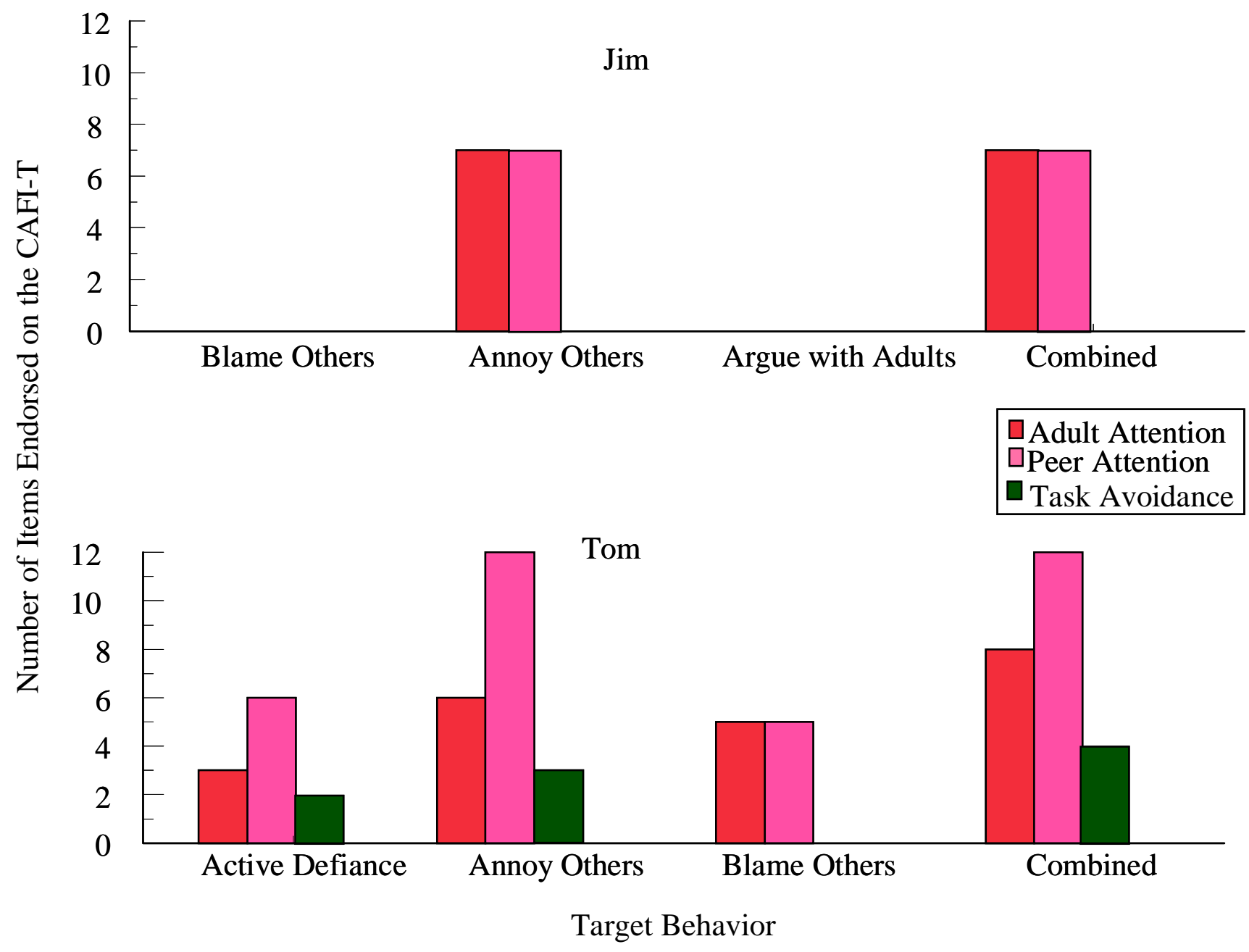

Figure 7. Number of items endorsed for a given consequence on the CAFI-T for Jim and Tom (Study 2). 


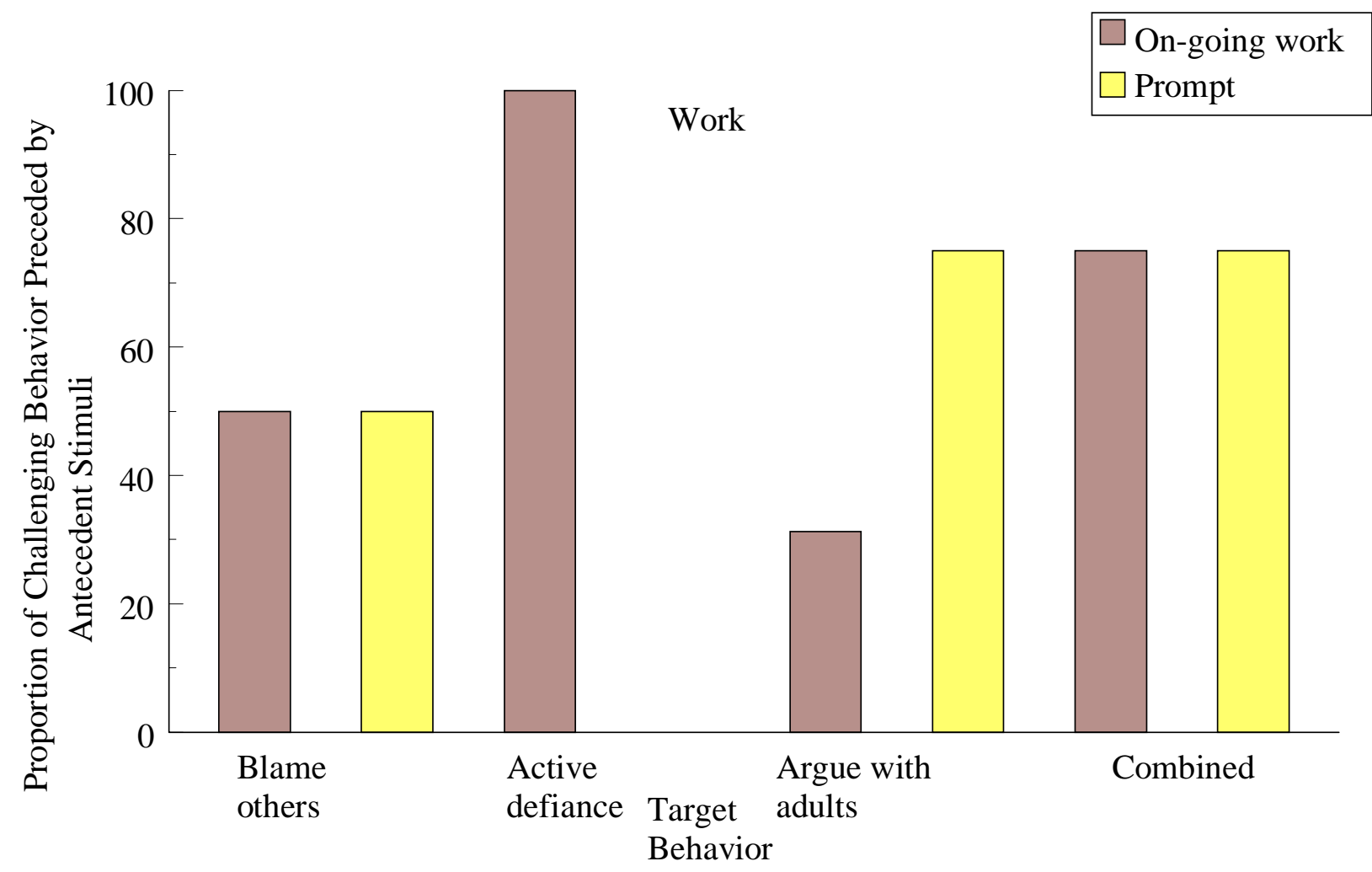

Figure 8. Proportion of challenging behavior preceded by antecedent stimuli in direct observations of Ben (Study 2). 


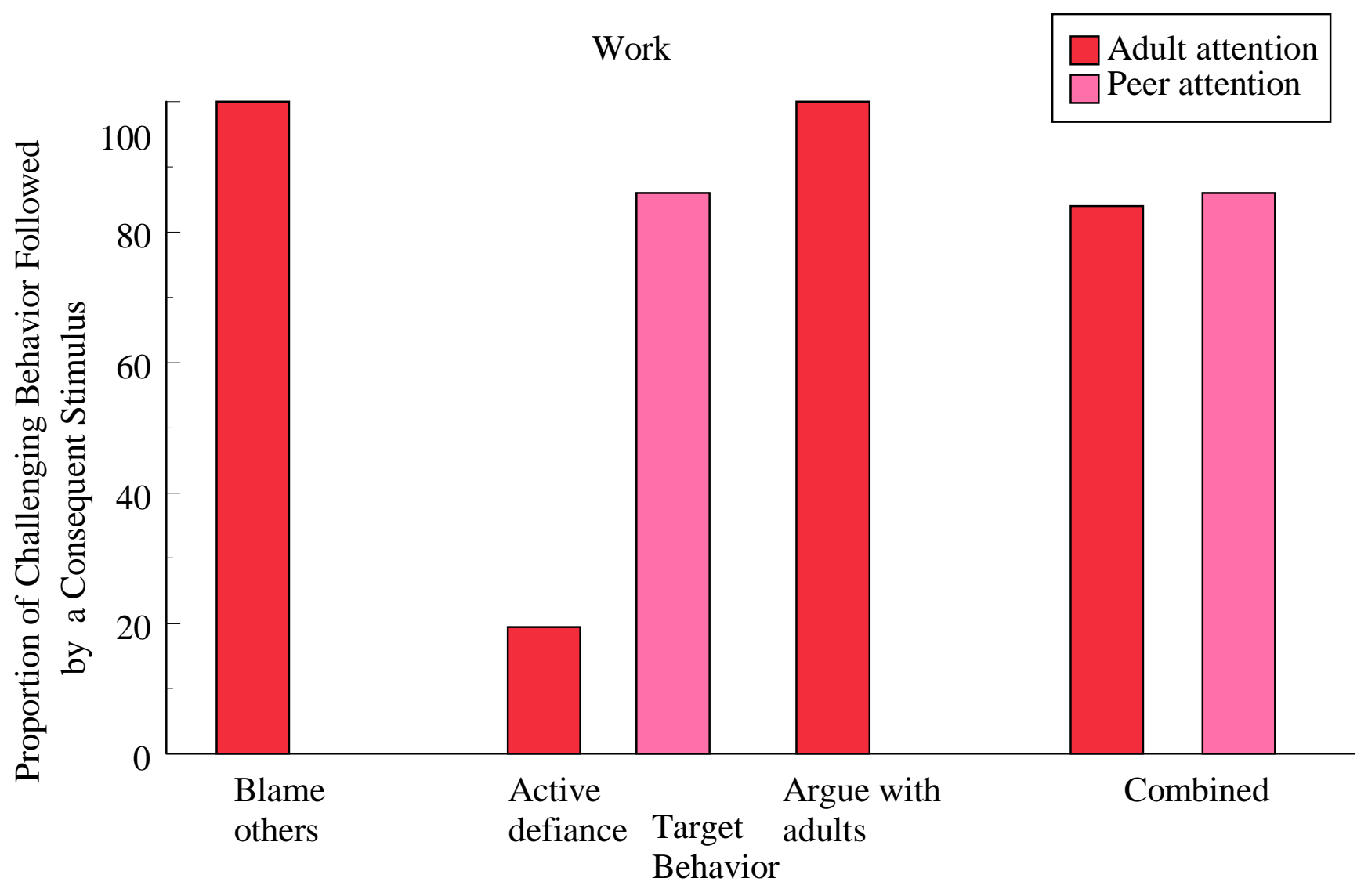

Figure 9. Proportion of challenging behavior preceding consequent stimuli in direct observations of Ben (Study 2). 


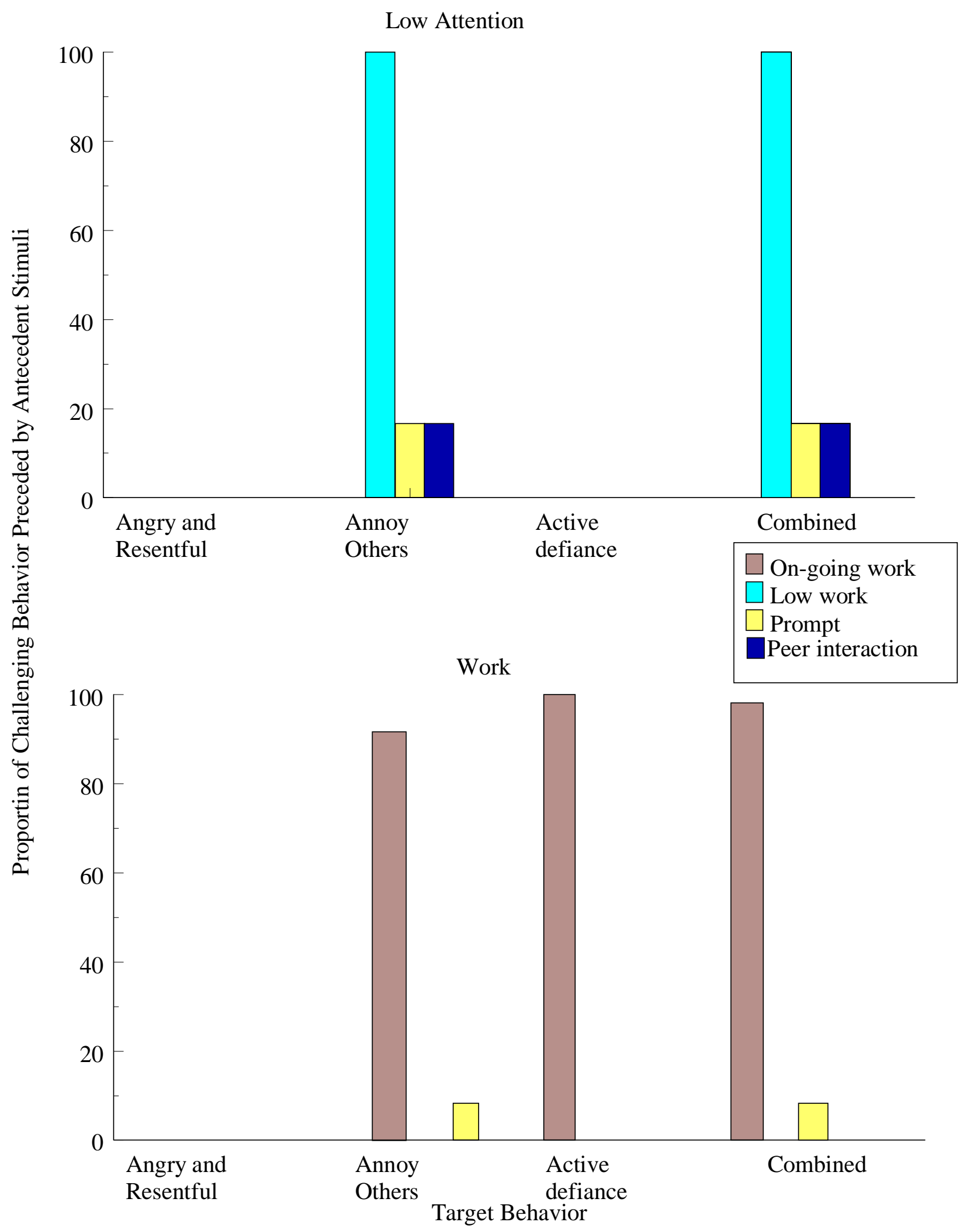

Figure 10. Proportion of challenging behavior preceded by antecedent stimuli in direct observations of Hal (Study 2). 


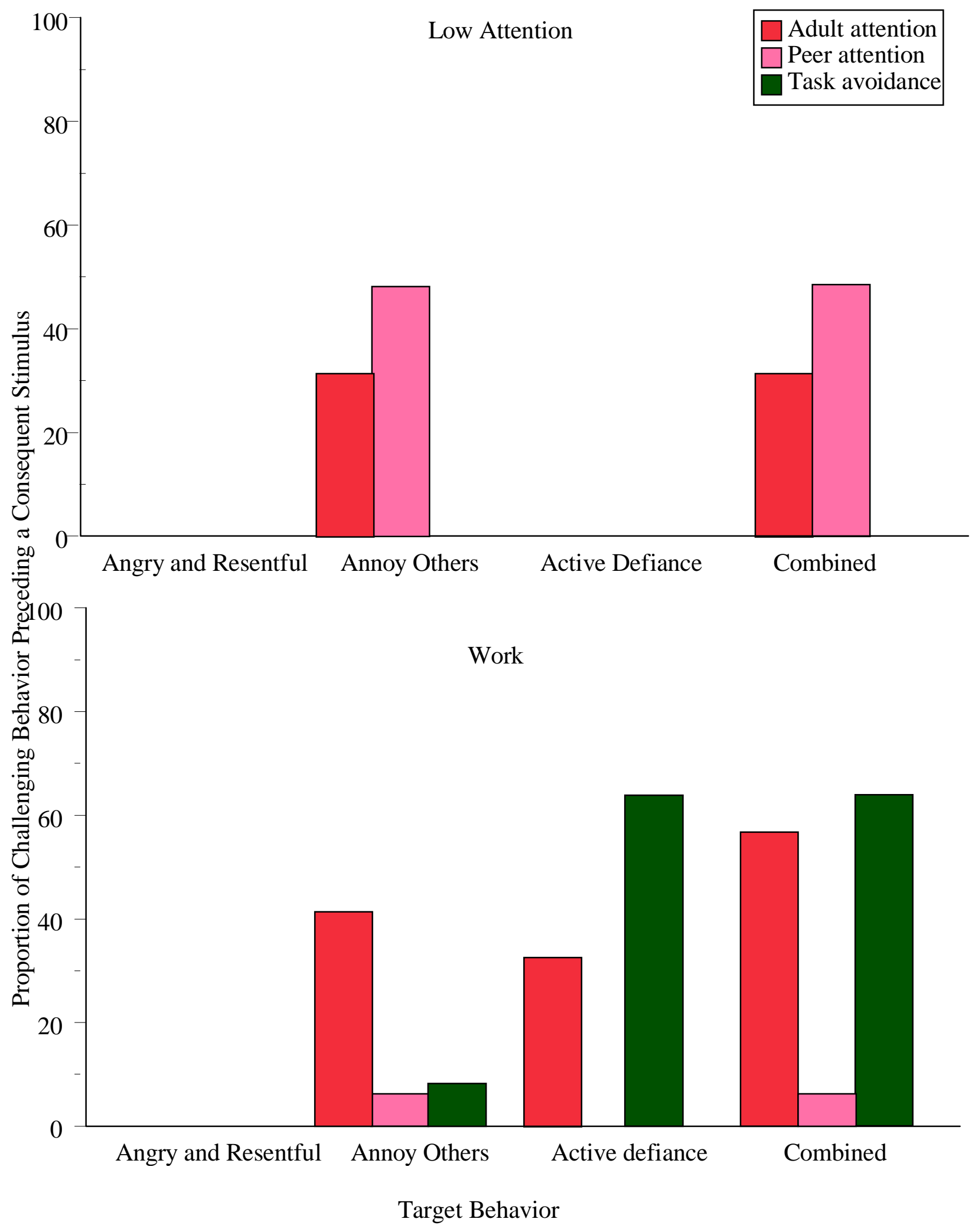

Figure 11. Proportion of challenging behavior preceding consequent stimuli in direct observations of Hal (Study 2). 


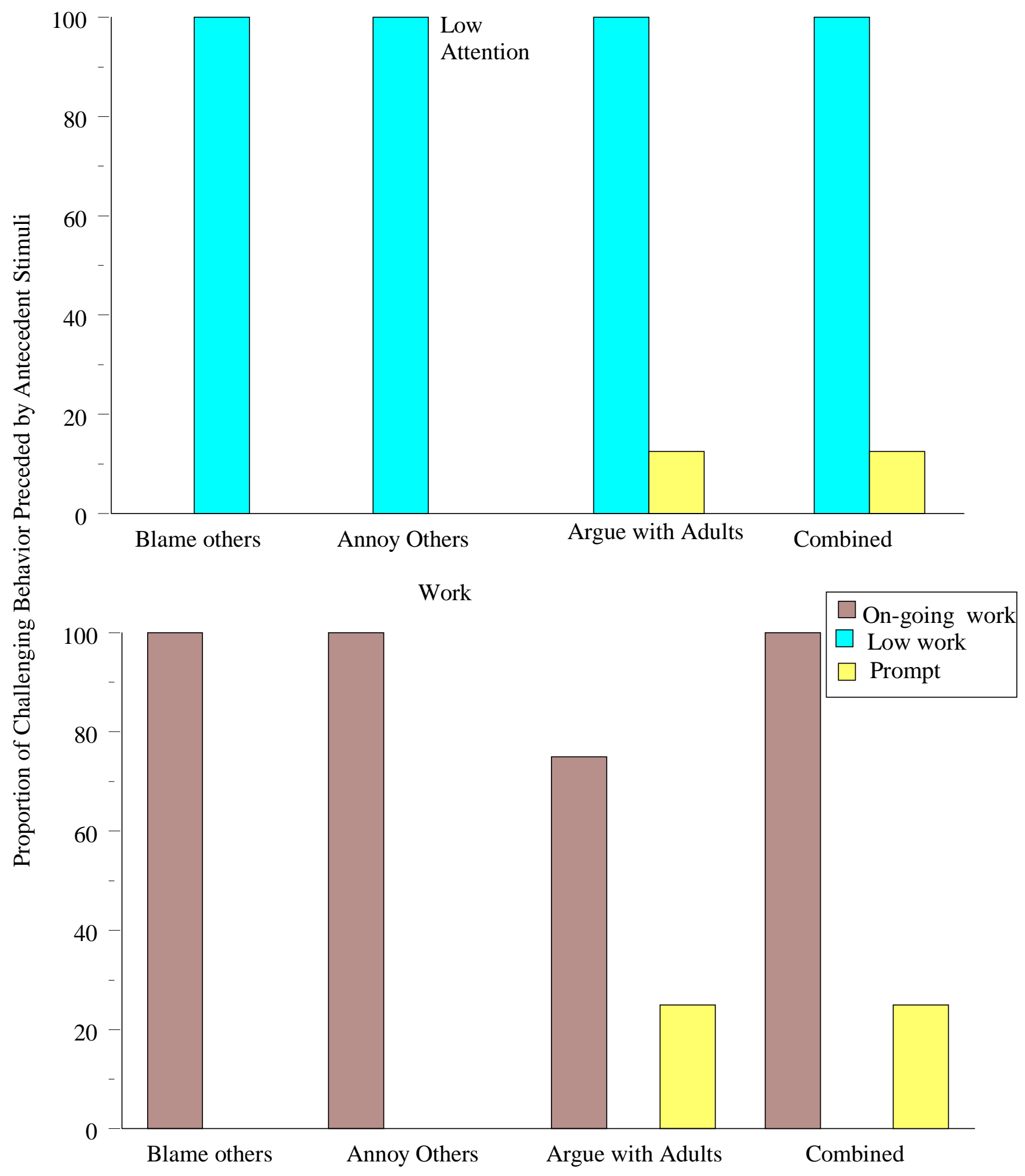

Target Behavior

Figure 12. Proportion of challenging behavior preceded by antecedent stimuli in direct observations of Jim (Study 2). 


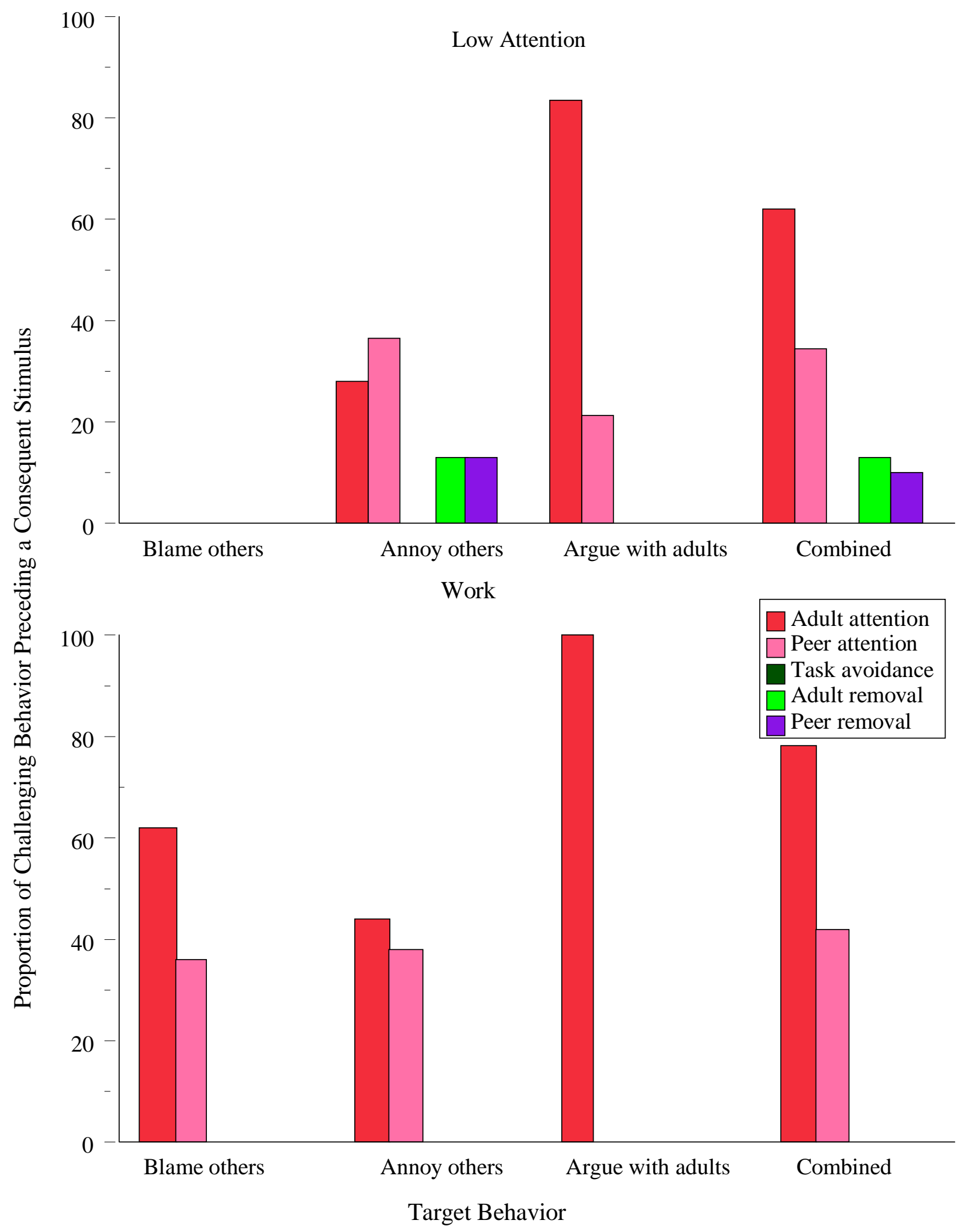

Figure 13. Proportion of challenging behavior preceding consequent stimuli in direct observations of Jim (Study 2). 


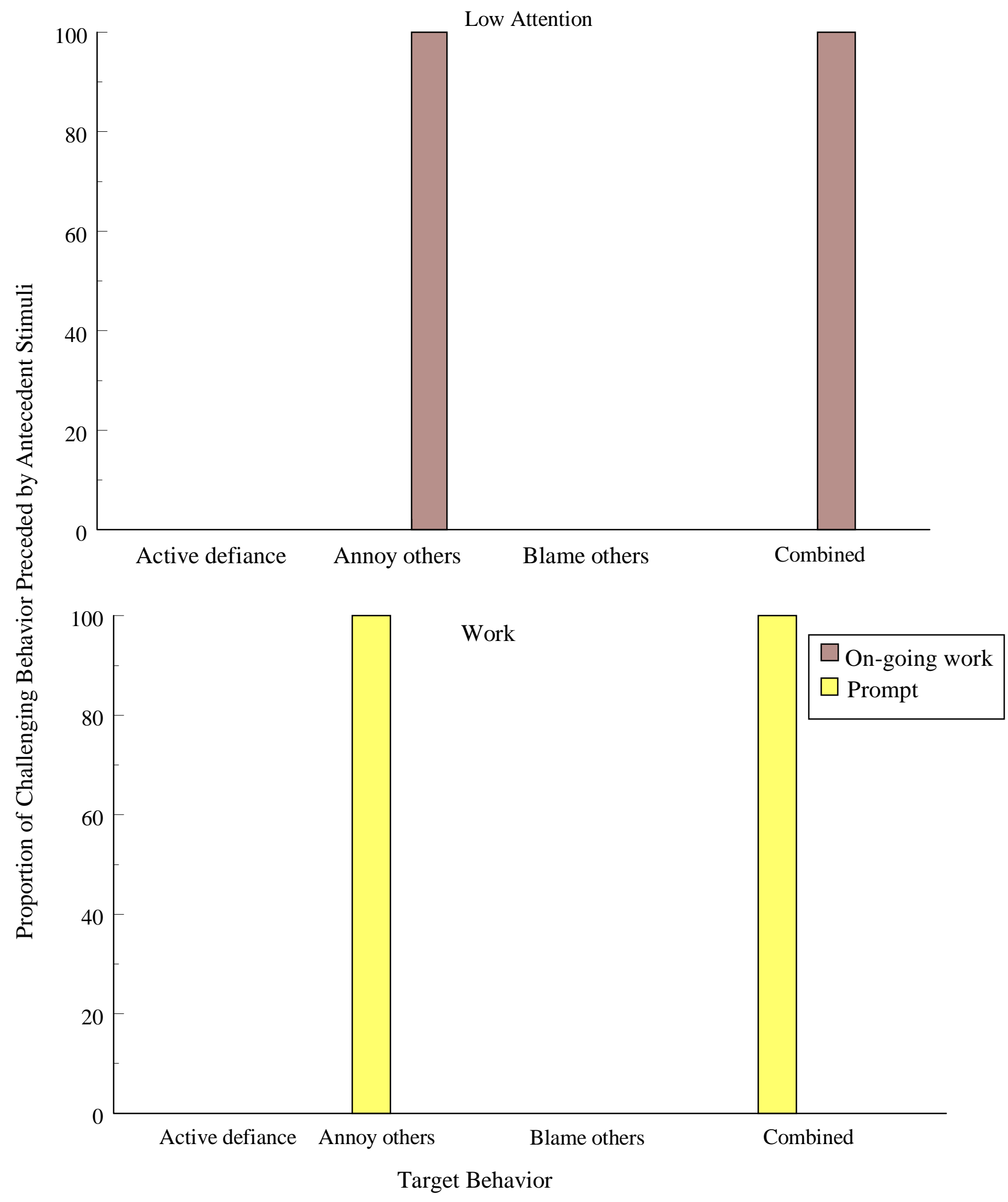

Figure 14. Proportion of challenging behavior preceded by antecedent stimuli in direct observations of Jim (Study 2). 


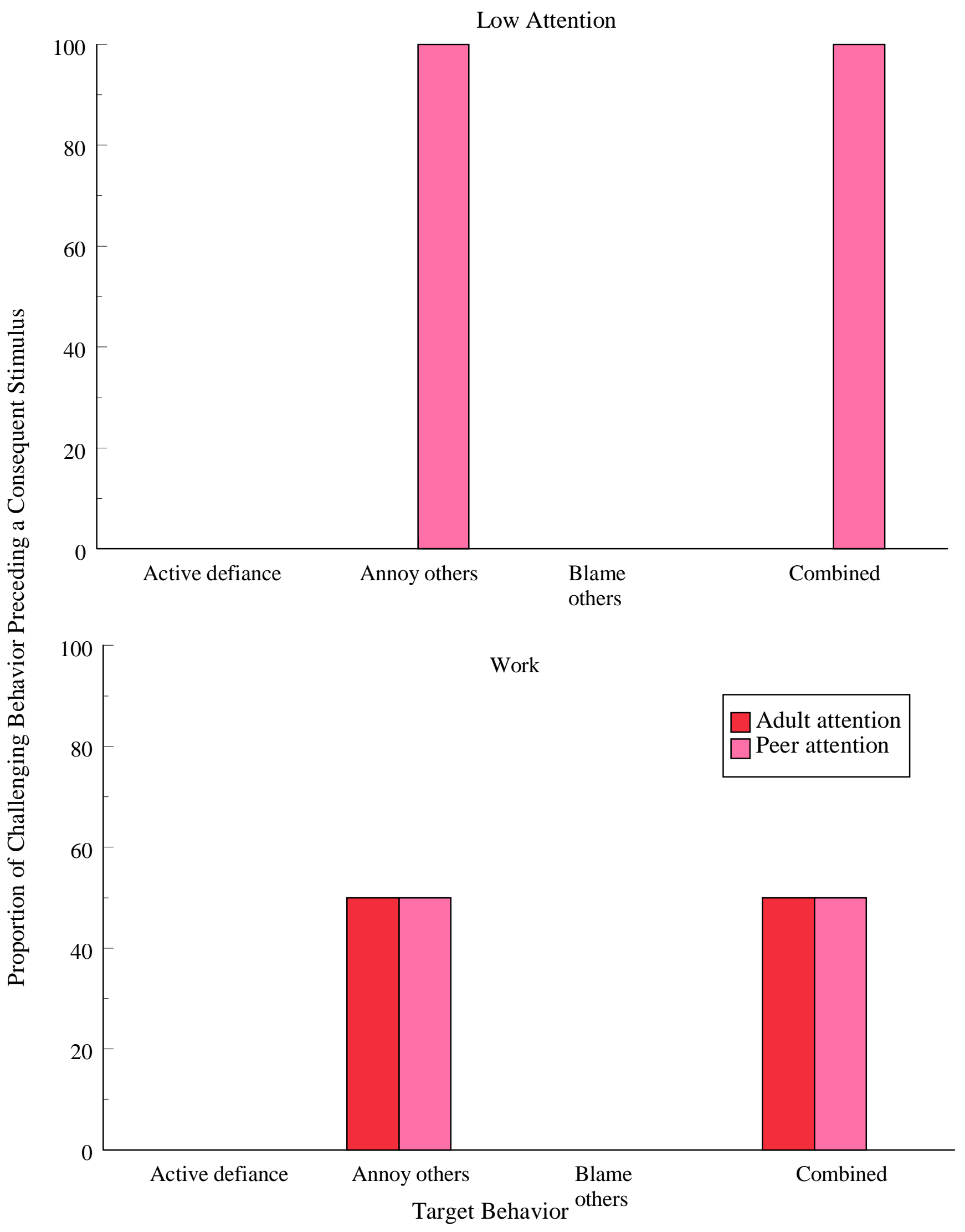

Figure 15. Proportion of challenging behavior preceding consequent stimuli in direct observations of Tom (Study 2). 
Appendix A

Clinical Analysis of Function Interview-Teacher Form

Child:

Teacher:

Interviewer:

\section{Part I}

Directions: In this section, many questions will be responded to based on a rating scale. The scale ranges from 1 to 5 . If, using this scale, the teacher responds to any question with a rating of 3,4 , or 5 , ask him or her what behaviors are more likely to occur and record those behaviors on the lines below the question. Then, for each behavior, ask the follow-up question provided in the parentheses after each question. Before beginning give the teacher a form that lists the behaviors you will be asking questions about.

Tell the teacher, "In this section I will be asking you questions about some of the situations in which (child's name) sometimes exhibits problem behavior. For each question you will respond using a rating scale that goes from 1 to 5 , like this (show the teacher the scale)."

1. On a scale of 1 to 5 , how likely are some of these problem behaviors to occur when only other children are present? (how do children typically respond when the child exhibits that behavior.)

\section{Behavior \\ Typical Response}

2.On a scale of 1 to 5, how likely are some of these problem behaviors to occur when only adults are present? (how do adults typically respond when the child exhibits that behavior.)

\section{Behavior}

\section{Typical Response}

3. On a scale of 1 to 5, how likely are some of these problem behaviors to occur when both children and adults are present? (how do others typically respond when the child exhibits that behavior.)

\section{$\underline{\text { Behavior }}$}

Typical Response

4. On a scale of 1 to 5, how likely are some of these problem behaviors to occur when no-one else is present? (how do people typically respond if they find out the behavior occurred.)

$$
\text { Behavior }
$$

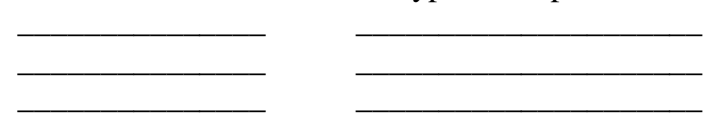
Typical Response
5

Very likely 
5. On a scale of 1 to 5, how likely are some of these problem behaviors to occur when (child's name) is asked to work on a task that he or she finds easy? (how do others typically respond when the child exhibits that behavior in this situation.)

Behavior

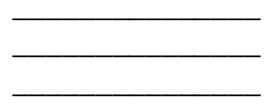

\section{Typical Response}

6. On a scale of 1 to 5, how likely are some of these problem behaviors to occur when (child's name) is asked to work on a task that he or she finds boring? (how do others typically respond when the child exhibits that behavior in this situation.)

Behavior
Typical Response

7. On a scale of 1 to 5 , how likely are some of these problem behaviors to occur when (child's name) is asked to work on a task that he or she finds difficult? (how do others typically respond when the child exhibits that behavior in this situation.)

\section{Behavior}

$$
\text { Typical Response }
$$

\section{On a scale of 1 to 5 , how likely are some of these} problem behaviors to occur when the child is asked to work on a group activity with other children? (how do others typically respond when the child exhibits that behavior in this situation.)

$\underline{\text { Behavior }}$

$\overline{ }$

9. On a scale of 1 to 5 , how likely are some of these problem behaviors to occur when the child is asked to work independently? (how do others typically respond when the child exhibits that behavior in this situation.)

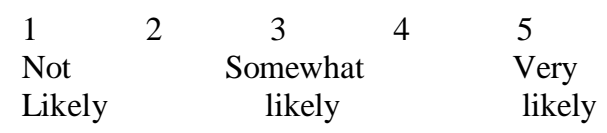

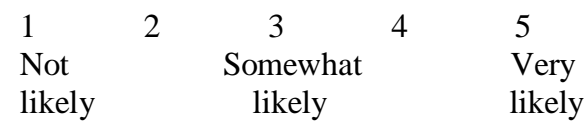

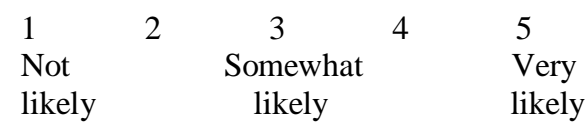

1 Not likely
2

$$
\text { Some }
$$

3

Somewhat likely
5

Very likely

\begin{abstract}
Behavior
\end{abstract}

$\begin{array}{lcccc}1 & 2 & 3 & 4 & 5 \\ \text { Not } & & \begin{array}{c}\text { Somewhat } \\ \text { likely }\end{array} & & \text { Very } \\ \text { likely } & & \text { likely }\end{array}$


10. On a scale of 1 to 5 , how likely are some of these problem behaviors to occur when the child is in a structured situation, such as seat work, where the expectations are clearly defined?

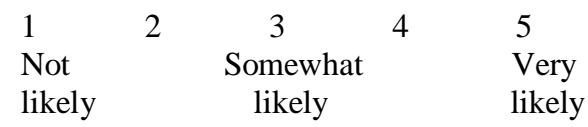

Behavior

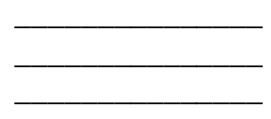

11. On a scale of 1 to 5, how likely are these problem behaviors to occur when the child is in an unstructured situation like recess or the cafeteria or free time?

\section{Behavior}

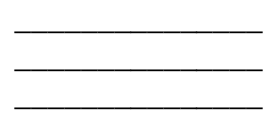

12. On a scale of 1 to 5 , how likely are some of these problem behaviors to occur when unexpected changes occur in the daily routine (e.g., fire drill, assembly)? (how do others typically respond when the child exhibits that behavior in this situation.)

Behavior

$$
\text { Typical Response }
$$

13. On a scale of 1 to 5 , how likely are some of these problem behaviors to occur when a preferred activity (e.g., recess) ends or a preferred item is removed (e.g., art supplies)? (how do others typically respond when the child exhibits that behavior in this situation.)

$$
\text { Behavior }
$$

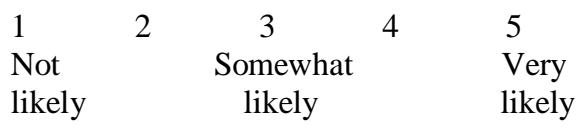

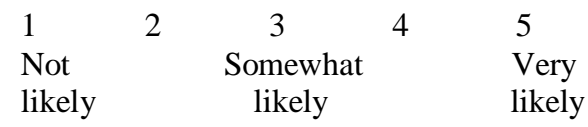

Part II. Now I would like to get some information about things that (Child's name) seems to like or enjoy

1. What classes or subjects does (Child's name) seem to enjoy? $\underline{\text { Class }}$ How often does this occur (e.g., daily, twice a week)

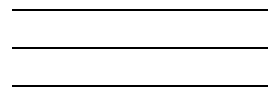

2. What leisure or play activities does (Child's name) seem to enjoy? Activity

\begin{tabular}{|c|c|}
\hline $\begin{array}{l}1 \\
\text { Not } \\
\text { likely }\end{array}$ & $\begin{array}{c}3 \\
\text { Somewhat } \\
\text { likely }\end{array}$ \\
\hline
\end{tabular}

How often does this occur (e.g., daily, twice a week)

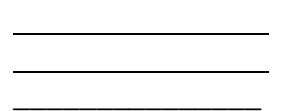


Part III. Now I would like to get some information about how (Child's name) gets along with other children

1. On a scale of 1 to 5 , does this child seem to enjoy playing with other children more or less than playing alone?

2. On a scale of 1 to 5 , do other children seek out (Child's name) to play more or less often than most other children are sought out?

3. On a scale of 1 to 5 , do other children seek out (Child's name) to work on group activities more or less often than most other children are sought out?

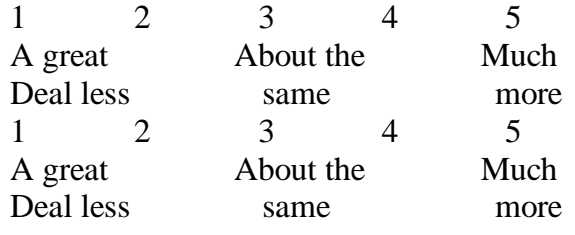

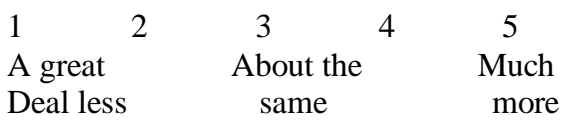

Part IV. In this section I will be asking some questions about general areas of (Child's life) that may affect his or her behavior in school. 1. On a scale of 1 to 5 , how do you think (Child's
name's) overall health is, compared to other students?

2. On a scale of 1 to 5, how much is (Child's name's) behavior affected by how he or she is feeling? (If 3 or above, ask if their behavior is better or worse when the child is not feeling well and circle the response.)

\section{Better}

Worse

3. On a scale of 1 to 5 , how do you think this child's diet is, compared to that of other children in the class?

\begin{tabular}{|c|c|c|c|c|}
\hline $\begin{array}{l}1 \\
\text { Much } \\
\text { worse }\end{array}$ & 2 & $\begin{array}{c}3 \\
\text { About the } \\
\text { same }\end{array}$ & 4 & $\begin{array}{l}5 \\
\text { Much } \\
\text { better }\end{array}$ \\
\hline 1 & 2 & 3 & 4 & 5 \\
\hline $\begin{array}{l}\text { Much } \\
\text { more }\end{array}$ & & $\begin{array}{l}\text { About the } \\
\text { same }\end{array}$ & & $\begin{array}{r}\text { Much } \\
\text { less }\end{array}$ \\
\hline 1 & 2 & 3 & 4 & 5 \\
\hline $\begin{array}{l}\text { Much } \\
\text { more }\end{array}$ & & $\begin{array}{l}\text { About the } \\
\text { same }\end{array}$ & & $\begin{array}{r}\text { Much } \\
\text { less }\end{array}$ \\
\hline
\end{tabular}

6. Do you think (Child's name) behavior is affected by the amount of sleep he or she gets? (If yes, how so?)

$\begin{array}{lcccc}1 & 2 & \begin{array}{c}3 \\ \text { About the } \\ \text { same }\end{array} & 5 \\ \begin{array}{l}\text { Much } \\ \text { worse }\end{array} & & \begin{array}{l}\text { Much } \\ \text { better }\end{array} \\ \begin{array}{l}1 \\ \text { Not at } \\ \text { all }\end{array} & 2 & \begin{array}{c}3 \\ \text { Somewhat A great }\end{array} & 5 \\ & & & \text { deal }\end{array}$

4. To what extent do you think this child's diet affects his behavior? (If 3 or above, ask how)

5. On a scale of 1 to 5, about how much sleep do you think (Child's name) gets, compared to others in the class?

YES 
7. Do you think that any of the following might be affecting (Child's name's) behavior at school? (If yes, ask how so?) If the teacher believes an item is not occurring, record that next to the item.

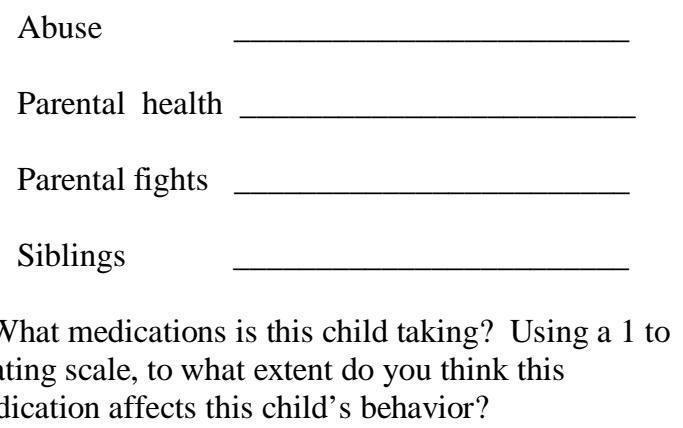

(a)

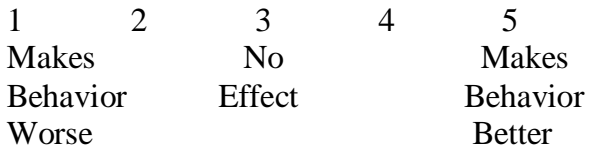

(b)

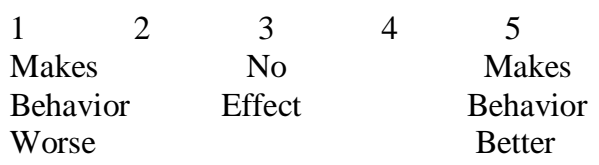

(c)

\begin{tabular}{|c|c|c|c|}
\hline 12 & 3 & 4 & 5 \\
\hline Makes & No & & Makes \\
\hline Behavior & Effect & & $\begin{array}{l}\text { Behavior } \\
\text { Better }\end{array}$ \\
\hline
\end{tabular}


Section V. In this section I will be asking questions about some of the good behaviors (Child's name) exhibits. These are behaviors you would like to see more of.

1. What positive strategies does (Child's name) sometimes use to get your attention? On a 1 to 5 scale, how often does this child exhibit each behavior?

(a)

(b)

(c)

2. What positive strategies does (Child's name) sometimes use to get peer's attention? On a 1 to 5 scale, how often does this child exhibit each behavior?

(a)

(b)

(c)

3. What positive strategies does (Child's name) sometimes use to let you know they want to take a break from work? On a 1 to 5 scale, how often does this child exhibit each behavior?

(a)

(b)

(c)

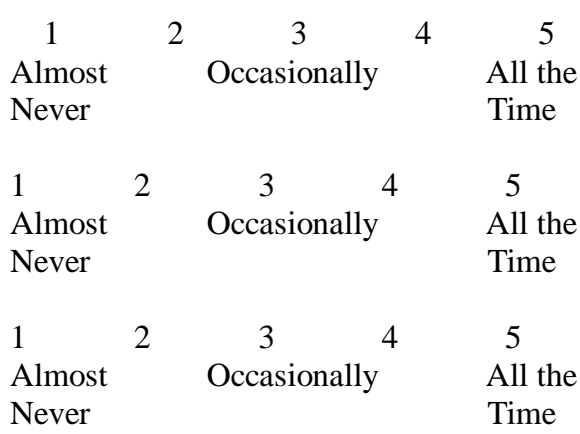

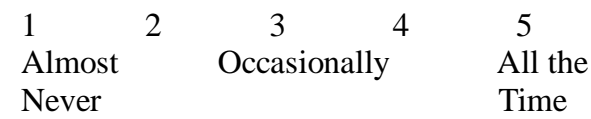

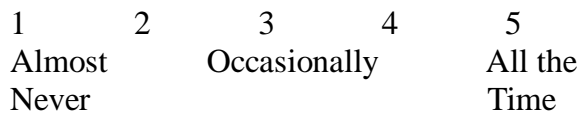

\begin{tabular}{|c|c|c|}
\hline 1 & 2 & 3 \\
\hline $\begin{array}{l}\text { Almost } \\
\text { Never }\end{array}$ & & Occasionally \\
\hline
\end{tabular}

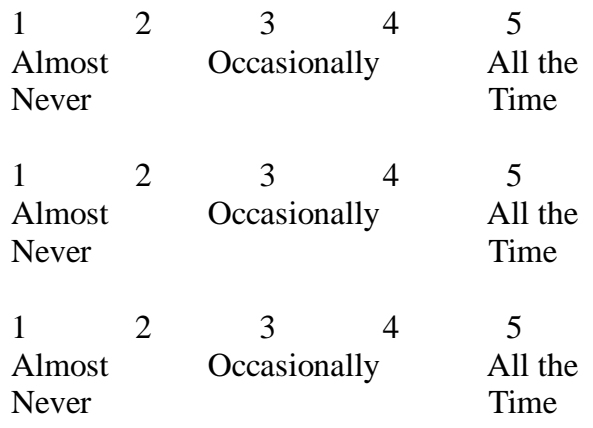


4. What positive strategies does (Child's name) sometimes use to let you know they want to play with a toy or engage in a preferred activity? On a 1 to 5 scale, how often does this child exhibit each behavior?

(a)

(b)

(c)

5. What positive strategies does (Child's name) sometimes use to let you know they want you to leave them alone? On a 1 to 5 scale, how often does this child exhibit each behavior?

(a)

(b)

(c)

6. What positive strategies does (Child's name) sometimes use to let other children know he or she wants to be left alone? On a 1 to 5 scale, how often does this child exhibit each behavior?

a)

(b)

(c)

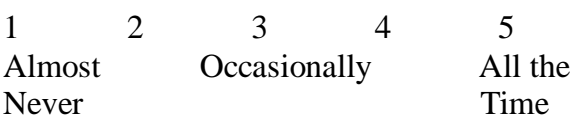

\begin{tabular}{|c|c|c|c|}
\hline 1 & 2 & 3 & 4 \\
\hline $\begin{array}{l}\text { Almost } \\
\text { Never }\end{array}$ & & Occasionally & \\
\hline 1 & 2 & 3 & 4 \\
\hline $\begin{array}{l}\text { Almost } \\
\text { Never }\end{array}$ & & Occasionally & \\
\hline
\end{tabular}

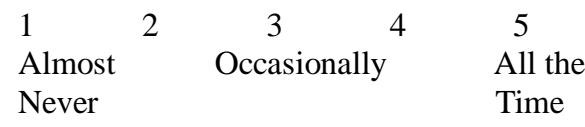

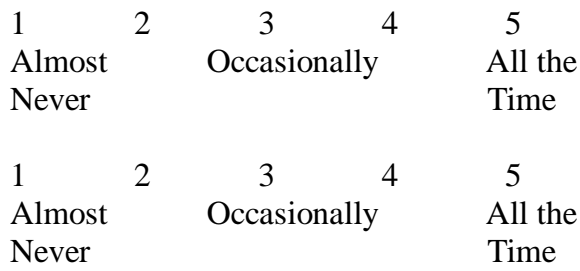

$\begin{array}{lccc}\begin{array}{l}1 \\ \text { Almost }\end{array} & 2 & \begin{array}{c}3 \\ \text { Occasionally }\end{array} & \begin{array}{c}5 \\ \text { All the } \\ \text { Tever }\end{array} \\ \begin{array}{l}\text { Time } \\ \text { Almost } \\ \text { Never }\end{array} & 2 & \begin{array}{c}3 \\ \text { Occasionally }\end{array} & \begin{array}{l}\text { All the } \\ \text { Time }\end{array} \\ \begin{array}{l}1 \\ \text { Almost } \\ \text { Never }\end{array} & & \text { Occasionally } & \begin{array}{l}\text { All the } \\ \text { Time }\end{array}\end{array}$


Participant:

\section{CAFI-T Summary Form}

\section{I. $\quad$ Setting Event Information}

Complete this section using information in Part IV. For each item, circle "yes" if that question was rated " 3 " or higher in the interview. Otherwise, circle "no."

\begin{tabular}{|l|l|}
\hline 1. Feeling ill (part IV, question 2) & Yes No \\
\hline 2. Diet (part IV, question 4) & Yes No \\
\hline 3. Not enough/too much sleep (part IV, question 6) & Yes No \\
\hline 4. Abuse (part IV, question 7) & Yes No \\
\hline 5. Parental Health (part IV, question 7) & Yes No \\
\hline 5. Parental fights (part IV, question 7) & Yes No \\
\hline 6. Siblings (part IV, question 7) & Yes No \\
\hline 7. Medication (part IV, question 8) & Yes No \\
\hline
\end{tabular}

\section{Antecedent Information}

Complete this section using information in Part I. For each item, circle "yes" if that question was rated " 3 " or higher in the interview. Otherwise, circle "no."

\begin{tabular}{|l|l|}
\hline 1. Presence of other children & Yes No \\
\hline 2. Presence of adults only & Yes No \\
\hline 3. Presence of children and adults & Yes No \\
\hline 4. Absence of other people & Yes No \\
\hline 5. Presentation of easy task & Yes No \\
\hline 6. Presentation of boring task & Yes No \\
\hline 7. Presentation of difficult task & Yes No \\
\hline 8. Presentation of group activity & Yes No \\
\hline 9. Presentation of independent work & Yes No \\
\hline 10. Presentation of structured situation & Yes No \\
\hline 11. Presentation of unstructured situation & Yes No \\
\hline 12. Unexpected change occurs & Yes No \\
\hline 13. Preferred activity/item is removed & Yes No \\
\hline
\end{tabular}




\section{Consequence Information}

Complete this section using information in Part I. For each item rated "3" or higher check off the identified consequence or consequences below

\begin{tabular}{|c|c|c|c|c|c|c|c|}
\hline Question & $\begin{array}{l}\text { Peer } \\
\text { Attention }\end{array}$ & $\begin{array}{l}\text { Adult } \\
\text { Attention }\end{array}$ & $\begin{array}{l}\text { Peer } \\
\text { Avoidance }\end{array}$ & $\begin{array}{l}\text { Adult } \\
\text { Avoidance }\end{array}$ & $\begin{array}{l}\text { Task } \\
\text { Presentation }\end{array}$ & $\begin{array}{l}\text { Task } \\
\text { Removal }\end{array}$ & $\begin{array}{l}\text { Preferred } \\
\text { Activity } \\
\text { Removal }\end{array}$ \\
\hline 1 & & & & & & & \\
\hline 2 & & & & & & & \\
\hline 3 & & & & & & & \\
\hline 4 & & & & & & & \\
\hline 5 & & & & & & & \\
\hline 6 & & & & & & & \\
\hline 7 & & & & & & & \\
\hline 8 & & & & & & & \\
\hline 9 & & & & & & & \\
\hline 10 & & & & & & & \\
\hline 11 & & & & & & & \\
\hline 12 & & & & & & & \\
\hline 13 & & & & & & & \\
\hline Totals & & & & & & & \\
\hline
\end{tabular}

What are the consequences that might be maintaining this child's behavior? (These are the consequences that were identified on 3 or more items.)

1.

3.

2.

4. 


\section{Skills Assessment}

Complete the first three questions using Part III. For each item, circle "yes" if that question was rated " 3 " or higher in the interview. Otherwise, circle "no." Complete the remaining items using Part V. Record the responses on the lines provided.

1. Avoids social interaction with peers

Yes No

2. Sought out by peers to play

Yes No

3. Sought out by peers to work

Yes No

4. Adult attention seeking skills:

5. Peer attention seeking skills:

6. Break seeking skills:

7. Tangible seeking skills:

8. Adult avoidance skills:

9. Peer avoidance skills: 


\section{Appendix B}

\section{Clinical Analysis of Function Interview-Child Form}

Child:

Interviewer:

\section{Section 1.}

Directions: In this section, many questions will be responded to based on a rating scale. The scale ranges from 1 to 5. If, using this scale, the child responds to any question with a rating of 3, 4, or 5, ask him or her what behaviors are more likely to occur and record those behaviors on the lines below the question. Then, for each behavior, ask the follow-up question provided in the parentheses after each question. Before beginning the interview give the child a sheet of paper that lists the behaviors you will be asking questions about. The sheet should list only challenging behaviors.

-Sometimes people behave differently around different people.

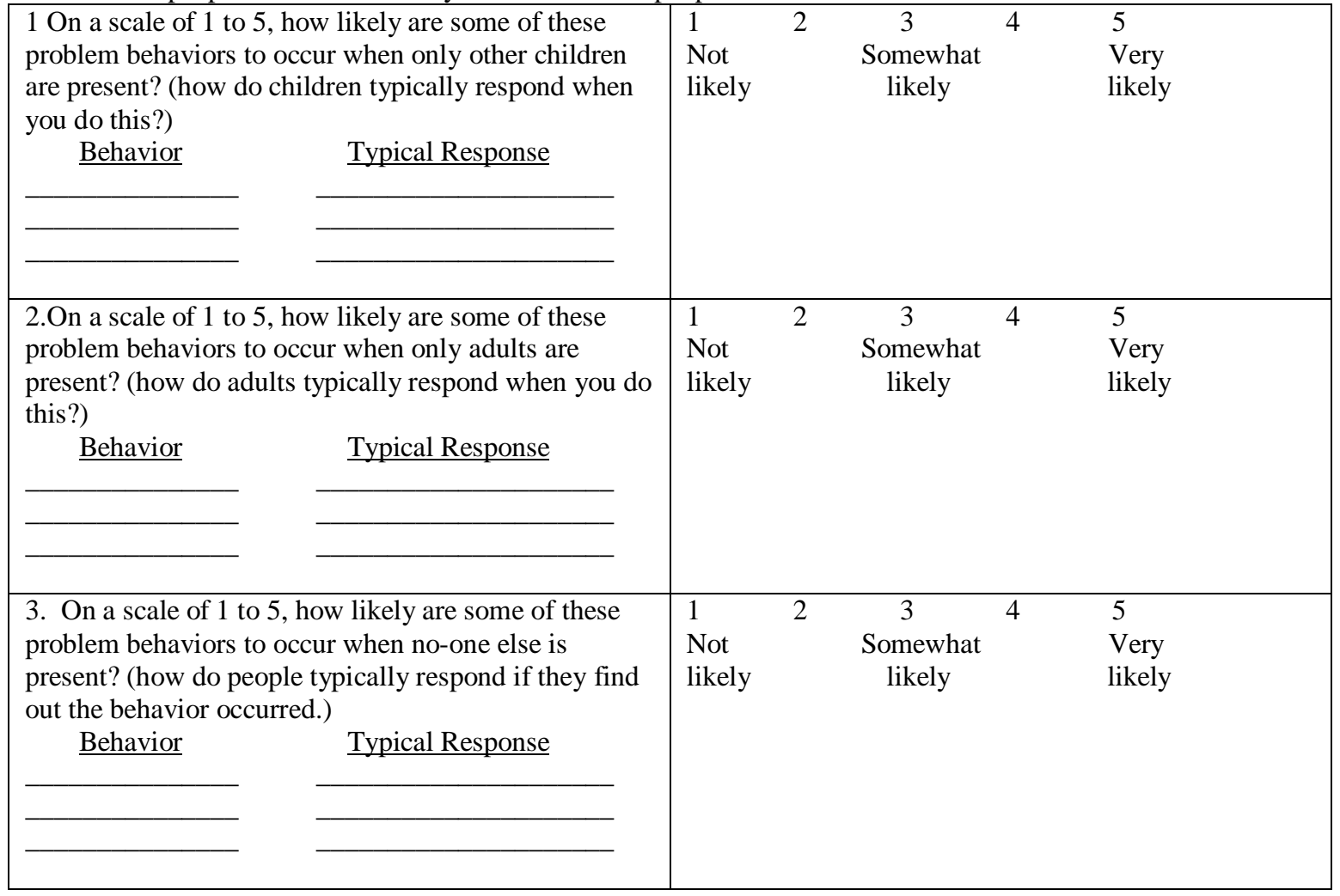




\begin{tabular}{|c|c|c|c|c|c|c|}
\hline \multicolumn{2}{|c|}{$\begin{array}{l}\text { 4. On a scale of } 1 \text { to } 5 \text {, how likely are some of these } \\
\text { problem behaviors to occur when you are asked to } \\
\text { work on a task that you find easy? (how do others } \\
\text { typically respond when you do this?) }\end{array}$} & $\begin{array}{l}1 \\
\text { Not } \\
\text { likely }\end{array}$ & 2 & $\begin{array}{c}3 \\
\text { Somewhat } \\
\text { likely }\end{array}$ & 4 & $\begin{array}{l}5 \\
\text { Very } \\
\text { likely }\end{array}$ \\
\hline Behavior & Typical Response & & & & & \\
\hline \multicolumn{2}{|c|}{$\begin{array}{l}\text { 5. On a scale of } 1 \text { to } 5 \text {, how likely are some of these } \\
\text { problem behaviors to occur when you are asked to } \\
\text { work on a task that you find difficult? (how do others } \\
\text { typically respond when you do this?) } \\
\text { Behavior }\end{array}$} & $\begin{array}{l}1 \\
\text { Not } \\
\text { likely }\end{array}$ & 2 & $\begin{array}{c}3 \\
\text { Somewhat } \\
\text { likely }\end{array}$ & 4 & $\begin{array}{l}5 \\
\text { Very } \\
\text { likely }\end{array}$ \\
\hline \multicolumn{2}{|c|}{$\begin{array}{l}\text { 6. On a scale of } 1 \text { to } 5 \text {, how likely are some of these } \\
\text { problem behaviors to occur when you are asked to } \\
\text { work on a group activity with other children? (how do } \\
\text { others typically respond when you do this?) } \\
\text { Behavior } \\
\text { Typical Response }\end{array}$} & $\begin{array}{l}1 \\
\text { Not } \\
\text { likely }\end{array}$ & 2 & $\begin{array}{c}3 \\
\text { Somewhat } \\
\text { likely }\end{array}$ & 4 & $\begin{array}{l}5 \\
\text { Very } \\
\text { likely }\end{array}$ \\
\hline \multicolumn{2}{|c|}{$\begin{array}{l}\text { 7. On a scale of } 1 \text { to } 5 \text {, how likely are some of these } \\
\text { problem behaviors to occur when you are asked to } \\
\text { work independently? (how do others typically respond } \\
\text { when you do this?) } \\
\text { Behavior }\end{array}$} & $\begin{array}{l}1 \\
\text { Not } \\
\text { likely }\end{array}$ & 2 & $\begin{array}{c}3 \\
\text { Somewhat } \\
\text { likely }\end{array}$ & 4 & $\begin{array}{l}5 \\
\text { Very } \\
\text { likely }\end{array}$ \\
\hline
\end{tabular}




\begin{tabular}{|c|c|c|c|c|c|c|}
\hline \multicolumn{2}{|c|}{$\begin{array}{l}\text { 8. On a scale of } 1 \text { to } 5 \text {, how likely are some of these } \\
\text { problem behaviors to occur when you are in a } \\
\text { structured situation, such as seat work, where the } \\
\text { expectations are clearly defined? }\end{array}$} & $\begin{array}{l}1 \\
\text { Not } \\
\text { likely }\end{array}$ & 2 & $\begin{array}{c}3 \\
\text { Somewhat } \\
\text { likely }\end{array}$ & 4 & $\begin{array}{l}5 \\
\text { Very } \\
\text { likely }\end{array}$ \\
\hline Behavior & Typical Response & & & & & \\
\hline \multicolumn{2}{|c|}{$\begin{array}{l}\text { 9. On a scale of } 1 \text { to } 5 \text {, how likely are these problem } \\
\text { behaviors to occur when you are in a situation without } \\
\text { a lot of rules, like recess or the cafeteria or free time? } \\
\text { (how do others typically respond when you act this } \\
\text { way?) } \\
\text { Behavior } \quad \text { Typical Response }\end{array}$} & $\begin{array}{l}1 \\
\text { Not } \\
\text { likely }\end{array}$ & 2 & $\begin{array}{c}3 \\
\text { Somewhat } \\
\text { likely }\end{array}$ & 4 & $\begin{array}{l}5 \\
\text { Very } \\
\text { likely }\end{array}$ \\
\hline \multicolumn{2}{|c|}{$\begin{array}{l}\text { 10. On a scale of } 1 \text { to } 5 \text {, how likely are some of these } \\
\text { problem behaviors to occur when unexpected changes } \\
\text { occur in the daily routine (e.g., fire drill, assembly)? } \\
\text { (how do others typically respond when you exhibit that } \\
\text { behavior in this situation?) } \\
\text { Behavior Typical Response }\end{array}$} & $\begin{array}{l}1 \\
\text { Not } \\
\text { likely }\end{array}$ & 2 & $\begin{array}{c}3 \\
\text { Somewhat } \\
\text { likely }\end{array}$ & 4 & $\begin{array}{l}5 \\
\text { Very } \\
\text { likely }\end{array}$ \\
\hline \multicolumn{2}{|c|}{$\begin{array}{l}\text { 11. On a scale of } 1 \text { to } 5 \text {, how likely are some of these } \\
\text { problem behaviors to occur when you are asked to stop } \\
\text { doing something you enjoy (e.g., recess)? (how do } \\
\text { others typically respond when you exhibit that } \\
\text { behavior in this situation?) } \\
\quad \text { Behavior }\end{array}$} & $\begin{array}{l}1 \\
\text { Not } \\
\text { likely }\end{array}$ & 2 & $\begin{array}{c}3 \\
\text { Somewhat } \\
\text { likely }\end{array}$ & 4 & $\begin{array}{l}5 \\
\text { Very } \\
\text { likely }\end{array}$ \\
\hline
\end{tabular}




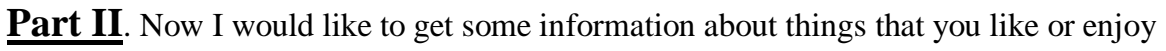

1. What classes or subjects do you enjoy?

Class

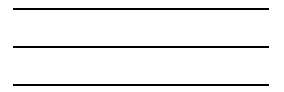

How often does this occur (e.g., daily, twice a week)

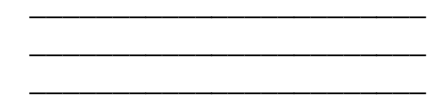

2. What leisure or play activities do you enjoy?

Activity
How often does this occur (e.g., daily, twice a week)

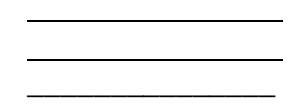

Part III. Now I would like to get some information about how you feel about other children you spend time with.

1. On a scale of 1 to 5 , does this child seem to enjoy playing with other children more or less than playing alone?

2. On a scale of 1 to 5 , do other children seek out (Child's name) to play more or less often than most other children are sought out?

3. On a scale of 1 to 5, do other children seek out (Child's name) to work on group activities more or less often than most other children are sought out?

\begin{tabular}{|c|c|c|c|}
\hline 1 & 2 & 3 & 4 \\
\hline $\begin{array}{l}\text { A great } \\
\text { deal less }\end{array}$ & & $\begin{array}{l}\text { About the } \\
\text { same }\end{array}$ & \\
\hline 1 & 2 & & 4 \\
\hline $\begin{array}{l}\text { A great } \\
\text { deal less }\end{array}$ & & $\begin{array}{l}\text { About the } \\
\text { same }\end{array}$ & \\
\hline 1 & 2 & 3 & 4 \\
\hline $\begin{array}{l}\text { A great } \\
\text { deal less }\end{array}$ & & $\begin{array}{l}\text { About the } \\
\text { same }\end{array}$ & \\
\hline
\end{tabular}


Part IV. In this section I will be asking some questions about areas of your life outside of school

1. On a scale of 1 to 5 , how do you think your overall health is, compared to other students?

2. On a scale of 1 to 5 , how much is your behavior affected by how he or she is feeling? (If 3 or above, ask if their behavior is better or worse when not feeling well and circle the response.)

\section{Better}

\section{Worse}

3. On a scale of 1 to 5 , how do you think your diet is, compared to that of other children in the class?

4. To what extent do you think your diet affects your behavior? (If 3 or above, ask how)

5. On a scale of 1 to 5, about how much sleep do you get compared to others in the class?

6. Do you think your behavior is affected by the amount of sleep you get? (If yes, how so?)

8. What medications are you taking? Using a 1 to 5 rating scale, to what extent do you think this medication affects your behavior?

(d)

(e)

(f)

\begin{tabular}{|c|c|c|c|c|}
\hline $\begin{array}{l}1 \\
\text { Much } \\
\text { worse }\end{array}$ & 2 & $\begin{array}{c}3 \\
\text { About the } \\
\text { same }\end{array}$ & 4 & $\begin{array}{l}5 \\
\text { Much } \\
\text { better }\end{array}$ \\
\hline 1 & 2 & 3 & 4 & 5 \\
\hline $\begin{array}{l}\text { Much } \\
\text { more }\end{array}$ & & $\begin{array}{l}\text { About the } \\
\text { same }\end{array}$ & & $\begin{array}{r}\text { Much } \\
\text { less }\end{array}$ \\
\hline 1 & 2 & 3 & 4 & 5 \\
\hline $\begin{array}{l}\text { Much } \\
\text { more } \\
\text { YES }\end{array}$ & & $\begin{array}{l}\text { About the } \\
\text { same } \\
\text { NO }\end{array}$ & & $\begin{array}{r}\text { Much } \\
\text { less }\end{array}$ \\
\hline
\end{tabular}

\begin{tabular}{|c|c|c|c|}
\hline 1 & 3 & 4 & 5 \\
\hline Makes & No & & Makes \\
\hline $\begin{array}{l}\text { Behavior } \\
\text { Worse }\end{array}$ & Effect & & $\begin{array}{l}\text { Behavior } \\
\text { Better }\end{array}$ \\
\hline
\end{tabular}

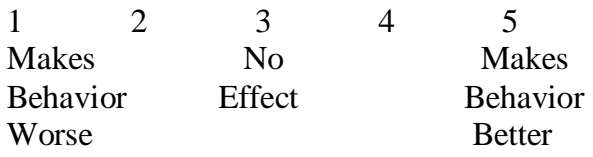

\begin{tabular}{|c|c|c|c|}
\hline 1 & 3 & 4 & 5 \\
\hline Makes & No & & Makes \\
\hline Behavior & Effect & & Behavior \\
\hline Worse & & & Better \\
\hline
\end{tabular}


Section V. In this section I will be asking questions about some of the good things you do.

1. What positive strategies do you sometimes use to get your teacher's attention? On a 1 to 5 scale, how often do you exhibit each behavior?

(a)

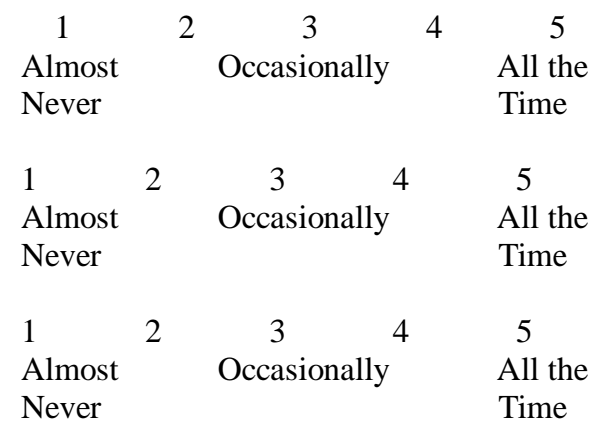

2. What positive strategies do you sometimes use to get other student's attention? On a 1 to 5 scale, how often do you exhibit each behavior?

(a)

(b)

(c)

3. What positive strategies do you sometimes use to let your teacher know you want to take a break from work? On a 1 to 5 scale, how often do you exhibit each behavior?

(a)

(b)

(c)

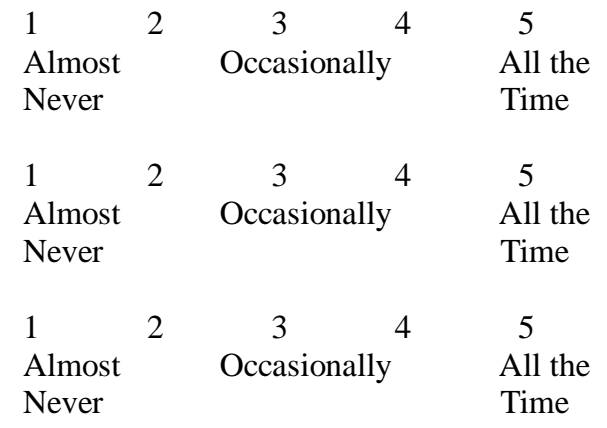


4. What positive strategies do you sometimes use to let your teacher know you want to play with a toy or do something you enjoy? On a 1 to 5 scale, how often do you exhibit each behavior?

(a)

(b)

(c)

5. What positive strategies do you sometimes use to let your teacher know you want him or her to leave you alone? On a 1 to 5 scale, how often do you exhibit each behavior?

(a)

(b)

(c)

6. What positive strategies do you sometimes use to let other children know you want to be left alone? On a 1 to 5 scale, how often do you exhibit each behavior?

a)

(b)

(c)

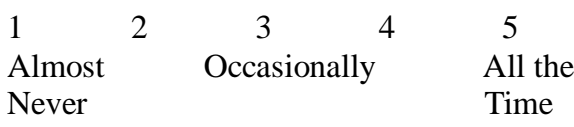

\begin{tabular}{|c|c|c|c|}
\hline 1 & 2 & 3 & 4 \\
\hline $\begin{array}{l}\text { Almost } \\
\text { Never }\end{array}$ & & Occasionally & \\
\hline 1 & 2 & 3 & 4 \\
\hline $\begin{array}{l}\text { Almost } \\
\text { Never }\end{array}$ & & Occasionally & \\
\hline
\end{tabular}

\begin{tabular}{|c|c|c|}
\hline 1 & 2 & $\begin{array}{ll}3 & 4\end{array}$ \\
\hline $\begin{array}{l}\text { Almost } \\
\text { Never }\end{array}$ & & Occasionally \\
\hline
\end{tabular}

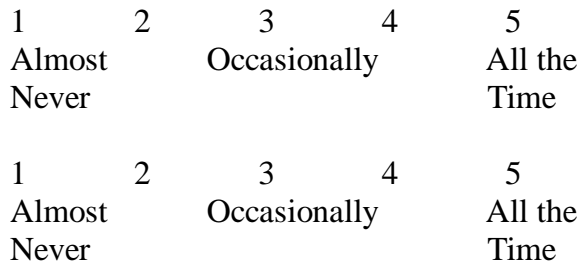

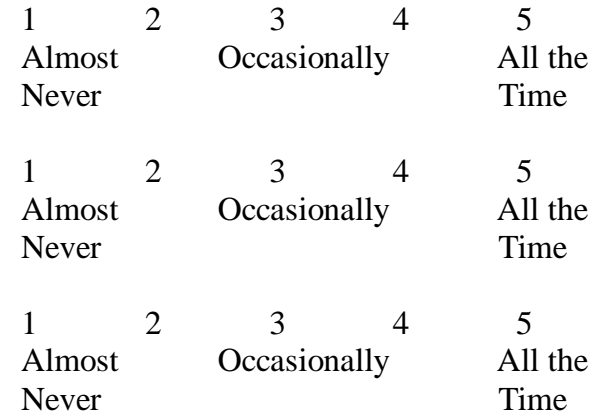




\section{Setting Event Information}

\section{CAFI-T Summary Form}

Complete this section using information in Part IV. For each item, circle "yes" if that question was rated " 3 " or higher in the interview. Otherwise, circle "no."

\begin{tabular}{|l|l|}
\hline 1. Feeling ill (part IV, question 2) & Yes No \\
\hline 2. Diet (part IV, question 4) & Yes No \\
\hline 3. Not enough/too much sleep (part IV, question 6) & Yes No \\
\hline 4. Abuse (part IV, question 7) & Yes No \\
\hline 5. Parental Health (part IV, question 7) & Yes No \\
\hline 5. Parental fights (part IV, question 7) & Yes No \\
\hline 6. Siblings (part IV, question 7) & Yes No \\
\hline 7. Medication (part IV, question 8) & Yes No \\
\hline
\end{tabular}

\section{Antecedent Information}

Complete this section using information in Part I. For each item, circle "yes" if that question was rated " 3 " or higher in the interview. Otherwise, circle "no."

\begin{tabular}{|l|l|}
\hline 1. Presence of other children & Yes No \\
\hline 2. Presence of adults only & Yes No \\
\hline 3. Presence of children and adults & Yes No \\
\hline 4. Absence of other people & Yes No \\
\hline 5. Presentation of easy task & Yes No \\
\hline 6. Presentation of boring task & Yes No \\
\hline 7. Presentation of difficult task & Yes No \\
\hline 8. Presentation of group activity & Yes No \\
\hline 9. Presentation of independent work & Yes No \\
\hline 10. Presentation of structured situation & Yes No \\
\hline 11. Presentation of unstructured situation & Yes No \\
\hline 12. Unexpected change occurs & Yes No \\
\hline 13. Preferred activity/item is removed & Yes No \\
\hline
\end{tabular}




\section{Consequence Information}

Complete this section using information in Part I. For each item rated "3" or higher check off the identified consequence or consequences below

\begin{tabular}{|c|c|c|c|c|c|c|c|}
\hline Question & $\begin{array}{l}\text { Peer } \\
\text { Attention }\end{array}$ & $\begin{array}{l}\text { Adult } \\
\text { Attention }\end{array}$ & $\begin{array}{l}\text { Peer } \\
\text { Avoidance }\end{array}$ & $\begin{array}{l}\text { Adult } \\
\text { Avoidance }\end{array}$ & $\begin{array}{l}\text { Task } \\
\text { Presentation }\end{array}$ & $\begin{array}{l}\text { Task } \\
\text { Removal }\end{array}$ & $\begin{array}{l}\text { Preferred } \\
\text { Activity } \\
\text { Removal }\end{array}$ \\
\hline 1 & & & & & & & \\
\hline 2 & & & & & & & \\
\hline 3 & & & & & & & \\
\hline 4 & & & & & & & \\
\hline 5 & & & & & & & \\
\hline 6 & & & & & & & \\
\hline 7 & & & & & & & \\
\hline 8 & & & & & & & \\
\hline 9 & & & & & & & \\
\hline 10 & & & & & & & \\
\hline 11 & & & & & & & \\
\hline 12 & & & & & & & \\
\hline 13 & & & & & & & \\
\hline Totals & & & & & & & \\
\hline
\end{tabular}

What are the consequences that might be maintaining this child's behavior? (These are the consequences that were identified on 3 or more items.)

1.

3.

2.

4. 


\section{Skills Assessment}

Complete this section using information in Part III. For each item, circle "yes" if that question was rated " 3 " or higher in the interview. Otherwise, circle "no." Complete the remaining items using Part V. Record responses on the lines provided.

1. Avoids social interaction with peers

$\begin{array}{ll}\text { Yes } & \text { No } \\ \text { Yes } & \text { No } \\ \text { Yes } & \text { No }\end{array}$

2. Sought out by peers to play

4. Adult attention seeking skills:

5. Peer attention seeking skills:

6. Break seeking skills:

7. Tangible seeking skills:

8. Adult avoidance skills:

9. Peer avoidance skills: 


\section{Appendix C \\ Functional Analysis of Problem Behavior: Parental Consent Form}

Introduction: I,

, have been asked to allow my child, , to

participate in this study. The research is being conducted by Cynthia Anderson, MA, who has explained the study to me. I understand that Cynthia is conducting this research study to partially fulfill the requirements for a doctoral degree in clinical psychology at West Virginia University.

Purposes of the Study: The purpose of this study is to determine whether an interview administered to teachers and classroom observations will provide information useful in developing a treatment designed to reduce the occurrence of challenging behaviors exhibited in the classroom.

Description of Procedures: This study will be performed at my child's school, My child's teacher will be asked a variety of questions about the challenging behavior my child sometimes exhibits. The purpose of these questions is to determine why these behaviors are occurring. These interviews will be audiotaped for later evaluation. These interviews will be carried out either by Cynthia Anderson or by a trained research assistant. I understand that a total of 10 children (including my own) and their teachers will be participating in this part of the study. Later in the study, interviews will be conducted with the teachers of four additional children. Also, in-school observations will be conducted with these children.

Benefits: I understand that this study may have direct benefits to my child because, upon completion of this study, if my child's teacher and I wish, a treatment plan based on the findings of the study will be prepared and made available. This treatment plan will specify strategies likely to be useful in reducing the rates of my child's challenging behaviors at school. If I wish, Cynthia Anderson will provide training to me and my child's teacher concerning the treatment plan.

Contact Persons: For more information about this research, I can contact Dr. Joseph Scotti, who is an associate professor in the Department of Psychology at West Virginia University and is supervising this research. He can be reached at (304) 293-2001 ext. 667

For information regarding my child's rights as a research participant, I may contact the Executive Secretary of the Institutional Review Board at (304) 293-7073.

Confidentiality: I understand that any information obtained as a result of my child's participation in this research will be kept as confidential as legally possible. I understand that these research records, just like hospital records, may be subpoenaed by court order or may be inspected by federal regulatory authorities. In any publications that may result from this research, neither my name nor that of my child nor any information from which we might be identified will be published without my consent. Audiotapes of the interview conducted with my child's teacher and will be stored in a locked cabinet and will be destroyed after they have been analyzed for the purposes of data collection.

Voluntary Participation: Participation in this study is voluntary. I understand that I may withdraw my child from this study at any time. Refusal to participate or withdrawal will involve no penalty or loss of benefits for me or my child from my child's school or from West Virginia University. I have been given an opportunity to ask questions about the research and I have received answers concerning areas I did not understand. Upon signing this form, I will receive a copy.

I willingly consent to my child's participation in this study.

Signature of Parent or Guardian

Signature of Investigator
Date:

Date: 
Appendix D

Functional Analysis of Problem Behavior: Teacher Consent Form

Introduction: I, , have been asked to allow to participate in this study. I understand that this study involves one of my students, , and that his or her parent or guardian has given permission for their participation. The research study is being conducted by Cynthia Anderson, MA, who has explained the study to me. I understand that Cynthia is conducting this study to partially fulfill the requirements for a doctoral degree in clinical psychology at West Virginia University.

Purposes of the Study: The purpose of this study is to determine whether an interview administered to teachers and classroom observations will provide information useful in developing a treatment designed to reduce the occurrence of challenging behaviors exhibited in the classroom.

Description of Procedures: This study will be performed at the school where I teach. I will be asked a variety of questions about the challenging behavior sometimes exhibits. The purpose of these questions is to determine why these behaviors are occurring. These interviews will be audiotaped for later evaluation. I understand that a total of 10 children and their teachers will be participating in this study. Later in the study, interviews will be conducted with the teachers of four additional children. Also, in-school observations will be conducted with these children

Benefits: I understand that this study may have direct benefits to my student because, upon completion of this study, if my student's parents and I wish, a treatment plan based on the findings of the study will be prepared and made available. This treatment plan will specify strategies likely to be useful in reducing the rates of my child's challenging behaviors at school. If I wish, Cynthia Anderson will provide training to me and my student's parents concerning the treatment plan.

Contact Persons: For more information about this research, I can contact Dr. Joseph Scotti, who is an associate professor in the Department of Psychology at West Virginia University and is supervising this research. He can be reached at (304) 293-2001 ext. 667

For information regarding my student's rights as a research participant, I may contact the Executive Secretary of the Institutional Review Board at (304) 293-7073.

Confidentiality: I understand that any information obtained as a result of my participation in this research will be kept as confidential as legally possible. I understand that these research records, just like hospital records, may be subpoenaed by court order or may be inspected by federal regulatory authorities. In any publications that may result from this research, neither my name nor that of the child nor any information from which we might be identified will be published without my consent and the consent of the child's guardian. Audiotapes of the interview conducted with me will be stored in a locked cabinet and will be destroyed after they have been analyzed for the purposes of data collection.

Voluntary Participation: Participation in this study is voluntary. I understand that I may withdraw from this study or that the child's parents may withdrawal their child from this study at any time. Refusal to participate or withdrawal will involve no penalty or loss of benefits for me or for the child from the school or from West Virginia University. I have been given an opportunity to ask questions about the research and I have received answers concerning areas I did not understand. Upon signing this form, I will receive a copy.

I willingly consent to participate in this study.

Signature of Teacher

Signature of Investigator
Date

Date 
Appendix E

DSM-IV STRUCTURED INTERVIEW FOR DISRUPTIVE BEHAVIOR DISORDERS

Child's Name:

Date: ___ _ I

Teacher's Name Interviewer:

Rating scale: $1=$ rarely $2=$ occasionally $\quad 3=$ pretty often $4=$ very often

Section I.

A. Compared with other children the same

age, how often does the child (do each

problem)?

1. Loses temper

2. Argue with adults

3 Actively defies or refuses adult

$\begin{array}{lll}1 & 3 & 4\end{array}$

requests or rules (e.g., refuses to sit

down when asked)

4. Deliberately does things that annoy $\quad \begin{array}{lllll}1 & 2 & 3 & 4\end{array}$

other people

5. Blames others for his or her own

$\begin{array}{llll}1 & 2 & 3 & 4\end{array}$

mistakes or misbehavior

6. Is touchy or easily annoyed by others $\quad \begin{array}{lllll}1 & 2 & 3 & 4\end{array}$

$\begin{array}{lllll}7 . \text { Is angry and resentful } & 1 & 2 & 3 & 4\end{array}$

$\begin{array}{lllll}\text { 8. Is spiteful or mean } & 1 & 2 & 3 & 4\end{array}$

B. To the best of your knowledge, how long Under six months Over six months have these problems been present? 


\section{Section II.}

A. Compared with other children the same

age, how often does the child (do each

problem)?

1. Bully, threaten, or intimidate others

2. Initiate physical fights

$1-2=3-4$

3. Has used a weapon in more than one

12

$\begin{array}{lll}2 & 3\end{array}$

fight

4. Has been physically cruel to people $\quad \begin{array}{lllll}1 & 2 & 3 & 4\end{array}$

5. Has been physically cruel to animals $\quad \begin{array}{lllll}1 & 2 & 3 & 4\end{array}$

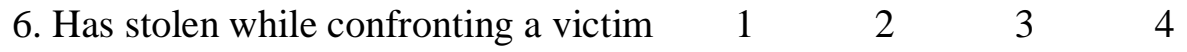

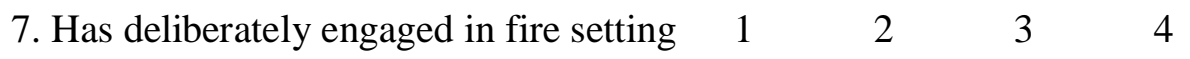

$\begin{array}{llllll}\text { 8. Has deliberately destroyed other's } & 1 & 2 & 3 & 4\end{array}$

property

9. Has broken into someone's house, $\quad \begin{array}{lllll}1 & 2 & 3 & 4\end{array}$

building, or car

$\begin{array}{lllll}\text { 10. Lies } & 1 & 2 & 3 & 4 \\ \text { 11. Has stole items without confronting a } & 1 & 2 & 3 & 4\end{array}$
victim

$\begin{array}{lllll}\text { 12. Stays out at night } & 1 & 2 & 3 & 4 \\ \text { 13. Has run away from home overnight, at } & 1 & 2 & 3 & 4\end{array}$
least twice

14. Is truant from school $\quad 1 \quad r \begin{array}{lll}2 & 3 & 4\end{array}$

B. To the best of your knowledge, how long Under six months Over six months have these problems been present? 


\section{Section III.}

A. Compared with other children the same

age, how often does the child (do each

problem)?

1. Fails to give close attention to details or makes careless mistakes in schoolwork, work, or other activities

2. Has difficulty sustaining attention in tasks or play

3. Does not seem to listen when spoken to $\quad \begin{array}{lllll}1 & 2 & 3 & 4\end{array}$ directly

4. Often does not follow through on $\begin{array}{llll}1 & 2 & 3 & 4\end{array}$ instructions and fails to finish schoolwork or chores

5. Has difficulty organizing tasks and activities

6. Avoids, dislikes, or is reluctant to engage in tasks that require sustained mental effort (such as homework)

7. Loses things necessary for tasks or activities at school or home

8 . Is easily distracted by noises, other $\begin{array}{llll}1 & 2 & 3 & 4\end{array}$ people, smells, etc.

9. Is forgetful in daily activities $\quad \begin{array}{lllll}1 & 2 & 3 & 4\end{array}$

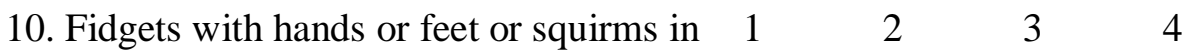
seat

11. Has difficulty remaining seated when it $1 \begin{array}{llll}2 & 2 & 3 & 4\end{array}$ is required 
12. Runs about or climbs on objects

$\begin{array}{llll}1 & 2 & 3 & 4\end{array}$

excessively

13. Has difficulty playing quietly

$\begin{array}{llll}1 & 2 & 3 & 4\end{array}$

14. Seems as if "on the go" or acts as if

$\begin{array}{llll}1 & 2 & 3 & 4\end{array}$

"driven by a motor"

15. Talks excessively

$12 \quad 2 \quad 3 \quad 4$

16. Blurts out answers to questions before

1

they have been completed

17. Has difficulty awaiting turn

18. Interrupts or intrudes on others

$\begin{array}{llll}1 & 2 & 3 & 4 \\ 1 & 2 & 3 & 4\end{array}$

B. To the best of your knowledge, how long

Under six months

Over six months have these problems been present? 


\section{DSM-IV SUMMARY}

Complete this sheet based only on responses $\mathrm{n}$ Section I.

1. Ask the teacher to look at the responses he or she circled in Section I. Ask him or her to identify the three biggest problems for him or her.

2. Record those responses in the left column.

2. For each item say, "you said that _(Child's name) frequently _(Behavior, e.g., loses his temper). When he/she does this, what sort of things does he/she do, what does this look like?"

--Remember, the goal is to get observable descriptions of behavior, things that you could see. Therefore, descriptions such as "yells," and "hits" are acceptable, while descriptions such as "gets frustrated," or "is mean" are not.

1.

Target Behavior Operational Definition

2.

3. 


\section{Appendix F}

\section{Clinical Analysis of Function Interview-Teacher Form}

Child:

Interviewer:

Teacher:

Part I. In this section I will be asking some questions about general areas of (Child's life) that may affect his or her behavior in school.

1. On a scale of 1 to 5 , how do you think (Child's name's) overall health is, compared to other students?

$\begin{array}{lcccc}\begin{array}{l}1 \\ \text { Much } \\ \text { Worse }\end{array} & 2 & \begin{array}{c}3 \\ \text { About the } \\ \text { same }\end{array} & \begin{array}{r}\text { Much } \\ \text { better }\end{array} \\ 1 & 2 & 3 & 4 & 5 \\ \begin{array}{l}\text { Not at } \\ \text { all }\end{array} & & \begin{array}{l}\text { Somewhat A great } \\ \text { deal }\end{array}\end{array}$

2. On a scale of 1 to 5 , how much is (Child's name's) behavior affected by how he or she is feeling? (If 3 or all deal child is not feeling well and circle the response.)

$$
\text { Better Worse }
$$

3. On a scale of 1 to 5 , how do you think this child's 1 diet is, compared to that of other children in the class?

4. To what extent do you think this child's diet affects his behavior? (If 3 or above, ask how)

5. On a scale of 1 to 5, about how much sleep do you think (Child's name) gets, compared to others in the class?

6. Do you think (Child's name) behavior is affected by the amount of sleep he or she gets? (If yes, how so?)

7. Do you think that any of the following might be affecting (Child's name's) behavior at school? (If yes, ask how so?) If the teacher believes an item is not occurring, record that next to the item.

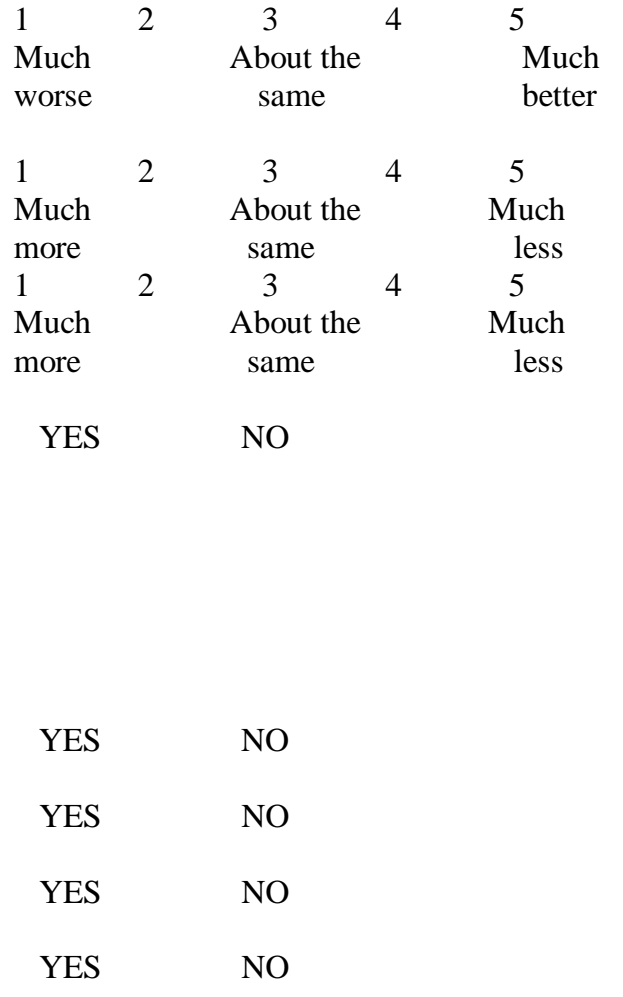


8. What medications is this child taking? Using a 1 to 5 rating scale, to what extent do you think this medication affects this child's behavior?

(g)

(h)

(i)

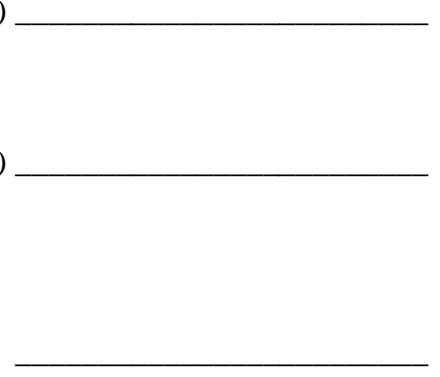

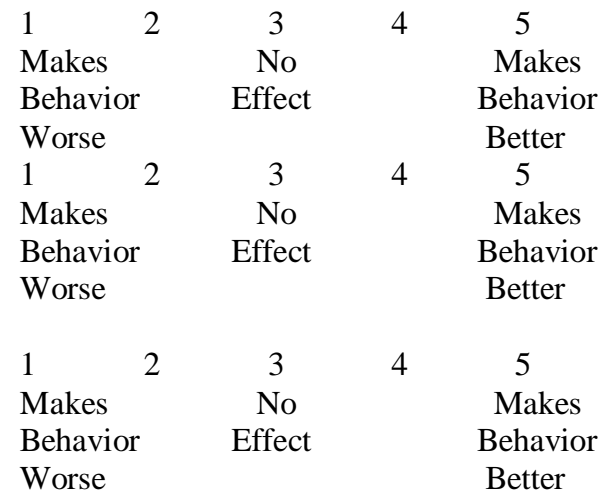

\section{Part II.}

Directions: In this section, many questions will be responded to based on a rating scale. The scale ranges from 1 to 5. If, using this scale, the teacher responds to any question with a rating of 3, 4, or 5, ask him or her what behaviors are more likely to occur and record those behaviors on the lines below the question. Then, for each behavior, ask the follow-up question provided in the parentheses after each question. Before beginning give the teacher a form that lists the behaviors you will be asking questions about.

Tell the teacher, "In this section I will be asking you questions about some of the situations in which (child's name) sometimes exhibits problem behavior. For each question you will respond using a rating scale that goes from 1 to 5 , like this (show the teacher the scale)."

1. On a scale of 1 to 5 , how likely are some of these problem behaviors to occur when only other children are present? (how do children typically respond when the child exhibits that behavior.)

Behavior

Typical Response

2.On a scale of 1 to 5 , how likely are some of these problem behaviors to occur when only adults are present? (how do adults typically respond when the child exhibits that behavior.)

Behavior

Typical Response

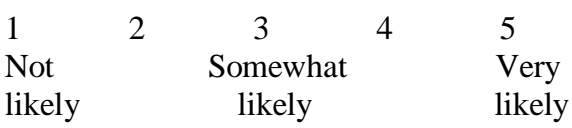

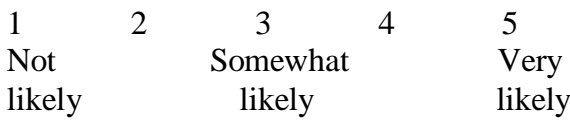

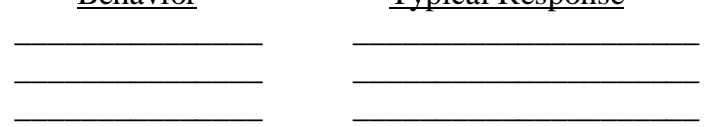

3. On a scale of 1 to 5 , how likely are some of these problem behaviors to occur when both children and adults are present? (how do others typically respond when the child exhibits that behavior.)

Behavior

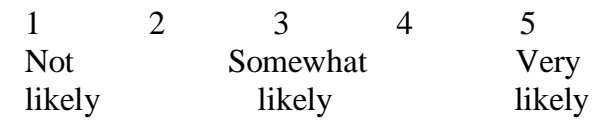


4. On a scale of 1 to 5 , how likely are some of these problem behaviors to occur when no-one else is present? (how do people typically respond if they find out the behavior occurred.)

$\underline{\text { Behavior }}$

\section{Typical Response}

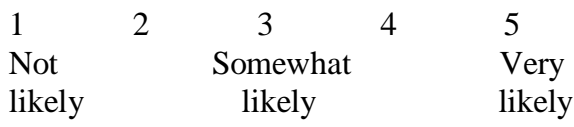

$\bar{\square} \bar{\square}$

5. On a scale of 1 to 5, how likely are some of these problem behaviors to occur when (child's name) is asked to work on a task that he or she finds easy? (how do others typically respond when the child exhibits that behavior in this situation.)

Behavior

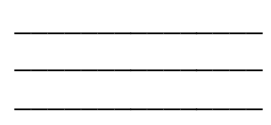

Typical Response

6. On a scale of 1 to 5 , how likely are some of these problem behaviors to occur when (child's name) is asked to work on a task that he or she finds boring? (how do others typically respond when the child exhibits that behavior in this situation.)

Behavior
Typical Response

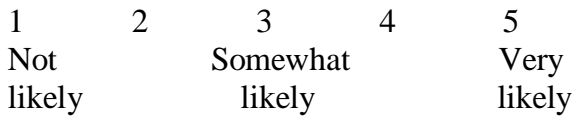

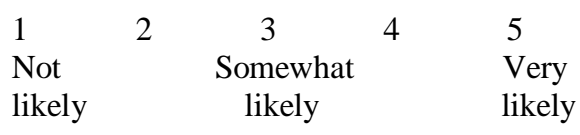

7. On a scale of 1 to 5 , how likely are some of these problem behaviors to occur when (child's name) is asked to work on a task that he or she finds difficult? (how do others typically respond when the child exhibits that behavior in this situation.)

Behavior

$\overline{ }$

8. On a scale of 1 to 5 , how likely are some of these problem behaviors to occur when the child is asked to work on a group activity with other children? (how do others typically respond when the child exhibits that behavior in this situation.)

Behavior

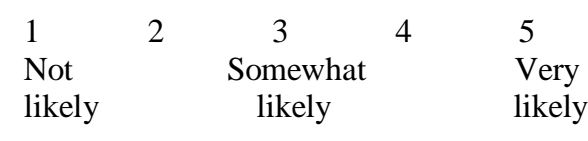

\begin{tabular}{|c|c|c|}
\hline 1 & 3 & 4 \\
\hline Not & Somewhat & \\
\hline likely & likely & \\
\hline
\end{tabular}


9. On a scale of 1 to 5, how likely are some of these problem behaviors to occur when the child is asked to work independently? (how do others typically respond when the child exhibits that behavior in this situation.)

$\underline{\text { Behavior }}$

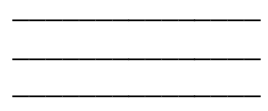

Typical Response

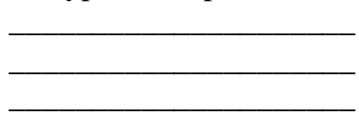

10. On a scale of 1 to 5 , how likely are some of these problem behaviors to occur when the child is in a structured situation, such as seat work, where the expectations are clearly defined?

$$
\text { Behavior }
$$

\section{Typical Response}

11. On a scale of 1 to 5 , how likely are these problem behaviors to occur when the child is in an unstructured situation like recess or the cafeteria or free time?

\section{Behavior}

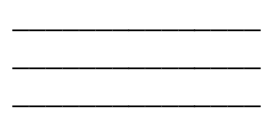

\section{Typical Response}

12. On a scale of 1 to 5 , how likely are some of these problem behaviors to occur when unexpected changes occur in the daily routine (e.g., fire drill, assembly)? (how do others typically respond when the child exhibits that behavior in this situation.)

Behavior
Typical Response

$\begin{array}{lcccc}1 & 2 & 3 & 4 & 5 \\ \begin{array}{l}\text { Not } \\ \text { likely }\end{array} & & \begin{array}{c}\text { Somewhat } \\ \text { likely }\end{array} & & \begin{array}{l}\text { Very } \\ \text { likely }\end{array} \\ 1 & 2 & 3 & 4 & 5 \\ \begin{array}{l}\text { Not } \\ \text { likely }\end{array} & & \begin{array}{c}\text { Somewhat } \\ \text { likely }\end{array} & \begin{array}{l}\text { Very } \\ \text { likely }\end{array}\end{array}$

$\begin{array}{lcccc}1 & 2 & 3 & 4 & 5 \\ \text { Not } & & \begin{array}{c}\text { Somewhat } \\ \text { likely }\end{array} & & \text { Very } \\ \text { likely } & & \text { likely }\end{array}$

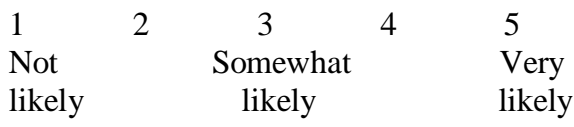

13. On a scale of 1 to 5 , how likely are some of these problem behaviors to occur when a preferred activity (e.g., recess) ends or a preferred item is removed (e.g., art supplies)? (how do others typically respond when the child exhibits that behavior in this situation.)

\section{Behavior}

\section{Typical Response}

$\begin{array}{lcccc}1 & 2 & 3 & 4 & 5 \\ \text { Not } & & \begin{array}{c}\text { Somewhat } \\ \text { likely }\end{array} & & \text { Very } \\ \text { likely } & & \text { likely }\end{array}$


Part III. Now I would like to get some information about how (Child's name) gets along with other children 1. On a scale of 1 to 5 , does this child seem to enjoy playing with other children more or less than playing alone?

2. On a scale of 1 to 5 , do other children seek out (Child's name) to play more or less often than most other children are sought out?

$1 \quad 2$
A great
deal less
1 A great
deal less

\begin{tabular}{|c|c|}
\hline \multirow{2}{*}{\multicolumn{2}{|c|}{$\begin{array}{l}\text { About the } \\
\text { same }\end{array}$}} \\
\hline & \\
\hline 3 & 4 \\
\hline $\begin{array}{l}\text { About the } \\
\text { same }\end{array}$ & \\
\hline
\end{tabular}

3. On a scale of 1 to 5, do other children seek out (Child's name) to work on group activities more or less often than most other children are sought out?

$\begin{array}{lcc}1 & 2 & 3 \\ \begin{array}{l}\text { A great } \\ \text { deal less }\end{array} & \begin{array}{c}\text { About the } \\ \text { same }\end{array} & \begin{array}{c}5 \\ \text { Much } \\ \text { more }\end{array}\end{array}$

4. What positive strategies does (Child's name) sometimes use to get your attention? On a 1 to 5 scale, how often does this child exhibit each behavior?

(a)

(b)

(c)

5. What positive strategies does (Child's name) sometimes use to get peer's attention? On a 1 to 5 scale, how often does this child exhibit each behavior?

(a)

(b)

(c)

\begin{tabular}{|c|c|c|c|}
\hline \multicolumn{2}{|l|}{1} & $\begin{array}{c}3 \\
\text { Occasionally }\end{array}$ & 4 \\
\hline 1 & 2 & 3 & 4 \\
\hline $\begin{array}{l}\text { Almost } \\
\text { Never }\end{array}$ & & Occasionally & \\
\hline 1 & 2 & 3 & 4 \\
\hline $\begin{array}{l}\text { Almost } \\
\text { Never }\end{array}$ & & Occasionally & \\
\hline
\end{tabular}

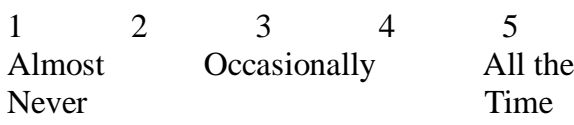

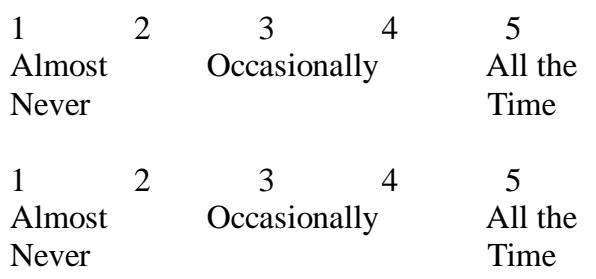


6. What positive strategies does (Child's name) sometimes use to let you know they want to take a break from work? On a 1 to 5 scale, how often does this child exhibit each behavior?

(a)

(b)

(c)

(b)

(c)

8. What positive strategies does (Child's name) sometimes use to let you know they want you to leave them alone? On a 1 to 5 scale, how often does this child exhibit each behavior? (a)

7. What positive strategies does (Child's name) sometimes use to let you know they want to play with a toy or engage in a preferred activity? On a 1 to 5 scale, how often does this child exhibit each behavior?

(a)

)

(c)

\begin{tabular}{|c|c|c|}
\hline & 2 & 3 \\
\hline & & Occasionally \\
\hline
\end{tabular}

\begin{tabular}{|c|c|c|c|}
\hline . & 2 & 3 & 4 \\
\hline $\begin{array}{l}\text { Almost } \\
\text { Never }\end{array}$ & & Occasionally & \\
\hline 1 & 2 & 3 & 4 \\
\hline $\begin{array}{l}\text { Almost } \\
\text { Never }\end{array}$ & & Occasionally & \\
\hline
\end{tabular}

Almost Occasionally All the Never Time

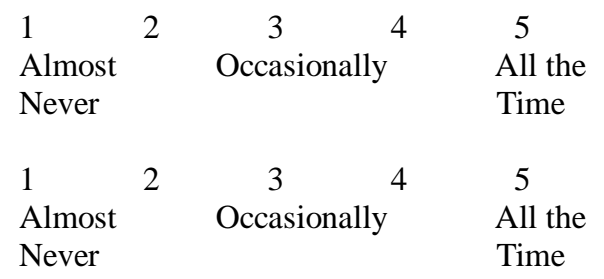

\begin{tabular}{|c|c|c|}
\hline \multicolumn{2}{|l|}{1} & 3 \\
\hline $\begin{array}{l}\text { Almost } \\
\text { Never }\end{array}$ & \multicolumn{2}{|c|}{$\begin{array}{l}\text { All the } \\
\text { Time }\end{array}$} \\
\hline
\end{tabular}

\begin{tabular}{|c|c|c|c|}
\hline 1 & 2 & 3 & 4 \\
\hline $\begin{array}{l}\text { Almost } \\
\text { Never }\end{array}$ & & Occasionally & \\
\hline 1 & 2 & 3 & 4 \\
\hline $\begin{array}{l}\text { Almost } \\
\text { Never }\end{array}$ & & Occasionally & \\
\hline
\end{tabular}


9. What positive strategies does (Child's name) sometimes use to let other children know they want to be left alone? On a 1 to 5 scale, how often does this child exhibit each behavior?

a)

(b)

(c)

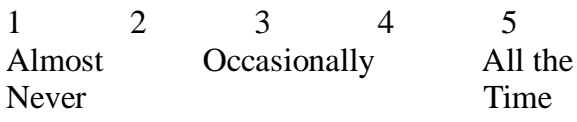

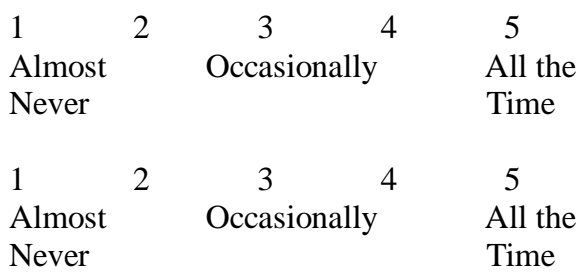


CAFI-T Summary Form

I. Setting Event Information Complete this section using information from Part I. If an item is rated "3" or higher, circle "yes," otherwise circle "no."

\begin{tabular}{|l|ll|}
\hline 1. Feeling ill (part I, question 2) & Yes $\quad$ No \\
\hline 2. Diet (part I, question 4) & Yes $\quad$ No \\
\hline 3. Not enough/too much sleep (part I, question 6) & Yes $\quad$ No \\
\hline 4. Abuse & Yes $\quad$ No \\
\hline 5. Parental Health & Yes $\quad$ No \\
\hline 5. Parental fights & Yes No & No \\
\hline 6. Siblings & Yes No & No \\
\hline 7. Medication & Yes & No \\
\hline
\end{tabular}

\section{Antecedent Information}

Complete this section using information in Part II. For each item, circle "yes" if that question was rated " 3 " or higher in the interview. Otherwise, circle "no."

\begin{tabular}{|l|ll|}
\hline 1. Presence of other children & Yes & No \\
\hline 2. Presence of adults only & Yes $\quad$ No \\
\hline 3. Presence of children and adults & Yes $\quad$ No \\
\hline 4. Absence of other people & Yes $\quad$ No \\
\hline 5. Presentation of easy task & Yes $\quad$ No \\
\hline 6. Presentation of boring task & Yes $\quad$ No \\
\hline 7. Presentation of difficult task & Yes $\quad$ No \\
\hline 8. Presentation of group activity & Yes $\quad$ No \\
\hline 9. Presentation of independent work & Yes $\quad$ No \\
\hline 10. Presentation of structured situation & Yes $\quad$ No \\
\hline 11. Presentation of unstructured situation & Yes & No \\
\hline 12. Unexpected change occurs & Yes $\quad$ No \\
\hline 13. Preferred activity/item is removed & Yes & No \\
\hline
\end{tabular}


III. Consequence Information Complete this section from Part II. For each item rated "3" or above, check off the identified consequences.

\begin{tabular}{|c|c|c|c|c|c|c|c|}
\hline Question & $\begin{array}{l}\text { Peer } \\
\text { Attention }\end{array}$ & $\begin{array}{l}\text { Adult } \\
\text { Attention }\end{array}$ & $\begin{array}{l}\text { Peer } \\
\text { Avoidance }\end{array}$ & $\begin{array}{l}\text { Adult } \\
\text { Avoidance }\end{array}$ & $\begin{array}{l}\text { Task } \\
\text { Presentation }\end{array}$ & $\begin{array}{l}\text { Task } \\
\text { Removal }\end{array}$ & $\begin{array}{l}\text { Preferred } \\
\text { Activity } \\
\text { Removal }\end{array}$ \\
\hline 1 & & & & & & & \\
\hline 2 & & & & & & & \\
\hline 3 & & & & & & & \\
\hline 4 & & & & & & & \\
\hline 5 & & & & & & & \\
\hline 6 & & & & & & & \\
\hline 7 & & & & & & & \\
\hline 8 & & & & & & & \\
\hline 9 & & & & & & & \\
\hline 10 & & & & & & & \\
\hline 11 & & & & & & & \\
\hline 12 & & & & & & & \\
\hline 13 & & & & & & & \\
\hline Totals & & & & & & & \\
\hline
\end{tabular}

IV. Skills Assessment Complete this section using information in Part III. For each item, circle "yes" if that question was rated " 3 " or higher in the interview. Otherwise, circle "no." Complete the remaining items by recording responses on the lines provided.
1. 1. Avoids social interaction with peers
Yes No
2. Sought out by peers to play
Yes No
3. Sought out by peers to work
Yes No
4. Adult attention seeking skills:
5. Peer attention seeking skills:
6. Break seeking skills:
7. Tangible seeking skills:
8. Adult avoidance skills:
9. Peer avoidance skills: 


\section{Appendix G}

Part I.

\section{Clinical Analysis of Function Interview-Child Form}

1. On a scale of 1 to 5 , how do you think your overall health is, compared to other students?

$\begin{array}{lcccc}\begin{array}{l}1 \\ \text { Much } \\ \text { worse }\end{array} & 2 & \begin{array}{c}3 \\ \text { About the } \\ \text { same }\end{array} & 4 & \begin{array}{c}5 \\ \text { Much } \\ \text { better }\end{array} \\ 1 & 2 & \begin{array}{c}3 \\ \text { About the } \\ \text { same }\end{array} & 4 & \begin{array}{c}\text { Much } \\ \text { better }\end{array} \\ \begin{array}{l}\text { worse } \\ 1\end{array} & 2 & \begin{array}{c}3 \\ \text { About the } \\ \text { worse }\end{array} & \text { same } & \begin{array}{c}\text { Much } \\ \text { better }\end{array} \\ \text { Yes } & & \text { No } & \end{array}$

4. Are there times during the day when you are typically hungry? (If yes, record those times below.)

2. On a scale of 1 to 5 , how different do you act depending on how you are feeling?

3. On a scale of 1 to 5 , how well do you think you eat, compared to other children in the class?

5. On a scale of 1 to 5 , how likely are some of these behaviors to occur when you are hungry? eat, compared to other children in the class?

Much
more

6. On a scale of 1 to 5, about how much sleep do you get, compared to others in the class?

1
Much
more

YES

$\begin{array}{ccc}3 & 4 & 5 \\ \text { About the } & & \begin{array}{l}\text { Much } \\ \text { less }\end{array}\end{array}$

7. Do you think your behavior is affected by the amount of sleep he or she gets? (If yes, how so?)

8. Are you taking any medication? Using a 1-5 rating scale, how much do you think this medication affects your behavior? (ask for each medication the child is taking)

(a)

\begin{tabular}{|c|c|c|c|}
\hline 12 & 3 & 4 & 5 \\
\hline $\begin{array}{l}\text { Makes } \\
\text { me worse }\end{array}$ & $\begin{array}{l}\text { No } \\
\text { affect }\end{array}$ & & $\begin{array}{l}\text { Makes me } \\
\text { better }\end{array}$ \\
\hline
\end{tabular}

(b)

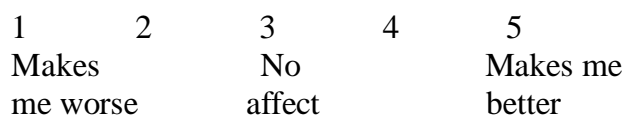

(c)

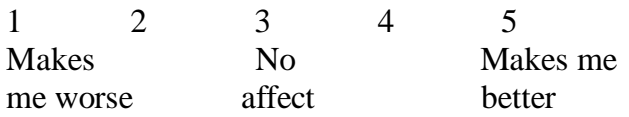




\section{Part II.}

In this section, you will be asking the child why he or she exhibits challenging behaviors. If the child answers "no," go on to the next item. If the child answers, "yes," ask the follow-up question. If the child does not answer or says, "I don't know" to the second question, show him or her the list of possible reasons and ask the child to pick the most likely reason. Record their response opposite the question.

Tell the child, "I am going to ask you questions about situations where children sometimes get in trouble. I want to know why you think these problems are happening so that we can figure out ways to make sure you don't get in trouble any more. Here is a list of behaviors that your teacher said you sometimes do (show the child the list). When I ask you questions, I want you to focus on these behaviors, okay?"

1. Sometimes children exhibit behaviors like these when only other children are present, when no adults are around. Situations like this might be in the bathroom or on the playground.

Do you ever do any of these things when only other children are around?

Why do you exhibit some of these behaviors when only children are around?

2. Sometimes children exhibit behaviors like these when only adults are around. This might occur when you are with a teacher after class or in the main office. Do you ever do any of these things when only adults are around?

Why do you exhibit some of these behaviors when only adults are around?

3. Sometimes children exhibit behaviors like these when both children and adults are around, like when you are in class.

Do you ever do any of these things when both children and adults are around?

Why do you exhibit some of these behaviors when both children and adults are around?

4. Sometimes children exhibit behaviors like these when no-one else is around, like when you are running an errand for a teacher, or when you are in the bathroom alone.

Do you ever do any of these things when no-one is around?

Why do you exhibit some of these behaviors when both children and adults are around?

5. Sometimes children exhibit behaviors like these when they are asked to work on something that they find easy.

Do you ever do any of these when you are asked to work on something easy?

Why do you exhibit some of these behaviors when your teacher asks you to work on something that is easy?
Yes No

Yes No

Yes No

Yes No

Yes No 
6. Sometimes children exhibit behaviors like these when they are asked to work on something that they find boring.

Do you ever do any of these when you are asked to work on something boring?

Why do you exhibit some of these behaviors when your teacher asks you to work on something that is boring?

7. Sometimes children exhibit behaviors like these when they are asked to work on something that they find difficult.

Do you ever do any of these when you are asked to work on something difficult?

Why do you exhibit some of these behaviors when your teacher asks you to work on something that is difficult?

8. Sometimes children exhibit behaviors like these when they are asked to work in a group with other children.

Do you ever do any of these when you are asked to work in a group?

Why do you exhibit some of these behaviors when you are asked to work in a group with other children?

9. Sometimes children exhibit behaviors like these when they are asked to work on something by themselves.

Do you ever do any of these when you are asked to work by yourself?

Why do you exhibit some of these behaviors when your teacher asks you to work on something by yourself?

10. Sometimes children exhibit behaviors like these when they are asked to work on something with very specific instructions, like in a work book.

Do you ever do any of these when you are asked to work on something specific?

Why do you exhibit some of these behaviors when your teacher asks you to work on something really specific?

11. Sometimes children exhibit behaviors like these when they are in an unstructured situation, like recess or the cafeteria.

Do you ever do any of these when you are in a situation like this?

Why do you exhibit some of these behaviors when are in a situation like this?

Yes No

Yes No

Yes No

Yes No

Yes No

Yes No 
12. Sometimes children exhibit behaviors like these when they something unexpected happens, like a fire drill or an assembly.

Do you ever do any of these when you are in a situation like this?

Yes No

Why do you exhibit some of these behaviors when are in a situation like this?

13. Sometimes children exhibit behaviors like these when something they enjoy, like recess or free time, ends.

Do you ever do any of these when you are in a situation like this?

Why do you exhibit some of these behaviors when are in a situation like this?

\section{Part III.}

1. On a scale of 1 to 5 , do you enjoy playing with other children more or less than playing alone?

Yes No

2. On a scale of 1 to 5 , do other children seek you out to play more or less often than most other children are sought out?

3. On a scale of 1 to 5 , do other children seek you out to work on group activities more or less often than most other children are sought out?

4. What positive strategies do you sometimes use to get an adult's attention? On a 1 to 5 scale, how often do you exhibit each behavior?

(a)

(b)

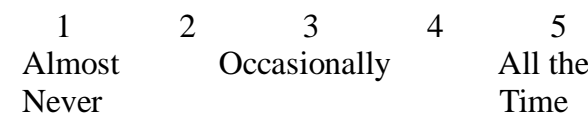

(c)

$\begin{array}{ccccc}\begin{array}{l}1 \\ \text { Almost } \\ \text { Never }\end{array} & 2 & \begin{array}{c}3 \\ \text { Occasionally }\end{array} & 4 & \begin{array}{l}5 \\ \text { All the } \\ \text { Time }\end{array} \\ 1 & 2 & 3 & 4 & 5 \\ \begin{array}{l}\text { Almost } \\ \text { Never }\end{array} & & \text { Occasionally } & & \begin{array}{l}\text { All the } \\ \text { Time }\end{array}\end{array}$


5. What positive strategies do you sometimes use to get other children's attention? On a 1 to 5 scale, how often do you exhibit each behavior?

(a)

(b)

(c)

6. What positive strategies do you sometimes use to let your teacher know you want to take a break from work? On a 1 to 5 scale, how often do you exhibit each behavior?

(a)

(b)

(c)

7. What positive strategies do you sometimes use to let your teacher know you want to play with a toy or engage in a preferred activity? On a 1 to 5 scale, how often do you exhibit each behavior?

(a)

(b)

(c)

8. What positive strategies do you sometimes use to let your teacher know you want them to leave you alone? On a 1 to 5 scale, how often do you exhibit each behavior?

(a)

(b)

(c)

\begin{tabular}{|c|c|c|c|}
\hline $\begin{array}{c}1 \\
\text { Almost } \\
\text { Never }\end{array}$ & 2 & $\begin{array}{c}3 \\
\text { Occasionally }\end{array}$ & 4 \\
\hline $\begin{array}{c}1 \\
\text { Almost } \\
\text { Never }\end{array}$ & 2 & $\begin{array}{c}3 \\
\text { Occasionally }\end{array}$ & 4 \\
\hline $\begin{array}{c}1 \\
\text { Almost } \\
\text { Never }\end{array}$ & 2 & $\begin{array}{c}3 \\
\text { Occasionally }\end{array}$ & 4 \\
\hline
\end{tabular}

$\begin{array}{ccccc}1 & 2 & 3 & 4 & 5 \\ \text { Almost } & & \text { Occasionally } & & \text { All the }\end{array}$

Never Time

$\begin{array}{ccccc}1 & 2 & 3 & 4 & 5 \\ \text { Almost } & & \text { Occasionally } & & \text { All the } \\ \text { Never } & & & \end{array}$

Never Time

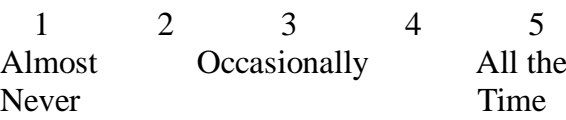

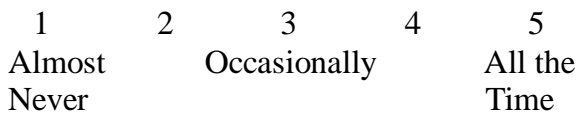

$\begin{array}{lcccc}1 & 2 & 3 & 4 & 5 \\ \text { Almost } & & \text { Occasionally } & & \text { All the } \\ \text { Never } & & & & \text { Time }\end{array}$

$\begin{array}{lcccc}1 & 2 & 3 & 4 & 5 \\ \text { Almost } & & \text { Occasionally } & & \text { All the } \\ \text { Never } & & & & \text { Time }\end{array}$

$\begin{array}{lcccc}\begin{array}{l}1 \\ \text { Almost } \\ \text { Never }\end{array} & 2 & \begin{array}{c}3 \\ \text { Occasionally }\end{array} & 4 & \begin{array}{c}5 \\ \text { All the } \\ \text { Time }\end{array} \\ 1 & 2 & 3 & 4 & 5 \\ \begin{array}{l}\text { Almost } \\ \text { Never }\end{array} & & \text { Occasionally } & & \begin{array}{l}\text { All the } \\ \text { Time }\end{array} \\ 1 & 2 & 3 & 4 & 5 \\ \begin{array}{l}\text { Almost } \\ \text { Never }\end{array} & & \text { Occasionally } & & \begin{array}{l}\text { All the } \\ \text { Time }\end{array}\end{array}$


9. What positive strategies do you sometimes use to let other children know they should leave you alone? On a 1 to 5 scale, how often do you exhibit each behavior?

a)

(b)

(c)

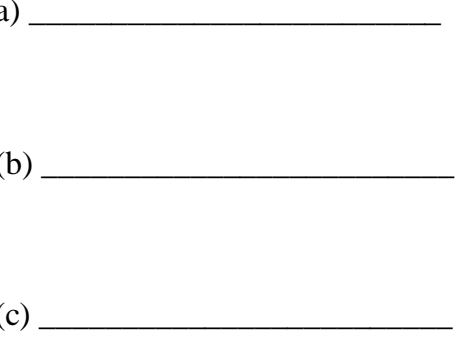

\begin{tabular}{|c|c|c|c|c|}
\hline $\begin{array}{c}1 \\
\text { Almost } \\
\text { Never }\end{array}$ & 2 & $\begin{array}{c}3 \\
\text { Occasionally }\end{array}$ & 4 & $\begin{array}{l}\quad 5 \\
\text { All the } \\
\text { Time }\end{array}$ \\
\hline $\begin{array}{c}1 \\
\text { Almost } \\
\text { Never }\end{array}$ & 2 & $\begin{array}{c}3 \\
\text { Occasionally }\end{array}$ & 4 & $\begin{array}{l}\quad 5 \\
\text { All the } \\
\text { Time }\end{array}$ \\
\hline $\begin{array}{c}1 \\
\text { Almost } \\
\text { Never }\end{array}$ & 2 & $\begin{array}{c}3 \\
\text { Occasionally }\end{array}$ & 4 & $\begin{array}{l}\quad 5 \\
\text { All the } \\
\text { Time }\end{array}$ \\
\hline
\end{tabular}




\section{CAFI-C Summary Form}

I. Setting Event Information Complete this section using information from Part I. If an item is rated "3" or higher, circle "yes," otherwise circle "no."

\begin{tabular}{|l|ll|}
\hline 1. Feeling ill (part I, question 2) & Yes & No \\
\hline 2. Diet (part I, question 5) & Yes $\quad$ No \\
\hline 3. Not enough/too much sleep (part I, question 7) & Yes & No \\
\hline 4. Medication & Yes & No \\
\hline
\end{tabular}

\section{Antecedent Information}

Complete this section using information in Part II. For each item, circle "yes" if that question was rated " 3 " or higher in the interview. Otherwise, circle "no."

\begin{tabular}{|l|l|}
\hline 1. Presence of other children & Yes No \\
\hline 2. Presence of adults only & Yes No \\
\hline 3. Presence of children and adults & Yes No \\
\hline 4. Absence of other people & Yes No \\
\hline 5. Presentation of easy task & Yes No \\
\hline 6. Presentation of boring task & Yes No \\
\hline 7. Presentation of difficult task & Yes No \\
\hline 8. Presentation of group activity & Yes No \\
\hline 9. Presentation of independent work & Yes No \\
\hline 10. Presentation of structured situation & Yes No \\
\hline 11. Presentation of unstructured situation & Yes No \\
\hline 12. Unexpected change occurs & Yes No \\
\hline 13. Preferred activity/item is removed & Yes No \\
\hline
\end{tabular}


III. Consequence Information Complete this section from Part II. For each item rated "3" or above, check off the identified consequences.

\begin{tabular}{|c|c|c|c|c|c|c|c|}
\hline Question & $\begin{array}{l}\text { Peer } \\
\text { Attention }\end{array}$ & $\begin{array}{l}\text { Adult } \\
\text { Attention }\end{array}$ & $\begin{array}{l}\text { Peer } \\
\text { Avoidance }\end{array}$ & $\begin{array}{l}\text { Adult } \\
\text { Avoidance }\end{array}$ & $\begin{array}{l}\text { Task } \\
\text { Presentation }\end{array}$ & $\begin{array}{l}\text { Task } \\
\text { Removal }\end{array}$ & $\begin{array}{l}\text { Preferred } \\
\text { Activity } \\
\text { Removal }\end{array}$ \\
\hline 1 & & & & & & & \\
\hline 2 & & & & & & & \\
\hline 3 & & & & & & & \\
\hline 4 & & & & & & & \\
\hline 5 & & & & & & & \\
\hline 6 & & & & & & & \\
\hline 7 & & & & & & & \\
\hline 8 & & & & & & & \\
\hline 9 & & & & & & & \\
\hline 10 & & & & & & & \\
\hline 11 & & & & & & & \\
\hline 12 & & & & & & & \\
\hline 13 & & & & & & & \\
\hline Totals & & & & & & & \\
\hline
\end{tabular}

IV. Skills Assessment Complete this section using information in Part III. For each item, circle "yes" if that question was rated " 3 " or higher in the interview. Otherwise, circle "no." Complete the remaining items by recording responses on the lines provided.

1. Avoids social interaction with peers

Yes No

2. Sought out by peers to play

Yes No

3. Sought out by peers to work

Yes No

4. Adult attention seeking skills:

5. Peer attention seeking skills:

6. Break seeking skills:

7. Tangible seeking skills:

8. Adult avoidance skills:

9. Peer avoidance skills: 
Appendix $\mathrm{H}$

Functional Analysis of Problem Behavior: Parental Consent Form

Introduction: I, , have been asked to allow my child, , to participate in this study. The research is being conducted by Cynthia Anderson, MA, who has explained the study to me. I understand that Cynthia is conducting this research study to partially fulfill the requirements for a doctoral degree in clinical psychology at West Virginia University.

Purposes of the Study: The purpose of this study is to determine whether an interview administered to teachers and classroom observations will provide information useful in developing a treatment designed to reduce the occurrence of challenging behaviors exhibited in the classroom.

Description of Procedures: This study will be performed at my child's school, My child's teacher will be asked a variety of questions about the challenging behavior my child sometimes exhibits. The purpose of these questions is to determine why these behaviors are occurring. These interviews will be audiotaped for later evaluation. Additionally, my child will be observed during the school day for a total of 4 hours. These observations will be carried out either by Cynthia Anderson or by a trained research assistant. The purpose of these observations is to determine the extent to which the information obtained in the interview with the teacher agrees with what is actually occurring at school. I understand that a total of 4 children (including my own) and their teachers will be participating in this phase of the study. I understand that an earlier phase of the study involved administering the interviews to the teachers of a total of 10 children.

Benefits: I understand that this study may have direct benefits to my child because, upon completion of this study, if my child's teacher and I wish, a treatment plan based on the findings of the study will be prepared and made available. This treatment plan will specify strategies likely to be useful in reducing the rates of my child's challenging behaviors at school. If I wish, Cynthia Anderson will provide training to me and my child's teacher concerning the treatment plan.

Contact Persons: For more information about this research, I can contact Dr. Joseph Scotti, who is an associate professor in the Department of Psychology at West Virginia University and is supervising this research. He can be reached at (304) 293-2001 ext. 667

For information regarding my child's rights as a research participant, I may contact the Executive Secretary of the Institutional Review Board at (304) 293-7073.

Confidentiality: I understand that any information obtained as a result of my child's participation in this research will be kept as confidential as legally possible. I understand that these research records, just like hospital records, may be subpoenaed by court order or may be inspected by federal regulatory authorities. In any publications that may result from this research, neither my name nor that of my child nor any information from which we might be identified will be published without my consent. Audiotapes of the interview conducted with my child's teacher and will be stored in a locked cabinet and will be destroyed after they have been analyzed for the purposes of data collection.

Voluntary Participation: Participation in this study is voluntary. I understand that I may withdraw my child from this study at any time. Refusal to participate or withdrawal will involve no penalty or loss of benefits for me or my child from my child's school or from West Virginia University. I have been given an opportunity to ask questions about the research and I have received answers concerning areas I did not understand. Upon signing this form, I will receive a copy.

I willingly consent to my child's participation in this study.

Signature of Parent or Guardian

Date

Signature of Investigator

Date 
Appendix I

Functional Analysis of Problem Behavior: Teacher Consent Form

Introduction: I, , have been asked to allow to participate in this study. I understand that this study involves one of my students, , and that his or her parent or guardian has given permission for their participation. The research study is being conducted by Cynthia Anderson, MA, who has explained the study to me. I understand that Cynthia is conducting this study to partially fulfill the requirements for a doctoral degree in clinical psychology at West Virginia University.

Purposes of the Study: The purpose of this study is to determine whether an interview administered to teachers and classroom observations will provide information useful in developing a treatment designed to reduce the occurrence of challenging behaviors exhibited in the classroom.

Description of Procedures: This study will be performed at the school where I teach. I will be asked a variety of questions about the challenging behavior sometimes exhibits. The purpose of these questions is to determine why these behaviors are occurring. These interviews will be audiotaped for later evaluation. Additionally, observations of the child will be conducted during the school day for a total of 4 hours. These observations will be carried out either by Cynthia Anderson or by a trained research assistant. The purpose of these observations is to determine the extent to which the interviews assess situations that actually occur in this child's school day. I understand that a total of 4 children and their teachers will be participating in this study.

Benefits: I understand that this study may have direct benefits to my student because, upon completion of this study, if my student's parents and I wish, a treatment plan based on the findings of the study will be prepared and made available. This treatment plan will specify strategies likely to be useful in reducing the rates of my child's challenging behaviors at school. If I wish, Cynthia Anderson will provide training to me and my student's parents concerning the treatment plan.

Contact Persons: For more information about this research, I can contact Dr. Joseph Scotti, who is an associate professor in the Department of Psychology at West Virginia University and is supervising this research. He can be reached at (304) 293-2001 ext. 667

For information regarding my student's rights as a research participant, I may contact the Executive Secretary of the Institutional Review Board at (304) 293-7073.

Confidentiality: I understand that any information obtained as a result of my participation in this research will be kept as confidential as legally possible. I understand that these research records, just like hospital records, may be subpoenaed by court order or may be inspected by federal regulatory authorities. In any publications that may result from this research, neither my name nor that of the child nor any information from which we might be identified will be published without my consent and the consent of the child's guardian. Audiotapes of the interview conducted with me will be stored in a locked cabinet and will be destroyed after they have been analyzed for the purposes of data collection.

Voluntary Participation: Participation in this study is voluntary. I understand that I may withdraw from this study or that the child's parents may withdrawal their child from this study at any time. Refusal to participate or withdrawal will involve no penalty or loss of benefits for me or for the child from the school or from West Virginia University. I have been given an opportunity to ask questions about the research and I have received answers concerning areas I did not understand. Upon signing this form, I will receive a copy.

I willingly consent to participate in this study.

Signature of Teacher

Date

Signature of Investigator

Date 


\section{Cynthia M. Anderson, M.A.}

October, 1998

\section{Personal Information:}

Business address:

Business phone:

E-mail:
Department of Psychology Munroe-Meyer Institute 985450 Nebraska Medical Center Omaha, NE 68198-5450

(402) 559-6408

cmanders@unmc.edu

\section{$\underline{\text { Education }}$}

1. West Virginia University Morgantown, West Virginia

Program: Child-Clinical Psychology (APA accredited)

Degree: Doctor of Philosophy (expected May, 1999)

Dissertation: Linking Functional Analysis with Diagnostic Classification: Development of Functional Analysis Methodology (defended)

Chairperson: Joseph R. Scotti, Ph.D.

2. West Virginia University

Morgantown, West Virginia

Program: Child-Clinical Psychology (APA accredited)

Degree: Master of Arts (December, 1995)

Thesis: Functionally derived treatments: An empirical validation

Chairperson: Joseph R. Scotti, Ph.D.

3. State University of New York at Binghamton (1993-1994)

Binghamton, New York

Program: Child Clinical Psychology

4. Hood College

Frederick, Maryland 21701

Major: Psychology

Degree: Bachelor of Arts (May, 1990) 


\section{Clinical Training Experience}

1. Pre-doctoral Intern

Nebraska Internship Consortium in Professional Psychology (APA approved)

Munroe-Meyer Institute

Omaha, NE, 68198

July, 1998-Present

Setting: APA approved internship in behavioral pediatrics. University Affiliated Program serving children with a wide range of pediatric health and behavioral concerns.

Duties: Provide behavior therapy for families and children; assist in conducting neuropsychological evaluations, conduct developmental evaluations of infants and toddlers; consult with hospital-based pediatric continuity clinic, conduct comprehensive interdisciplinary evaluations of children seen in neurobehavioral clinic.

Supervisor: William Warzak, $\mathrm{PhD}$

\section{Graduate Clinician}

University Affiliated Center for Developmental Disabilities (UACDD)

Morgantown, WV, 26505

Part-time position

July, 1997-July, 1998

Setting: University Affiliated Program serving children and adults with a wide range of developmental disabilities or behavior disorders.

Duties: Provided individual, small, and large group training on positive behavior support to parents and school personnel; conducted psychological evaluations and outpatient therapy; supervised graduate students providing services.

Supervisor: Donald Kincaid, Ed.D.

\section{Graduate Therapist}

Quin Curtis Center for Psychological Service, Research and Training

Morgantown, WV, 26506

Part-time position

August, 1995-August, 1997

Setting: University-based outpatient training clinic serving children, adolescents, and adults.

Duties: Provided therapy for adults with anxiety disorders, children and adolescents with disruptive behavior disorders and their families, and children with medical noncompliance.

Supervisors: Daniel W. McNeil, Ph.D., Christina Adams, Ph.D. 


\section{Graduate Clinician}

University Affiliated Center for Developmental Disabilities (UACDD)

Morgantown, WV

Part-time position

August, 1996-July, 1997

Setting: University Affiliated Program serving children and adults with a wide range of developmental disabilities or behavior disorders.

Duties: Provided direct consultation to individuals working with people exhibiting challenging behavior, facilitated teams providing positive behavior, conducted individual, small, and large group trainings to service providers, developed and taught semester long course on positive behavior support.

Supervisor: Donald Kincaid, Ed.D.

\section{Graduate Therapist}

Valley Community Mental Health Center

Kingwood, WV.

Part-time position

July, 1995- July, 1996

Setting: Community mental health center serving children, adolescents, and adults.

Duties: Conducted behaviorally oriented assessment and treatment for adults and children presenting with internalizing and externalizing disorders.

Supervisors: Robert Hawkins, Ph.D.; Kevin Larkin; Ph.D., Sharon McMillen, M.S.

\section{Project Assistant}

\section{School Consultation Project}

Morgantown, WV.

Part-time position

August, 1994-July, 1995

Setting: Community based service for school districts throughout West Virginia.

Duties: Provided consultational support to schools working with children emitting challenging behavior; assisted in teaching a semester long course on managing challenging behavior; trained and supervised undergraduate students working on the project.

Supervisor: Joseph R. Scotti, Ph.D. 


\section{Training Assistant}

The Children's Unit for Training and Evaluation, State University of New York

Binghamton, NY.

Part-time position

January, 1994-February, 1994

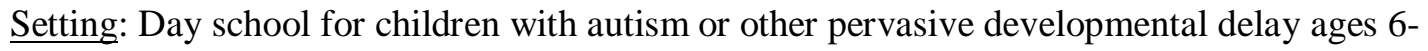
17.

Duties: Implemented educational programs with children with behavior disorders, assisted in the implementation of behavior management plans for children with excess behaviors.

Supervisor: Raymond G. Romanczyk, Ph.D.

\section{Professional Positions}

\section{Clinical Specialist II}

Kennedy Krieger Institute, Baltimore, MD

Full-time position

June, 1993-August, 1993

Setting: Inpatient treatment unit for children with developmental disabilities exhibiting severe challenging behavior

Duties:

Programmatic: Responsibilities outlined for Clinical Specialist I position.

Staff training: Supervised Clinical Specialist I staff, responsibilities outlined for Clinical Specialist I position.

Supervisor: Cathleen Piazza, Ph.D.

\section{Clinical Specialist I}

Kennedy Krieger Institute, Baltimore, MD

Full-time position (40 hours per week)

May, 1990-May, 1993

Setting: Same as outlined for Clinical Specialist II position.

Duties:

Programmatic: Conducted analog functional assessments and assisted in development of behavioral treatment plans; monitored the implementation and efficacy of behavioral treatment protocols by direct-care staff.

Staff training: Assisted in training new staff in functional analysis methodology and behavior management techniques.

Supervisor: Cathleen Piazza, Ph.D. 


\section{Practicum Student}

Kennedy Krieger Institute, Baltimore, MD

Part-time unfunded position

January, 1990-May, 1990

Duties: Collected and analyzed behavioral data, assisted in the development of behavioral treatment plans, assisted in the preparation of unit schedules for clients.

Supervisor: Cathleen Piazza, Ph.D.

\section{Honors and awards}

Honor Society of Phi Kappa Phi (1998-present)

Don Hake Award for Outstanding Graduate Student of 1998

\section{Teaching experience}

\section{Graduate level courses}

Special Topics: Issues in Field Experience (Positive Behavior Support) (1997, Spring). Head instructor for an off-campus graduate course; University Affiliated Center for Developmental Disabilities and West Virginia University, Moundsville, WV.

Special Topics: Issues in Field Experience (Positive Behavior Support) (1996, Fall). Instructor for an off-campus graduate; University Affiliated Center for Developmental Disabilities and West Virginia University, Elkins, WV.

Behavior Analysis I (1996, Fall). Discussion leader for a required course for clinical psychology graduate students; Department of Psychology, West Virginia University, Morgantown, WV.

Behavioral Assessment-II (1996, Spring). Graduate teaching assistant for graduate course for students in child and adult clinical masters and doctoral programs; Department of Psychology, West Virginia University, Morgantown, WV.

Introduction to Clinical Psychology (1995, Fall). Co-instructor for graduate course for first year students in child and adult clinical masters and doctoral programs; Department of Psychology, West Virginia University, Morgantown, WV.

Non-aversive Interventions in the Classroom (1995, Spring). Co-instructor for an off-campus graduate course for special education teachers and professionals working with children exhibiting challenging behavior; School Consultation Project and the Department of Psychology, West Virginia University, Morgantown, WV. 


\section{Undergraduate courses}

Survey of Clinical Psychology (1996, Fall). Instructor for undergraduate course designed for juniors and seniors majoring in psychology; Department of Psychology, West Virginia University, Morgantown, WV.

Applying to Graduate School (1995, Fall). Co-instructor for undergraduate course designed for college seniors applying to psychology graduate programs; Department of Psychology, West Virginia University, Morgantown, WV.

Exceptional children (1995, Spring). Graduate teaching assistant for undergraduate course for psychology majors; Department of Psychology, West Virginia University, Morgantown, WV.

Abnormal Psychology (1994, Spring). Graduate teaching assistant for undergraduate course for psychology majors; Department of Psychology, State University of New York at Binghamton, Binghamton, NY.

Social Psychology (1993, Fall). Graduate teaching assistant for undergraduate course for psychology majors; Department of Psychology, State University of New York at Binghamton, Binghamton, NY.

\section{$\underline{\text { Guest Lectures }}$}

Managing Difficult Behavior. (1997, March ). Graduate course: Professional Development Seminar; University Affiliated Center, West Virginia University, Morgantown, WV.

Elimination, Tic, and Seizure Disorders. (1996, April). Undergraduate course: Exceptional Children; West Virginia University, Morgantown, WV.

Utility of Functional Analysis Methodology in Assessing and Treating Challenging Behavior (1996, February). Undergraduate course: Exceptional Children; West Virginia University, Morgantown, WV.

Challenging Behavior: Assessment and Treatment (1995, September). Undergraduate course: Exceptional Children; West Virginia University, Morgantown, WV.

Reduction of Self-injurious Behaviors Through the Use of Applied Behavior Analysis. (1993, November). Graduate course: Behavior modification; Hood College, Frederick, MD.

Using Behavior Analytic Strategies to Manage Challenging Behavior. (1992, November). Graduate class : Behavior modification; Hood College, Frederick, MD.

Training Parents and Staff in the Implementation of Behavior Management Techniques. (1991, October: Undergraduate course: Behavior modification; Hood College, Frederick, MD. 
Treatment of Severe Behavior Disorders in Developmentally Disabled Children. (1990, October). Undergraduate course: Behavior modification at Hood College, Frederick, MD

\section{$\underline{\text { Publications }}$}

Journal Articles

Anderson, C. M., Freeman, K. A., \& Scotti, J. R. (1999). Evaluation of the generalizability (reliability and validity) of analog functional assessment methodology. Behavior Therapy, 30, 3150.

Freeman, K. A., Anderson, C. M., Haak Azer, R. Girolami, P. A., \& Scotti, J. R. (1998). Why functional analysis is enough: A response to Reiss and Havercamp. American Journal on Mental Retardation, 103, 80-91.

Anderson, C. M. (1998) "Why is she hitting us?" The importance of functional analysis in guiding intervention. The Positive Behavior Support Newsletter, 1, 3-4

Anderson, C. M., Hawkins, R. P., \& Scotti, J. R. (1997). Private events in behavior analysis: Conceptual basis and clinical relevance. Behavior Therapy, 28, 157-179.

Masia, C. L., Anderson, C. M., McNeil, D. W., \& Hawkins, R. P. (1997). Impact of managed care on graduate training. Behavior Therapist, 20, 145-148.

Anderson, C. M. (1996). Clinical practicum training: Advantages and disadvantages for students. West Virginia Journal of Psychological Research and Practice, 5, 73-78.

Piazza, C. C., Anderson, C. M., \& Fisher, W. (1993). Teaching self feeding skills to patients with Rett Syndrome. Developmental Medicine and Child Neurology,35, 991-996.

Reviews

Hawkins, R. P., Anderson, C. M., \& Eifert, G. (1998). [Review of the book] Behavior and personality: Psychological behaviorism. Child and Family Behavior Therapy, 20, 75-82.

Hawkins, R. P., Anderson, C. M., \& Eifert, G. (1998). A broad perspective to guide behavior analysis [Review of the book] Behavior and personality: Psychological behaviorism. Journal of Applied Behavior Analysis, 31 .

Hawkins, R. P., \& Anderson, C. M. (1997). Behavioral Assessment that gets at "causes:" has functional assessment of clinical cases arrived? [Review of the book] Functional analysis in clinical psychology. Contemporary Psychology, 42, 832-834. 
Scotti, J. R., Anderson, C. M., \& Mullen, K. (1995), [review of the book], Severe learning disabilities and challenging behaviors: Designing high quality services. Journal of the Association for Persons with Severe Handicaps, 20, 164-165.

Book Chapters

Anderson, C. M., Bahl, A. B., \& Kincaid, D. W. (in press). A person-centered approach to providing support to an adolescent with a history of parental abuse. In J. R. Scotti \& L. H. Meyer (Eds.), Behavioral intervention: Principles, models and practices. Baltimore: Paul H. Brookes.

Anderson, C. M., Freeman, K. A., \& Mullen, K. (in press). Assessment and intervention with excess behaviors: A series of cases from the School Consultation Project. In J. R. Scotti \& L. H. Meyer (Eds.) New directions for behavioral intervention: Principles, models, and practices. Baltimore: Brooks Publishing.

Manuscripts Under Review

Anderson, C. M., \& Bahl, A. (1998). Facilitating positive outcomes through positive behavior support: A case study. Manuscript under review at Journal of Positive Behavior Support.

Anderson, C. M., \& Freeman, K. A. (1998). Positive Behavior Support: Expanding the Application of Applied Behavior Analysis. Manuscript under review at Behavior Analyst.

Anderson, C. M., Hawkins, R. P., Freeman, K. A., \& Scotti, J. R. (1998). Private events: Do they belong in a science of human behavior? Manuscript under review at Behavior Analyst.

Anderson, C. M., Ruggerio, K., \& Adams, C. D. (1998). The use of functional assessment in treatment development for a child with HIV and medication noncompliance. Manuscript under review at Journal of Pediatric Psychology.

Freeman, K. A., Anderson, C. M., \& Scotti, J. R. (1997). A structured descriptive methodology: Increasing agreement between descriptive and experimental analyses. Manuscript under review at Education and Training in Mental Retardation

Manuscripts In Preparation

Anderson, C. M. (in preparation). Effective treatment of challenging behavior in schools: A call for functional diagnostics and functionally-derived treatments.

Anderson, C. M., \& Chase, P. N. (in preparation). Altruism and altruistic behavior: A behavior analytic perspective.

Anderson, C. M., \& Scotti, J. R. (in preparation). Evaluation of the utility of a teacheradministered functional assessment interview.

Warzak, W., \& Anderson, C. M. (in preparation). Parenting brain-injured children. To appear in M. Fine \& S. W. Lee (Eds.), The third handbook on parent education: The changing faces of parenting and parent education. NY: Academic Press. 


\section{Professional Presentations}

Paper Presentations

Anderson, C. M., \& Chase, P. N. (1998, November). Why we help: toward a behavioral explanation of altruism. In P. N. Chase and A. Rabalais (Chairs), Behavior analytic interpretations of complex social phenomena. Paper to be presented at the $32^{\text {nd }}$ annual convention of the Association for Advancement of Behavior Therapy.

Anderson, C. M., \& Spaulding, S. A. (1998, November). Providing positive behavior support in school settings: A multi-component approach. In A. B. Bahl \& C. D. Adams (Chairs), New directions in school-based interventions for disruptive behavior. Paper to be presented at the $32^{\text {nd }}$ annual convention of the Association for Advancement of Behavior Therapy.

Venable, R. R., Adams, C. D., \& Anderson, C. M. (1998, November). A brief study skills program for adolescents with attention deficit hyperactivity disorder. In A. B. Bahl \& C. D. Adams (Chairs), New Directions in School-based Interventions for Disruptive Behavior. Paper to be presented at the $32^{\text {nd }}$ annual convention of the Association for the Advancement of Behavior Therapy.

Anderson, C. M., Freeman, K. A., \& Kincaid, D. K. (1998, May). Using functional assessment information to produce meaningful lifestyle outcomes. In D. K. Kincaid (Chair), Positive behavior support: Highlighting outcomes. Paper presented at the $24^{\text {th }}$ annual convention of the Association for Behavior Analysis, Orlando, FL.

Anderson, C. M., Spaulding, K. A., \& Kincaid, D. K. (1998, May). Positive behavior support in the classroom: Supporting a child with conduct disturbances in school. In D. K. Kincaid (chair), Expanding the Application of Positive Behavior Support. Paper presented at the $24^{\text {th }}$ Annual Convention for the Association for Behavior Analysis, Orlando, FL.

Anderson, C. M., \& Eifert, G. H. Empirically Validated Treatments: Right idea, Wrong Strategy. A Call for Functionally Derived Treatments. (1997, May) In. C. L. Masia and R. P. Hawkins (Chairs), Managed care and behavior analysis: Do they mesh? Paper presented at the $23^{\text {rd }}$ Annual Convention for the Association for Behavior Analysis, Chicago, IL.

Anderson, C. M., Hawkins, R. P., \& Scotti, J. R. (1997, May). Private events in the science of human behavior. In R. P. Hawkins and J. Forsyth (Chairs), Behavior analysts: What do they think about thinking and feeling? Paper presented at the $23^{\text {rd }}$ Annual Convention for the Association for Behavior Analysis, Chicago, IL. 
Bowman, R., Anderson, C. M., Freeman, K. A., \& Dumm, K. (1997, May). Gathering empirical evidence for far-reaching changes: Outcome measures and positive behavior support. In D. K. Kincaid (Chair), Improving treatment modalities: Incorporating person centered planning approaches within a behavior analytic perspective. Paper presented at the $23^{\text {rd }}$ Annual Convention for the Association for Behavior Analysis, Chicago, IL.

Dumm, K., Bahl, A., Freeman, K. A., Anderson, C. M., \& Kincaid, D. K. (1997, May). Exploring the philosophical commonalities between person centered planning and behavior analysis. In D. K. Kincaid (Chair), Improving treatment modalities: Incorporating person centered planning approaches within a behavior analytic perspective. Paper presented at the $23^{\text {rd }}$ Annual Convention for the Association for Behavior Analysis, Chicago, IL.

Freeman, K. A., Anderson, C. M., Dumm, K., \& Kincaid, D. K. (1997, May). Functional analysis methodologies: Exploration of procedures applicable in everyday clinical settings. In D. K. Kincaid (Chair), Improving treatment modalities: Incorporating person centered planning approaches within a behavior analytic perspective. Paper presented at the $23^{\text {rd }}$ Annual Convention for the Association for Behavior Analysis, Chicago, IL.

Kincaid, D. K., Freeman, K. A., Anderson, C. M., Dumm, K., \& Bahl, A. (1997, May). Positive behavior support: A marriage between behavior analysis and person centered planning. In D. K. Kincaid (Chair), Improving treatment modalities: Incorporating person centered planning approaches within a behavior analytic perspective. Paper presented at the $23^{\text {rd }}$ Annual Convention for the Association for Behavior Analysis, Chicago, IL.

Anderson, C. M., Freeman, K. A., Mgleary, K., \& Scotti, J. R. (1996, May). Functionallyderived treatments: an empirical validation. In J. R. Scotti (chair), Current and functional trends in the use of functional analysis methodologies. Paper presented at the $22^{\text {nd }}$ Annual Convention for the Association for Behavior Analysis, San Francisco, CA.

Anderson, C. M., Hawkins, R. P., Spaulding, S. A., \& Bahll, A. (1996, May). Data-based decision making in community behavioral health centers: Is it happening? In J. R. Matthews \& \& R. P. Hawkins (Chairs), Second symposium on clinical service as science: Use of data for monitoring and decision making. Paper presented at the $22^{\text {nd }}$ Annual Convention for the Association for Behavior Analysis, San Francisco, CA.

Freeman, K. F., Anderson, C. M., Kojima, M., \& Scotti, J. R. (1996, May). Comparing typical and "structured" descriptive techniques with experimental analyses in determining the function of excess behavior. In J. R. Scotti (chair), Current and functional trends in the use of functional analysis methodologies. Paper presented at the $22^{\text {nd }}$ Annual Convention for the Association for Behavior Analysis, San Francisco, CA.

Anderson, C. M., \& McNeil, D. (1996, April). Clinical Practicum Training: Students' Perspectives. Paper presented in D. W. McNeil (Chair), Clinical practicum training in the "real world": Advantages for clients, trainees, and mental health agencies, Paper presented at the spring convention for the West Virginia Psychological Association, Charleston, WV.

\section{Poster Presentations}

Anderson, C. M., Ruggiero, K. J., \& Adams, C. D. (1998, November). Functionally derived treatment for pill refusal: A case study involving a child with HIV. Poster to be presented at the $32^{\text {nd }}$ annual convention of the Association for Advancement of Behavior Therapy. 
Anderson, C. M., Mullen, K. B., \& Hawkins, R. P. (1996, May). Assessment of treatment outcome in a community mental health setting. Poster presented at the $22^{\text {nd }}$ Annual Convention for the Association for Behavior Analysis, San Francisco, CA.

Anderson, C. M., Mullen, K., Freeman, K. A., Lewis, J., Weigle, K., Kirk, K., \& Scotti, J. R. (1995, May). Assessment of a course designed to increase educators' understanding of behavioral principles and functional assessment methodologies. Poster presented at the $21^{\text {st }}$ Annual Convention for the Association for Behavior Analysis, Washington, D.C.

Freeman, K. A., Anderson, C. M., Mullen, K., Boccio, K., \& Scotti, J. R. (1995, May). A comparison of three forms of graphical representations of functional assessment data on ability to identify maintaining variables. Poster presented at the $21^{\text {st }}$ Annual Convention for the Association for Behavior Analysis, Washington, D.C.

Scotti, J. R., Mullen, K., Anderson, C. M., Freeman, K. A., Weigle, K., Robertson, M., Boccio, K., Tanner, C., \& Long, E. (1995, May) Functional analysis of excess and positive replacement skills: A series of cases from the School Consultation Project. Poster presented at the $21^{\text {st }}$ Annual Convention for the Association of Behavior Analysis, Washington, D.C.

Arnett, G., Thomas, S., Keim, K., Kennamer, E., Foster, A., Sine, A., Dumm, K., Markus, M., Tanner, C., Anderson, C. M., \& Scotti, J. R. (1995, April). Outcome of a graduate course on nonaversive intervention: Level of information and identification of function of excess behavior. Poster presented at the West Virginia University Psi Chi Undergraduate Conference conducted at the Spring Conference of the West Virginia Psychological Association, Charleston, WV. [first Place Award for Applied Clinical Presentations.]

Thomas, S., Arnett, G., Kennamer, E., Keim, K., Sine, A., Foster, A., Dumm, K., Tanner, C., Markus, M., Anderson, C. M., \& Scotti, J. R. (1995, April). Outcome of a graduate course on nonaversive intervention: Level of information and selection of intervention strategy. Poster presented at the West Virginia University Psi Chi Undergraduate Conference conducted at the Spring Conference of the West Virginia Psychological Association, Charleston, WV.

Matthews, A., Weiner, T., Delmolino, L., Anderson, C. M., \& Romanczyk, R. G. (1994, May). Assessing the effects of Naltrexone on the treatment of self-injurious behavior II: Comparison of teacher rating scales with parental rating scales. Poster presented at the $20^{\text {th }}$ Annual Convention for the Association of Behavior Analysis, Atlanta, GA. 
Freeman, K. A., Anderson, C. M., Piazza, C. C. \& Fisher, W. (1993, October) Practical applications of operant treatment strategies for patients with Rett Syndrome. Poster presented at the Annual Convention for the American Association of University Affiliated Programs, Bethesda, MD.

Anderson, C. M., Piazza, C. C. \& Freeman, K. A. (1993, May). Evaluations of operant treatment strategies in the treatment of destructive behaviors in clients with Rett Syndrome. Poster presented at the $19^{\text {th }}$ Annual Convention for the Association for Behavior Analysis, Chicago, IL.

Jung, J., Fisher, W., Anderson, C. M., Grace, N., Bowman, L., Hagopian, L., Carpenter, R. (1993, May). Pharmacological treatment of food stealing and hyperphagia in three persons with Prader-Willie Syndrome. Poster presented at the $19^{\text {th }}$ annual convention of the Association for Behavior Analysis, Chicago, IL.

Anderson, C. M., Piazza, C. C., Fisher, W., Herndon, L., Rifkin, R. (1992, May). Training self feeding skills in clients with Rett Syndrome. Poster presented at the $18^{\text {th }}$ annual convention for the Association for Behavior Analysis, San Francisco, CA.

Langdon, N., Fisher, W., Grace, N. C. , Anderson, C. M., Piazza, C. C., Sherer, M., \& Chin, S. (1992, May). Training parents to implement behavioral protocols for children with destructive behavior disorders. Poster presented at the $18^{\text {th }}$ annual convention for the Association for Behavior Analysis, San Francisco, CA.

Fleishell, J., Langdon, N., Lou, K. K., Anderson, C. M., Gerson, A., Piazza, C. C., Fisher, W., \& Cataldo, M. (1992, May). Evaluation of the effects of pharmacologic treatments on destructive behavior. Poster presented at the $18^{\text {th }}$ annual convention for the Association for Behavior Analysis, San Francisco, CA.

\section{Workshops}

National

Freeman, K. A., Anderson, C. M., \& Kincaid, D. K. (1998, May). Introduction to Person centered planning. 24th Annual Convention for the Association for Behavior Analysis, Chicago, IL.

Freeman, K. A., \& Anderson, C. M. (1998, April). Person-Centered Planning and Clinical Problem Solving. 1998 Sharing Our Best Conference, Beatrice, NE.

Anderson, C. M., Freeman, K. A., \& Kincaid, D. K. (May, 1997). Person centered planning and behavior analysis: What it is, how to do it. 23rd Annual Convention for the Association for Behavior Analysis, Chicago, IL. 


\section{$\underline{\text { Regional }}$}

Scotti, J. R., \& Anderson, C. M. (1998, March). Functional Behavioral Assessment: Developing Effective Interventions for Challenging Behavior in the School Setting. Workshop for teachers, school psychologists, and school administrators in West Virginia.

Scotti, J. R., \& Anderson, C. M. (1998, March). Functional Behavioral Assessment. Spring conference of the West Virginia School Psychologists Association.

Anderson, C. M., Freeman, K. A., Kincaid, D. K., Spaulding, S. A., \& Girolami, P. (1997, August). Positive Behavior Support in the Schools: An introduction. Workshop presented to teachers and administrators in a 3-county region of West Virginia.

Freeman, K. A., \& Anderson, C. M. (1997, August). Providing Positive Behavior Support in

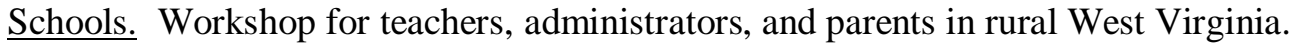

Bowman, R., \& Anderson, C. M. (1996, October). Introduction to Positive Behavior Support. West Virginia Head Start Association's State Conference, Charleston, WV.

Bowman, R. \& Anderson, C. M. (1995, June). Sexual Abuse Prevention Workshop. Potomac Center, Romney, WV.

Scotti, J. R., Anderson, C. M., Mullen, K. B., \& Freeman, K. A. (1995, May). An introduction to the School Consultation Project and strategies for nonaversive intervention with excess behaviors. Wiley Ford Elementary School, Wiley Ford, WV.

Scotti, J. R., Mullen, K., \& Anderson, C. M. (1995, March). Overview of functional assessment and nonaversive intervention with the excess behavior of students with severe disabilities. T. A. Lowerey Elementary School, Shenandoah Junction, WV.

Anderson, C. M. (1992, February). Antecedent, behavior, consequence. Lilian Vernon School, Baltimore, MD.

Anderson, C. M. (1991, August). The Role of Applied Behavior Analysis in the Treatment

of Behavior Problems in the Classroom. Florida Public School, 38, Florida, Puerto Rico.

\section{Professional Presentations Under Review}

Anderson, C. M. (Under review). Explaining helping: Are humans altruistic? Paper to be presented in J. R. Kraft (chair) Conceptual and Experimental Analyses of Social Behavior. Symposium submitted to the $33^{\text {rd }}$ Annual Convention of the Association for Behavior Analysis.

Freeman, K. A., \& Anderson, C. M. (under review). Person-Centered Planning II: An Advanced Perspective. Workshop submitted to the $33^{\text {rd }}$ Annual Convention of the Association for Behavior Analysis. 


\section{$\underline{\text { Editorial Activities }}$}

\section{Guest Reviewer}

Journal of Applied Behavior Analysis, September, 1998.

Behavior Therapy, January, 1998.

Journal of the Association for Persons with Severe Handicaps, June, 1997

\section{Co-reviewer}

Journal of Clinical Child Psychology, March, 1996.

Behavior Therapy, March, 1996.

Journal of the Association for Persons with Severe Handicaps, February, 1996.

Journal of Cognitive and Behavioral Practice,, January, 1996.

Journal of the Association for Persons with Severe Handicaps, February, 1995.

\section{Department Activities}

1. Student Representative, Nebraska Internship Consortium in Professional Psychology (October, 1998-June, 1999)

2. Graduate Training Committee Student Representative, West Virginia University August, 1997-May, 1998

2. Child Clinical Training Committee Student Representative August, 1996-May, 1997

\section{Undergraduate Honors Thesis Committee member} August, 1994-May, 1995; August, 1996-May, 1997

\section{Professional Activities}

1. Member of American Psychological Association 1996-present

3. Member of the American Association on Mental Retardation 1998-present

2. Member of Association for the Advancement of Behavior Therapy 1994-present

3. Member of Association for Behavior Analysis 1990-present 
4. Member of the ABA Clinical SIG Committee on Guidelines and Procedures 1996-1997

5. Member of the Human Rights Committee for the Mental Retardation and Developmental Disabilities Program, Valley Community Mental Health Center, Morgantown, WV 1994-1995

6. Member of the Task Force on Best Practices in Providing Supports to Persons with Developmental Disabilities, West Virginia Department of Health and Human Resources, Office of Behavioral Health Services 1994-1995

\section{Professional References}

Joseph R. Scotti, Ph.D.

Department of Psychology

West Virginia University

P.O. Box 6040

Morgantown, WV 26506-6040

Donald W. Kincaid, Ed.D.

University Affiliated Center for Developmental Disabilities

Research and Office Park

955 Hartman Run Road

Morgantown, WV 26505-8334

Christina D. Adams, Ph.D.

Department of Psychology

West Virginia University

P.O. Box 6040

Morgantown, WV 26506-6040

William J. Warzak, Ph.D.

Department of Psychology

Munroe-Meyer Institute

985450 Nebraska Medical Center

Omaha, NE 68198-5450 